Spring 1-15-2019

\title{
Physical Therapists' Perceptions of Barriers to the Use of Evidence-based Fall Prevention Intervention with Individuals of 65 Years of Age or Older
}

Charles Agbonghae

University of St. Augustine for Health Sciences

DOI: https://doi.org/10.46409/sr.IHIJ8448

Follow this and additional works at: https://soar.usa.edu/dissertations

Part of the Community Health and Preventive Medicine Commons, Health Services Research Commons, and the Physical Therapy Commons

\section{Recommended Citation}

Agbonghae, C. (2019). Physical Therapists' Perceptions of Barriers to the Use of Evidence-based Fall Prevention Intervention with Individuals of 65 Years of Age or Older. [Doctoral project, University of St Augustine for Health Sciences]. SOAR @ USA: Student Dissertations Collection. https://doi.org/10.46409/ sr.IHIJ8448

This Dissertation is brought to you for free and open access by the Student Research at SOAR @ USA. It has been accepted for inclusion in Student Dissertations by an authorized administrator of SOAR @ USA. For more information, please contact soar@usa.edu, erobinson@usa.edu. 
PHYSICAL THERAPISTS' PERCEPTIONS OF BARRIERS TO THE USE OF EVIDENCEBASED FALL PREVENTION INTERVENTIONS WITH INDIVIDUALS OF 65 YEARS OF AGE OR OLDER

By

Charles A. Agbonghae

A Dissertation Presented in Partial Fulfillment of the Requirement for the Degree of

DOCTOR OF HEALTH SCIENCE

University of St. Augustine for Health Science

December, 2018. 
PERCEPTIONS OF EVIDENCE-BASED INTERVENTIONS

Copy Right by Charles A. Agbonghae, 2018

All Rights Reserved 
PHYSICAL THERAPISTS' PERCEPTIONS OF BARRIERS TO THE USE OF EVIDENCEBASED FALL PREVENTION INTERVENTIONS WITH INDIVIDUALS OF 65 YEARS OF

\section{AGE OR OLDER}

By

Charles A. Agbonghae

Has been approved

December 2018

APPROVED:

STEVEN M. GERARDI, Ph. D., Dissertation Chair

MANUEL DOMENICH, Ed.D., Committee Member

MARILYN MILLER, Ph.D., Committee Member

SUNDDIP AGUILAR, Ed.D., Interim Program Director

ACCEPTED AND SIGNED:
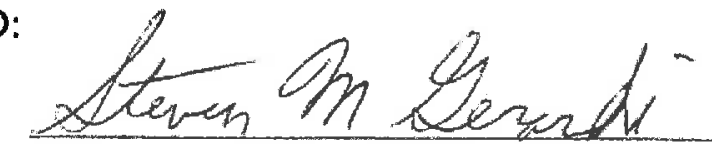

STEVEN M. GERARDI, PH.D.

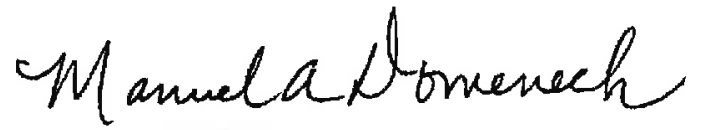

MANUEL DOMENICH, ED.D.

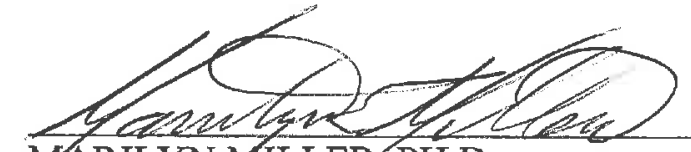

MARILYNAILLER, PH.D.

Sunddip Aguilar, Cd.D.

SUNDDIP AGUILAR, ED.D. 


\begin{abstract}
Falls are a problem in the elderly population. Evidence-based fall prevention programs are available but physical therapists do not always utilize them. The literature identifies a number of barriers to clinician's use of evidence-based interventions in general but there is limited knowledge of barriers to the use of evidence-based interventions in the clinical practice area of fall prevention. The purpose of this study was to identify barriers perceived by physical therapists to the use of evidence-based fall prevention interventions with individuals of 65 years of age or older. The study utilized an on-line survey of physical therapists licensed in Texas. The study validated five previously identified barriers (lack of time, patient's exercise tolerance, professional knowledge deficit, health system bureaucracy, and lack of facility support) and identified six additional barriers perceived by physical therapists to the use of evidence-based fall prevention interventions with individuals of 65 years of age or older (patient comorbidity, lack of resources, productivity expectation, staffing needs, insurance regulations, and remuneration).
\end{abstract}




\section{Acknowledgements}

To God be the glory, honor and power for His help and grace to me throughout this program. I wish to express my sincere appreciation to Dr. Steven Gerardi, Dr. Tony Domenech and Dr. Marilyn Miller, my dissertation supervisors, for their guidance. Also, special appreciation to my family for their support and encouragement throughout this program. 


\section{List of Tables}

Table 1: Ranking of reported perceived barriers to the implementation of evidence-based fall

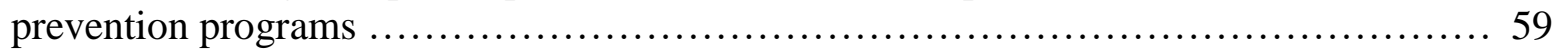

Table 2: Mean ranking of perceived barriers to the implementation of evidence-based fall

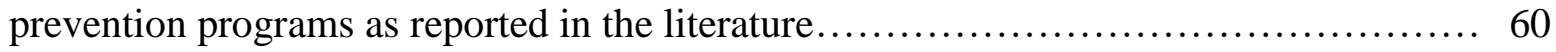

Table 3: Additional perceived barriers to the implementation of evidence-based fall prevention

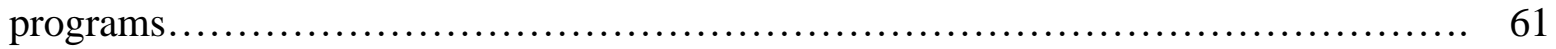




\section{Table of Contents}

Acknowledgements.................................................. ii

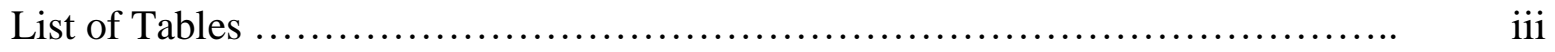

Chapter One _ $\quad 1$

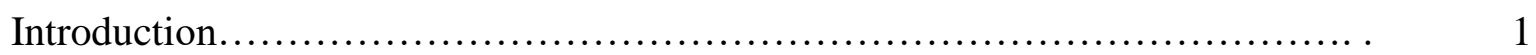

Background.................................................... 2

Statement of the Problem ................................................................... 4

Purpose of the Study............................................ 5

Significance of the Study........................................ 5

Research Question.............................................. 6

Research Design ............................................... 6

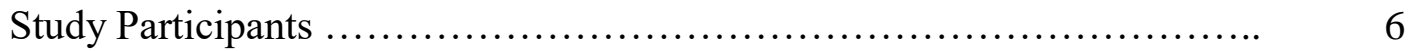

Data Collection................................................... 7

Data Analysis ................................................. 7

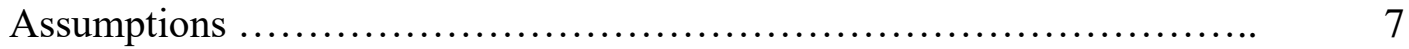

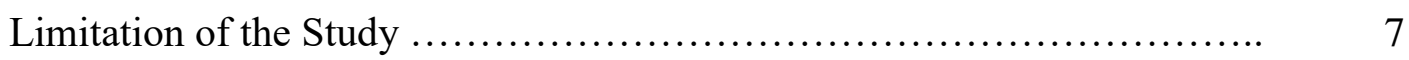

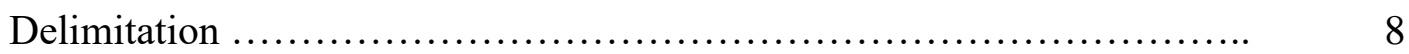

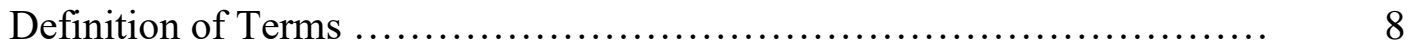

Organization of the Remainder of the Study.......................... 9

$\begin{array}{ll}\text { Chapter Two } & 10\end{array}$

Review of the Literature........................................... 10

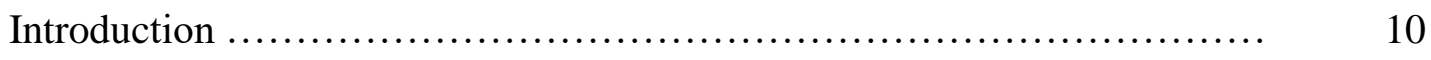

Overview .................................................. 10

Consequences of Falls.......................................... 11

Economic Cost of Falling ...................................... 12

Etiology and Risk Factors Associated with Falls....................... 14

Medication Risk Factor ........................................... 14 
Chronic and Acute Disease Risk Factors ........................... 15

Age-related Musculoskeletal Weakness ............................. 17

Use of Assistive Device ....................................... 19

Poor Cognition ............................................... 19

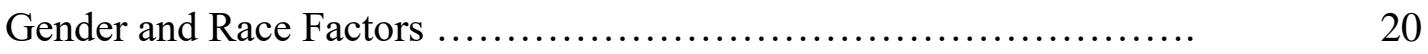

Environmental or Extrinsic Risk Factor ............................ 20

Theoretical Framework ........................................ 21

Evidence-based Fall Intervention Programs ......................... 22

Compendium's Simple Therapy Interventions ....................... 24

Stay safe, Stay Active Program ................................ 24

Otago Exercise Program ......................................... 24

LiFE (Lifestyle Approach to Reducing Falls Through Exercise) ......... 26

Erlangen Fitness Intervention ............................... 26

Senior Fitness and Prevention (SEFIP) ...................... 27

Adapted Physical Activity Program .......................... 27

Tai Chi: Moving for Better Balance, Central Sydney Tai Chi Trial, \&

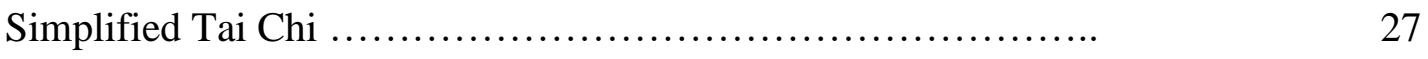

Australian Group Exercise Program .......................... 29

Yaktrax Walker ......................................... 29

Veteran Affairs Group Exercise Program ........................ 30

Falls Management Exercise (FaME) Intervention ................. 30

Music-based Multitask Exercise Program ........................ 30

Multi-target Stepping Program (MTS) $\ldots \ldots \ldots \ldots \ldots \ldots \ldots \ldots \ldots \ldots \ldots \ldots \ldots \ldots$

Other Single Therapy Intervention Exercises .................... 31

Balance Exercise Program ..................................... 31

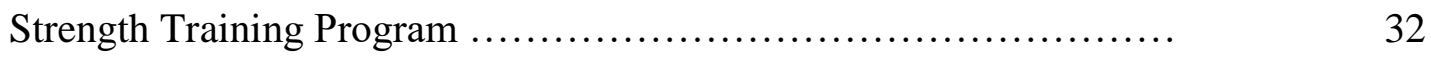

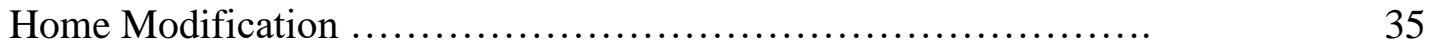

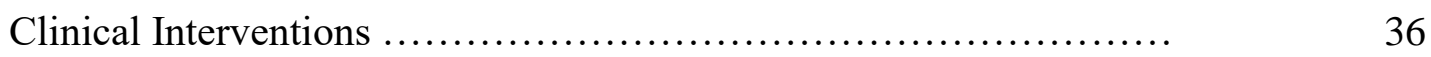


Multifaceted Interventions ................................. 37

Stepping On ........................................ 37

PROFET (Prevention of Falls in the Elderly Trial) ................ 37

Accident and Emergency Fallers ........................... 37

The NoFalls Intervention .................................. 38

The Study of Accidental Falls in the Elderly (SAFE) Health and Exercise

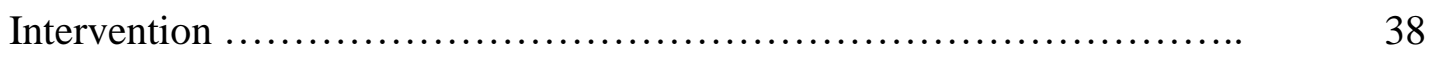

Falls Team Prevention Program .............................. 39

KAAOS (Falls and Osteoporosis Clinic) ........................ 39

Multifactorial Fall Prevention Program ........................... 40

Nijmegen Falls Prevention Program (NFPP) for Adults with Osteoporosis ... $\quad 40$

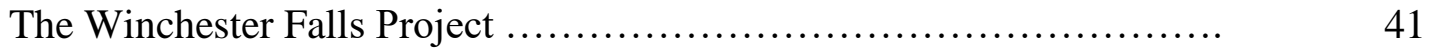

Yale FICSIT (Frailty and Injuries: Cooperative Studies of Intervention

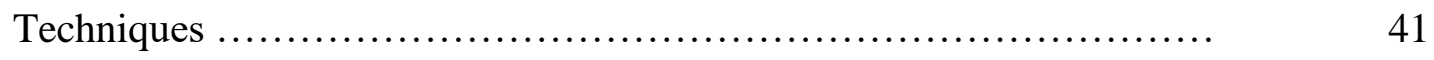

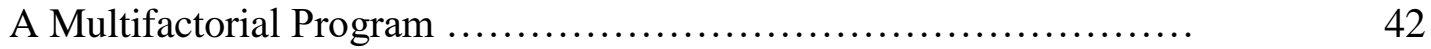

Multifaceted Combination of Balance and Strength interventions ....... 42

STEADI Fall Prevention Measure ................................ 44

Physical Therapists Behaviors and Attitudes in Using Evidenced-based Practice 45

Promoting Action on Research Implementation in Health Services ........ 46

Barriers to Exercises in Older Adults ............................... 47

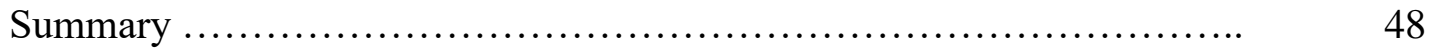

Chapter Three

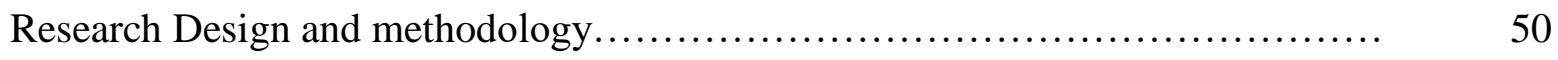

Introduction .............................................. 50

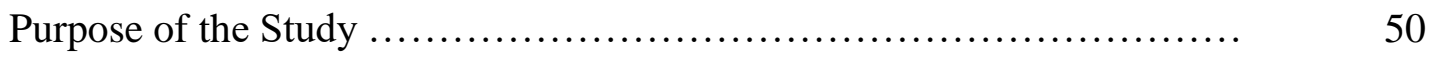

Research Question ............................................ 51

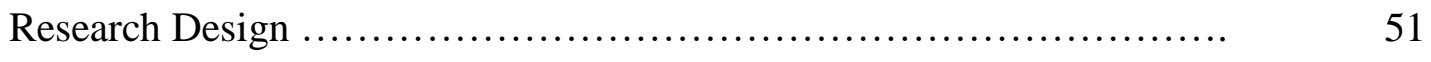

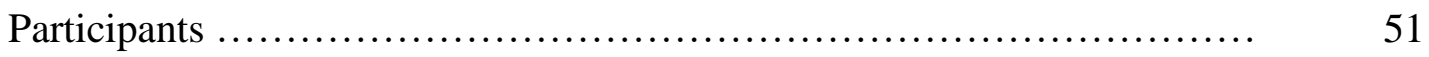


Data Collection Procedures ..................................... 52

Data Analysis .......................................... 53

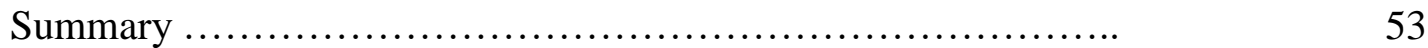

Chapter Four

Analysis of Data........................................ 55

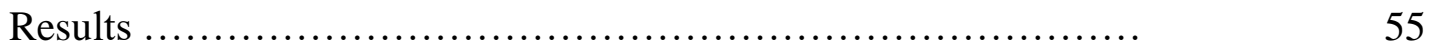

Demographics of the Respondents .......................... 55

Familiarity of CDC Compendium and STEADI Tool Kit............... 56

Use of Evidence-based Interventions.............................. 56

Research Question and the Results ............................ 58

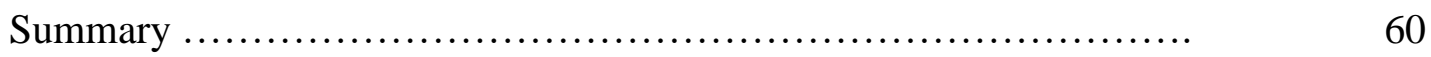

Chapter Five ___ 62

Summary, Conclusions, and Recommendations for Future Research ...... 62

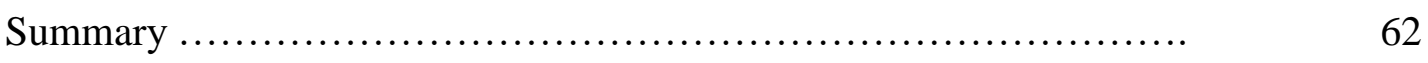

Discussion and Implications of Findings ......................... 64

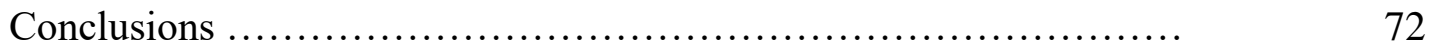

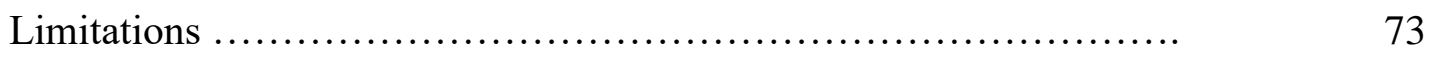

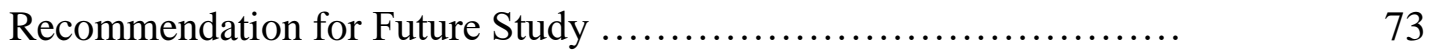

Recommendation for Physical Therapy Practice ................... 74

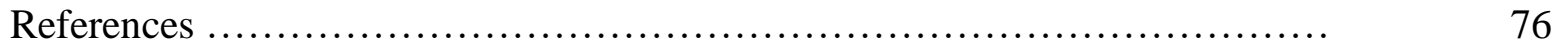

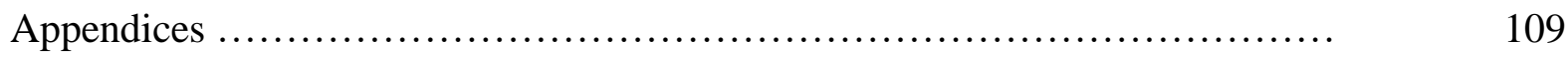

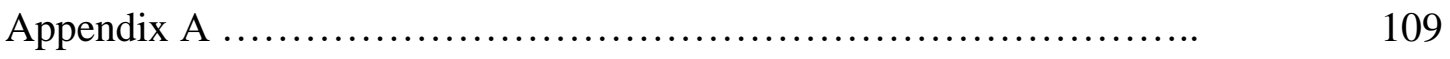

Appendix B ............................................ 111

Appendix C ............................................. 113

Appendix D............................................ 114 
Appendix E................................................ 


\section{Chapter One}

\section{Introduction}

Falls are a major public health concern in the older adults' population (Weir \& Culmer, 2004). Falling is one of the leading causes of injury, debility, institutionalization and premature death in individuals 65 years and above (Kruschke \& Butcher, 2017; United States Preventive Services Task Force [USPSTF], 2017). Over the last decade, the incidence of falls and fallrelated injuries and deaths in older adults has increased (Stevens, 2005). The current estimate is that more than one out of every three older adults fall each year (Al-Aama, 2011) and of these, over half are by adults over the age of 80 years (Burns, Stevens \& Lee, 2016; Center for Disease Control [CDC], 2014). About two-thirds of the older adults who fall will experience another fall within six months (Al-Aama, 2011; Avanecean, Calliste, Contreras, Lim, \& Fitzpatrick, 2017; CDC, 2015).

The World Health Organization (WHO) defined a fall as an "event which results in a person coming to rest inadvertently on the ground or floor or other lower level" (Avanecean, Calliste, Contreras, Lim, \& Fitzpatrick, 2017, p. 3008). This unplanned descent to the floor, with or without injury, considerably impacts older adults' functional abilities and psychological disposition to activities of daily living (Jackson, 2016; Kruschke \& Butcher, 2017; Soriano, DeCherrie \& Thomas, 2007). The fear of falling among older adults is a major factor that leads to sedentary life-style, reduced quality of life, difficulty walking, and inability to perform activities of daily living (Enderlin et al., 2015). The destructive health effects of physical inactivity and sedentary lifestyle and their contributions to general morbidity and mortality have been advocated by global and regional public health institutions (CDC, 2017; WHO, 2013). Globally, physical inactivity-related deaths per year account for about 3.2 million deaths (WHO, 
2013), according to the Center for Disease Control (2017), the estimate is that about 300,000 deaths per year in the US are due to physical inactivity. Physical inactivity and sedentary lifestyle tend to increase with age, and it also increases the risk of developing multiple noncommunicable chronic diseases and grave outcome with falls (Blair, Sallis, Hutber, \& Archer, 2012; CDC, 2017).

The Center for Disease Control (2015) and the American Geriatric Society (2011) have recommended the use of specifically tailored physical activities and environmental modification as some of the most effective evidence-based interventions in the management of falls in older adults. Similarly, the United States Preventive Services Task Force (2017) issued a final guidance and report in 2017 on the prevention of falls and fractures in older adults. This guidance by USPSTF, recommends the use of exercise, such as mobility, strength and balance training, as an effective intervention in the prevention of falls in the older adults population at risk of falls.

Physical therapists and other health care professionals have reported positive attitudes in the use of evidence-based intervention because it promotes quality patients' outcomes (Jette et al 2003). However, lack of consistent use of fall management guidelines, and inadequate training in the use of evidence-based practice have been reported among physical therapists, and other health care professions, as barriers in the use of evidence-based practice guidelines (Jette, et al., 2003; Loganathan, Ng, Tan \& Low, 2015).

\section{Background}

Each year, approximately $30 \%$ to $40 \%$ of adults 65 year and above, experiences a fall (Avin, et al, 2015). Falls can result in non-injury or mild to severe injuries such as skin lacerations, traumatic brain injuries, and skeletal fractures (CDC, 2014; WHO, 2004). The direct 
health care cost in the management of falls in the United States is approximately $0.2 \%$ of the annual total health care expenditure (Ambrose, Paul \& Hausdorff, 2013). As the population of older adults in the United States increases, senescence-related health issues become increasingly relevant to various stakeholders (Lutz, Sanderson, \& Scherbov, 2008).

One of the major age-related health care issues of utmost importance to the older adults is falling and its consequences (Lee, Kim, Chang, Nam, Kim, Cho, et al., 2018). Falls and the consequences of falling have been reported to correlate with the use of evidence-based practice by physical therapists and other health care professionals (Stenberg \& Wann-Hansson, 2011). In a study by Stenberg and Wann-Hansson (2011), the consistent use of clinical practice guidelines by health care professionals (therapists, physicians, and nurses) in an acute hospital setting was found to be an effective means of reducing falling among the older adults population using the acute care facility. However, for unknown reasons, the authors found that evidence-based practice guidelines were not consistently used and implemented by health care professionals such as physical therapists, occupational therapists, physicians, and nurses.

In a similar study, Stroud (2014) and Salbach, Jagial, Korner-Bitensky, Rappolt, and Davis, (2007), found that physical therapists do not consistently use innovative evidence-based practice guidelines in the care of older adults at risk for falls. The most common barrier among physical therapists for not utilizing evidence-based practice, according to Stroud (2014) and Fruth, Van Veld, Despos, Martin, Hecker, and Sincroft (2010) was lack of time to search literature. Nilsagard and Lohse (2010) in another study found that physical therapists frequently fail to use evidence-based practice guidelines due to poor support and lack of interest from the management of their facilities. Salbach, et al. (2007) found another barrier why physical 
therapists often do not use available evidence in health care as being due to poor understanding of the evidence and lack of knowledge in analyzing the components.

The Stenberg and Wann-Hansson study raises the question about what physical therapists and other health care professional perceive as barriers to the implementation of the practice guidelines in clinical interventions. Stroud (2014) and Gudjonsdottir and Arnadottir (2015), demonstrated that the gap between clinical research and implementation is increasing and needs to be bridged. The need for consistent implementation of available clinical evidence in the management of falls among older adults cannot be over-emphasized.

\section{Statement of the Problem}

Falls are a significant public health issue because of its huge economic cost to the society, and impacts on the quality of life, activities of daily living, longevity and institutionalization of the older adults' population (Weir \& Culmer, 2004). With the projected growth of this population segment (United States Census Bureau, 2010), the problem of falling will likely become an even greater public health concerns among stakeholders in the health care sector. The current evidence-based practice in the management of falls in older adults includes the identification of the relevant intrinsic and extrinsic causative factors and designing appropriate corrective measures (AGS, 2011; CDC, 2015; USPSTF, 2017). Evidence-based practice guidelines recommend the use of accurate assessment techniques, relevant exercise prescription, environmental modification and measures to monitor progress (CDC, 2015; USPSTF, 2017).

Despite the availability of numerous evidence-based fall intervention programs and studies that highlight the effectiveness of fall treatment interventions(Carter, et al., 2003; Rapp, Lamb, Gisela, Ranjit, Lindermann, \& Becker, 2008), the literature demonstrates that physical therapists do not always use these evidence-based programs (Jette, et al., 2003; Loganathan, Ng, 
Tan \& Low, 2015; Stroud, 2014). The literature shows that among physical therapists and other health care professionals, there is a growing gap between clinical research synthesis and the implementation of evidence-based practice in clinical practice (Gudjonsdottir \& Arnadottir, 2015; Jette, et al., 2003; Loganathan, Ng, Tan \& Low, 2015; Stroud, 2014). There is limited literature on physical therapists' perceptions on the use of evidence-based practice in fall intervention programs. The available literature shows physical therapists have a positive opinion and attitudes toward the use of evidence-based practice and a majority view it as being valuable in achieving positive health outcomes (Stroud, 2014). Available literature also shows the that barriers commonly cited by physical therapists include lack of time to search databases, lack of support from facility management, knowledge deficit of the evidence and health system bureaucracy (Fruth et al., 2010; Hannes, Staes, Goedhuys \& Aertgeerts, 2009; Salbach, et al., 2007).

\section{Purpose of the Study}

The purpose of this mixed methods study was to identify barriers perceived by physical therapists to the use of evidence-based fall prevention interventions with individuals of 65 years of age or older.

\section{Significance of the Study}

Physical therapists play a major role in the prevention and treatment of falls in the older adult population (Carter, et al., 2003; Rapp, Lamb, Gisela, Ranjit, Lindermann, \& Becker, 2008). Physical therapists frequently utilize evidence-based clinical practice as part of their patient's plan of care (AGS, 2011; CDC, 2015; USPSTF, 2017). The purpose of this study was to identify barriers perceived by physical therapists to the use of evidence-based fall prevention interventions with individuals of 65 years of age or older. Data analysis was done to determine if 
availability of time, patient's exercise tolerance, lack of support from facility management, health system bureaucracy, professional's knowledge of evidence-based practice, and other factors, contributed as barriers perceived by physical therapists to the use of evidence-based practices in fall prevention program in older adults.

Determining physical therapists' perceptions and attitudes toward the use of evidencebased practice guidelines for fall management and prevention, could positively impact patient outcomes (Jette, et al., 2003). The identification and elimination of the barriers among physical therapists using evidence-based practice guideline will potentially improve the delivery of care to the older adults and reduce the direct and indirect health care costs (Jette, et al., 2003; Stenber \& Wann-Hansson, 2011; Ward, Baloh, Zhu \& Stewart, 2017). The need to implement and consistently utilize evidence-based practice guidelines in clinical practice cannot be overemphasized; it enhances the delivery of quality treatment and benefit to older adults who are at risk of falling (French, Thomas, Baker, Burton, Pennington \& Roddam, 2009; Ward, Baloh, Zhu $\&$ Stewart, 2017).

\section{Research Question}

This mixed methods research study seeks to answer the following question:

RQ 1. What are the barriers perceived by physical therapists to the use of evidence-based fall prevention programs with individuals of 65 years of age or older?

\section{Research Design}

This study utilized a mixed method descriptive design. This study employed a web-based questionnaire in order to gather both quantitative and qualitative data to evaluate the topic under investigation. This study utilized an online survey platform (PsychData) to collect data to 
investigate and identify the barriers perceived by physical therapists to the use of evidence-based fall prevention interventions with individuals of 65 years of age or older.

\section{Study Participants}

This study surveyed a sample of physical therapists licensed in the state of Texas practicing in various health care settings (home health, out-patient, acute care, skilled nursing facilities, \& in-patient rehabilitation). Licensed physical therapists' emails were obtained from the Texas State Board of Physical Therapy Examiners.

\section{Data Collection}

After Institutional Review Board (IRB) approval of this research, notification emails were sent to the potential study participants inviting them to participate. The e-mail notifications contained the Uniform Resource Locator (URL) where the online survey was completed. The survey was conducted using the online survey platform called PsychData. Data collected was then exported to the current Statistical Package for the Social Sciences (SPSS) software package for data analysis.

\section{Data Analysis}

Quantitative data analysis was completed using the current version of the predictive analytics software, SPSS, version 25. Responses from the participants, obtained from PschyData, were exported to SPSS. Analyses were done using descriptive statistics to answer the research question and describe the items in the survey. The qualitative data was analyzed using the qualitative thematic coding method (Trochim \& Donnelly, 2008).

\section{Assumptions}

The following assumptions support the study:

1. Participants will truthfully answer the questions provided. 
2. The instructions provided to the participants will be clear, understandable and sufficient.

3. The questions provided will be relevant to the content areas of the study.

\section{Limitation of the Study}

The following limitations impacted the mixed methods study:

1. The study sample may not be an accurate representation of all physical therapists.

2. The study may not be generalizable.

3. The sample size.

\section{Delimitations}

The following delimitations were related to the study:

1. The study will be limited to physical therapists licensed in the state of Texas.

2. The surveyed questions will be designed to provide answers to the research questions.

\section{Definition of Terms}

The mixed methods study utilizes the following definition of terms:

Fall - An event which results in a person coming to rest inadvertently on the ground or floor or other lower level (Avanecean, Calliste, Contreras, Lim, \& Fitzpatrick, 2017). Extrinsic Fall Risk Factors - Environmental or external factors that contribute to falls (Tideiksaar, 2010).

Intrinsic Fall Risk Factors - Are factors dependent on the physiological, pathophysiological status of patients and or use of pharmacological agents (Tideiksaar, 2010).

Co-morbidity - The presence of two or more illnesses in the same person (Masnoon, Shakib, Kalisch-Ellet, \& Caughey, 2017).

Exercise tolerance - Ability to cope or endure exercise intensity. 
Activities of Daily Living - Activities performed as part of daily routine (Saito, Murata, Aida \& Kondo, 2017).

Balance - Individual's ability to maintain or restore the equilibrium state of upright stance, without having to change the base of support (Wang, et al., 2010).

Multifactorial Fall Intervention - Use of multiple strategies of balance and strength training measures to reduce fall incidence ( Diener \& Mitchell, 2005).

Polypharmacy - The use of multiple medications, usually, three or more. (Masnoon, Shakib, Kalisch-Ellet, \& Caughey, 2017).

Gait Variability - Gait variability is the measure of rhythmicity or quality of gait cycle. Lack of Support from Facility - No encouragement or provision of equipment to access current research evidence from facility management (Salbach, et al., 2007).

\section{Organization of the Remaining Chapters}

Chapter one contained an overview and the background of the research, it also included a clear and concise problem statement, purpose of the study, and that sequentially pointed and led to chapter two, where there is the review of relevant body of literature for the study. The literature review demonstrated and outlined currently used evidence-based guidelines in the management and prevention of falls in older adults. Chapter three described the research question and the instrument used for data collection, this chapter also illustrated the statistical methods that were used to answer the research question. Chapter four provided the data statistical analyses results into identifying the barriers perceived by physical therapists to the use of evidence-based fall prevention interventions with individuals of 65 years of age or older. Chapter five provided the research conclusions and recommendations for future study. 


\section{Chapter Two \\ REVIEW OF LITERATURE}

\section{Introduction}

The purpose of this study was to identify barriers perceived by physical therapists to the use of evidence-based fall prevention interventions with individuals of 65 years of age or older.

\section{Overview}

The United States (U.S.) Census Bureau (2010) projects that the population of the United States will increase from "310 million to 439 million between 2010 and 2050" (p. 1). During this same period, the population of older adults (65 years and above) in the US is expected to increase by "20\% to 89 million people” (United States Census Bureau, 2010, p. 1). The Census Bureau projected that in 2050 , the elderly population will nearly double its estimated population of “43.1 million in 2012” (US Census Bureau, 2010, p. 1). This projected growth, according to the bureau, will present a wide range of challenges to various stakeholders and to the healthcare industry. Because of this population surge among this age group, various health care professionals will face more of the health-related problems commonly encountered by this age group (Tideiksaar, 2010).

The contributing factors to this growth in the elderly population are due, in part, to increased life expectancy in the U.S., and the advances in medical science (Michael, Lin, Whitlock, Gold, Fu, O'Connor, et al. 2010). According to the US National Center for Health Statistics (2016) life expectancy is higher among older adults in the current generation compared to previous generations, and that life expectancy, in general, increased from 76.8 years to 78.8 years from 2010 to 2015 (76.8 years for males and 81.2 years for females). In 2010, of the approximately 2.6 million Americans who turned 65 years or older, nearly 1.8 million of them 
died, with an annual net gain in the overall population of almost 820,000 individuals ((Federal Interagency Forum on Aging Related Statistics, 2012). The increasing life expectancy and upward trend in the growth rate of population of older adults clearly highlight the magnitude of the health care responsibilities posed by this aging population.

\section{Consequences of Falls}

A fall is the phenomena of unintentionally coming to rest on the ground or another low level surface with or without loss of consciousness when it is not a consequence of sudden onset of paralysis, epileptic seizure, excess alcohol intake or overwhelming force (Carter, et al., 2002). Falls present both a physical and a psychological challenge to the elderly population. With approximately a third of all individuals 65 years and over experiencing a fall each year (Tinetti, Baker, McAvay, Claus, Garrett, \& Gottschalk, 1994; Tinetti \& Williams, 1997), the ramification of falls is literally a matter of life and death. The most common fall- related injuries leading to hospitalization in the elderly are fractures of the femoral neck, tibia, fibula, radius, ulna, vertebrae, pelvis and ribs, with hip fractures being the most serious (Lord, Sherrington, \& Menz, 2001). In the year 2000, among the elderly population, there were almost 750,000 hospitalizations. Falls accounted for $45 \%$ of these in-patient hospitalizations, and fractures were the most common diagnosis, with hip fractures accounting for 314,006 of all the fracture cases (Boye, Van Lieshout, Van Beeck, Hartholt, Van Der Cammen, \& Patka, 2012). In the elderly population, falls account for over $90 \%$ of all hip fractures and the likelihood of hip fracture increases with age; older adults 85 years or above are nearly 15 times more likely to have a hip fracture than individuals 60 years to 65 years of age (Court-Brown, Clement, Duckworth, Biant \& McQueen, 2017; Thorell, Ranstad, Midlov, Borgquist \& Halling, 2014). 
Fall-related traumatic brain injury is another serious and debilitating consequence of falls in the elderly, with falls accounting for nearly $61 \%$ of all traumatic brain injuries (TBI) in individuals 65 years and above in the U.S. (Boye, et al., 2012). In Australia, fall-related TBI were the second most common diagnosis accounting for $20 \%$ of all fall-related injuries (Bradley, 2013). Fall-related TBI are associated with marked cognitive decline and increased onset and progression of dementia symptoms in the elderly (Luukinen, et al., 2005). In the US, fall-related deaths among older adults have taken an upward turn, in the last decade, it was estimated that each year, at least 25,000 older adults died because of falls (CDC, 2015).

Health related quality of life and functional outcomes are substantially decreased after experiencing a fall with injuries in the elderly, and in severe cases, these consequences can lead to placement in long-term care facilities due to care-provider dependence in activities of daily living (Boye et al., 2012). In a Dutch population based study, Hartholt et al. (2011), conducted research on elderly patients who have had hip fractures due to a fall, using the EuroQol-5D (EQ5D). The authors found a significant decrease in quality of life 9 months after the fractures in these domains: mobility (90\% of patients), self-care (54\%), usual activities (73\%), pain/discomfort (69\%), anxiety/depression (28\%), and cognition (38\%). Falls and associated instability can be markers of poor health, decline in physical function and loss of autonomy in older adults (Lord \& Close, 2018). According to the National Center for Injury Prevention and Control, in 2010, falls were responsible for 52\% of all unintentional deaths in individuals 65 years of age and above. In the US in 2003, falls were the leading cause of injuries resulting in deaths in the elderly population, and the ninth overall cause of death in this age group (Michael et al., 2010).

\section{Economic Cost of Falling}


Falling in the elderly population is not only responsible for high risk of injuries and unintentional deaths, but also contributes to a high economic burden on the health care system. The costs associated with providing health care for the elderly is astronomically high. In 2011, the total health care expenses for the elderly, in the U.S., was $\$ 414.3$ billion, which was over \$100 billion higher than inflation-adjusted expenses for 2001 (AHRQ, 2014). In 2002, the elderly constituted about $13 \%$ of the US population, but were responsible for $36 \%$ of total US health care expenditure, averaging $\$ 11,089$ per year, per patient (AHRQ, 2014). In 2013, the estimated total healthcare cost for fall injuries in the elderly was \$34 billion (CDC, 2014). With the projected growth in this population group, researchers expect that both the costs and number of falls are going to keep rising. In 2015, the estimated total direct health care costs attributable to fatal and non-fatal falls was approximately $\$ 50$ billion (Burns, Stevens \& Lee, 2016). For nonfatal falls, Medicare paid approximately $\$ 28.9$ billion, Medicaid $\$ 8.7$ billion, while private and other payers paid $\$ 12.0$ billion, and overall medical spending for fatal falls was estimated to be \$754 million (Florence, Bergen, Atherly, Burns, Stevens \& Drake, 2018).

Fall-related injuries are among the most costly category of injury in older adults (Florence et al., 2018). Older individuals who experienced a fall commonly had larger healthcare utilization costs compared to non-fallers for the year 2002 (Shumway-Cook, Ciol, Hoffman, Dudgeon, Yorkston, \& Chan, 2009). The indirect health care costs include the loss of productivity by family members and other caregivers involved in the care of the older adults (WHO, 2007). The overall health care costs associated with falls constitute a huge economic burden on society. In addition to the economic burden, falls can also have a negative impact on emotional and psychological well-being. Many older adults who sustain a fall develop a fear of 
falling that decreases quality of life and causes them to limit their activities (Kim, Lockhart \& Roberto, 2009).

\section{Etiology and Risk Factors Associated With Falls}

There are numerous risk factors associated with falls because of the many different causes of falls. The complex interplay of both intrinsic and extrinsic factors resulting in an inability to maintain balance in response to changes in sensory information can cause falls in the elderly (Wang, Skubic, Abbott, \& Keller, 2010). The intrinsic factors are risk factors occurring within the older individual, and are usually internal, while external or environmental risk factors make up the extrinsic factors (Tideiksaar, 2010). Rubenstein (2006) found that risk factors are either modifiable or non-modifiable. Some of the modifiable risk factors for falls are the use of multiple medications by older adults (polypharmacy), low economic status, inadequate access to health care, sedentary life-style, and poor ergonomic building design (Rubenstein, 2006; WHO, 2007). Non-modifiable risk factors include age, poor cognition, fear of falling, comorbidity, female gender, and race (Rubenstein, 2006). Other risk factors include previous falls, use of alcohol, hazardous behaviors and use of mobility devices such as canes, walkers and crutches (Pountney, 2009).

\section{Medication Risk Factor}

Older adults tend to have high incidence of chronic comorbidities and use of multiple medications (Pariente et al., 2008; Paul, Gieroba, \& Mangoni, 2007). The use of multiple medications and certain classes of medications has been associated with the risk of falls in the older adults (Jong, Van der Elst \& Hartholt, 2013; Thorell, Ranstad, Midlov, Borgquist \& Halling, 2014). Ziere, Dieleman, Hofman, Pols, Van Der Cammen, and Stricker, (2006) found that $21 \%$ of older adults used at least four or more medications (polypharmacy) and experienced 
more severe adverse drug reactions and falls compared to the general population. The classes of medications commonly responsible for falls in older adults are antidepressants, antihypertensives, neuroleptics and antipsychotics, diuretics, beta blockers, sedatives and hypnotics, narcotics, benzodiazepines, and nonsteroidal anti-inflammatory drugs (Richardson, Bennett \& Kenny, 2014; Woolcott, 2009). In a meta-analysis of observational studies Leipzig, Cumming \& Tinetti (1999) found that older adults who use these classes of medications have higher likelihood of falling compared to those who do not use these medications. Darowski, Chambers, and Chambers (2009) found that these medications produce sedation, impaired reaction times, impaired balance, orthostatic hypotension, and cardiac function disturbances in the older adults which increase the risks of falling.

\section{Chronic \& Acute Disease Risk Factors}

The incidence and prevalence of falls in the elderly may increase with the presence of chronic and acute diseases (Fuller, 2000; Lawlor, Patel \& Ebrahim, 2003). The elderly population is particularly susceptible to commonly occurring acute illnesses and infections such Influenza, Pneumonia and Urinary Tract Infection, with a third of all deaths occurring in individuals 65 years and over, as a result of these infections (Mouton, Bazaldua, Pierce \& Espino, 2001). Common chronic diseases in the elderly include Arthritides, heart failure, cancers, Parkinson's disease, dementia, diabetes, chronic obstructive pulmonary disease, chronic kidney disease, and cerebro-vascular accident (Berg \& Cassells, 1992; National Council on Aging [NCOA], 2017; Pearlman \& Uhlmann, 1987).

Degenerative joint arthritis is a progressive debilitating disorder that contributes substantially to the risk of falls in the elderly (American Geriatrics Society [AGS], 2011). Osteoarthritis of the joints in the lower extremities can result in joint pain, stiffness, swelling and 
difficulty with ascending, and descending stairs, and increases the likelihood of tripping and falls (Tideiksaar, 2010). Osteoarthritis affects more than 50\% of older adults aged 65 , and $70 \%$ of adults 75 years of age or older (Verbrugge, Gates, \& Ike, 1991; Verbrugge, Lepkowski, \& Konkol, 1991).

Congestive heart failure is one of the leading cardiovascular diseases recognized as a major risk factor for falls in the elderly (Jansen, Bhangu, De Rooij, Daams, Kenny \& Van der Velde, 2016) mainly because of its association with orthostatic hypotension (Tideiksaar, 2010). Orthostatic hypotension is associated with changes in position, from sitting to standing, supine to standing or standing to sitting. In the United Kingdom, about $77 \%$ of patients with cardiovascular diseases, including congestive heart failure, present in the Emergency Room with syncope and fall (Carey \& Potter, 2001). One major factor with congestive heart failure is the attendant shortness of breath with minimal exertions. This tends to limit endurance with activities of daily and general exercise tolerance.

Parkinson's disease, a progressive degenerative disorder of the brain, is primarily characterized by tremors, rigidity and festinating gait, affecting elderly patients. Elderly patients with this chronic disease present with increased falls risk and a recurrent fall which is more than double for people with other neurological diseases (Allen, Schwarzel \& Canning, 2013). The unusually high incidence of falls in Parkinson's disease is attributed to postural instability, freezing of gait, lower extremity muscle weakness, and cognitive impairment (Allen, Schwarzel \& Canning, 2013).

Cardiovascular accident (stroke) also results in neuromusculoskeletal dysfunctions with resultant impairments in mobility, sensory deficits, transfers and safety with routine activities of daily living. It is caused by disturbances in the hemodynamics in the brain parenchymal such as 
vascular rupture, thrombosis and embolism. In the acute phase of stroke, fall is one of the commonly encountered complications (Tsur \& Segal, 2010). Similarly, in the rehab phase of stroke, falls are also a common occurrence especially during transfers and mobility training (Nyberg \& Gustafson, 1995). The majority of strokes occur in the elderly, with about $43 \%$ of strokes happening in individuals above 70 years old ((Robins \& Baum, 1981). The prominent risk factors for falls after a stroke include poor cognition, depression, visual neglect, balance dysfunction and muscle weakness (Tsur \& Segal, 2010). In a 12-month study to identify fall status among 115 stroke participants (mean age 70.2 yrs), Ashburn, Hyndman, Pickering, Yardley and Harris (2008) found 55\% of the participants (95\% confidence interval (CI) 46-64) experienced one or more falls, $42 \%$ (95\% CI 33-51) experienced repeated falls, and 54\% experienced near-falls.

\section{Age-related Musculoskeletal Weakness.}

Age-related physiological changes occur in all human systems as individuals advance in age. In the musculoskeletal system age-related physiological changes are evidenced in the strength, power, tone, endurance and the skeletal architecture (Boss \& Seegmiller, 1981; Tideiksaar, 2010). The chronic progressive bone-thickness loss (osteoporosis) in the older adults is particularly significant due to its relevance in fractures following a fall (Netelenbos, et al., 2008). With age the extracellular bio-availability of calcium and vitamin D continues to decrease, coupled with bone resorption, this results in thin bone trabeculae or fragility symptoms raising the likelihood of fracture with minimal ground impact against the bone (Gallagher \& Tella, 2014). Older adults develop more balance and gait deficits due to loss of flexibility, tendon calcification, loss of spinal curvatures, loss of joint cartilage and decreased gait speed (Tideiksaar, 2010). 
Loss of lean body mass and general muscle atrophy are common age-related physiological changes in the musculoskeletal system; in the presence of degenerative joints disease, these result in decreased mobility and slow reaction time (Boss \& Seegmiller, 1981; Kahla, Barkaoui \& Merzouki, 2018). Slow reaction time is a time lapse between the brain receiving a signal and the person responding to that signal. This delay in reaction to perturbation makes the older adult vulnerable to falling. Age-related physiological changes in the musculoskeletal system also affect the postural sway in older adults (Tideiksaar, 2010; Wang, Skubic, Abbott, \& Keller, 2010). Postural sway is the postural movements made by an individual in order to maintain a balanced position, and can be measured by the total displacement of the center of mass relative to the base of support over time; this is an important concept in dynamic balance and safety in the performance of activities of daily living (Cho, Lee, Lee, Lee \& Lee, 2014).

Age-related physiological changes in the older adults can also manifest in balance deficits, slow gait speed, decreased muscle strength, and increased gait variability (Laroche, Greenleaf, Croce \& Mcgaughy, 2014). Hausdorff (2005) and Springer, Giladi, Peretz, Yogev, Simon \& Hausdorff (2006) reported that older adults who demonstrate increased gait variability were significantly slower in responding to the displacement of center of mass outside the base of support, and were five time more likely to fall. Gait variability is the measure of rhythmicity of gait cycle, it increases with age, and results in poor gait quality and likelihood of falls in older adults (Hausdorff, 2005).

The ability to perform simple dual task of walking and talking simultaneously, can be compromised with aging. Hollman, Kovash, Kubik and Linbo (2007) found that in older adults, the inability to walk and talk simultaneously is a strong predictor of poor mobility and increased 
fall risk. Priest, Salamon and Hollman (2008) demonstrated that gait variability and gait instability in older adults is due primarily to deficits in the central nervous system's ability to coordinate motor output which make individuals in this age group susceptible to falling.

\section{Use of Assistive Devices}

Older adults who use assistive devices such as canes, crutches, and walkers have increased fall risks (Bradley \& Hernandez, 2011). The use of assistive devices in older adults is meant to provide increased base of support, enhance static and dynamic balance, and reduce the fear of falling (Bradley \& Hernandez, 2011; West, Bhat, Stevens \& Bergen, 2015). But the use of these devices can put older adults at 2.5 times more at risk of falling compared to non-users (West, Bhat, Stevens \& Bergen, 2015). Bateni and Maki (2005) reported that the use of assistive devices such as canes and walkers can contribute to increased gait quality and balance, these devices can also result in falls in certain situations and terrain were their use requires increased strength and high metabolic demands. The use of assistive devices, such as canes, crutches or walkers, can be beneficial to the older adults, but they can also represent potential fall risk (Liu, Quiben, Holmes, Connors \& Salem, 2017).

\section{Poor Cognition}

Falls in older adults with neurodegenerative disease such as dementia and other cognitive deficits are significantly higher than those who are cognitively intact (Amboni, Barone \& Hausdorff, 2013). Mobility function is a complex interaction of the automatic motor function of the higher brain centers and the executive functions that demands attention, motivation and safety judgement of both external and internal cues (Amboni et al., 2013; Rao, Gilman \& Louis, 2014; Yogev-Seligmann, Hausdorff \& Giladi, 2008). Older adults with impaired cognition nearly always exhibit poor gait quality, decreased balance, lower gait speed and cadence, and other gait 
abnormalities that predispose them to greater incidence of falls and fall-related injuries (Amboni, Barone \& Hausdorff, 2013; Rao, Gilman \& Louise, 2014; Verghese et al., 2006). The annual incidence of falls, injuries and institutionalization among cognitively impaired older adults is approximately $80 \%$ higher than the cognitively intact older adults (Herman, Mirelman, Giladi, Schweiger, \& Hausdorff, 2010; Montero-Odasso, Verghese, Beauchet \& Hausdorff, 2012).

\section{Gender and Race Factors}

Gender and race have been observed to predispose to falling in older adults. Women tend to fall more frequently than men, and are far more likely to incur fractures when they fall (National Center for Injury Prevention and Control [NCIPC], 2003; WHO, 2004). The CDC (2014) estimated that the annual incidence of non-fatal injuries by older adult females was $50 \%$ more than the rate for older adult males, and that older adult females accounted for nearly $76 \%$ of all fall-related hip fractures seen in the emergency room. In another report, the CDC (2008) found that Caucasian older adults fall more frequently than Black, Hispanic, and Other NonHispanic older adults, and that African Americans are generally less likely to experience any fall than Whites in the United States.

\section{Environmental or Extrinsic Risk Factors}

Environmental hazards are important contributory factors to falls in older adults with or without multiple intrinsic falls risk factors (Rubenstein, 2006). According to the Center for Disease Control's National Center for Injury Prevention and Control (2015) about 55\% of falls among older adults occurred inside the home, while about $20 \%$ of falls injuries occurred outside the home. The majority of falls that occur in the home environment occurs in the bedroom, bathroom, kitchen and the stairs areas (Tideiksaar, 2010). Common examples of extrinsic risk factors that contribute to trips or slips inside the home include poor household fittings, poor 
fitting shoes, clutter on the floor; or inadequate use of an assistive device, such as a cane, crutches or walkers; slippery floors; and poor lighting (Chase, Mann, Wasek \& Arbesman 2012; Lord, Menz \& Sherrington 2006; Unsworth \& Mode, 2003).

Other important extrinsic falls risk factors are loose rugs, raised doorways, poorly-placed shelves, pets, low toilet seat, lack of stair handrails, poor stair design, lack of bathroom grab bars, low bed or chair, and obstacles or other tripping hazards (Unsworth \& Mode, 2003). Community environmental hazards that can contribute to falls in older adults include poorly designed sidewalks, pavement cracks, inadequate street markings, slippery floors, and obstacles (Chase, Mann, Wasek \& Arbesman 2012; Tideiksaar, 2010). The reduction of hazards in the household and community environment is an important component of an effective fall prevention program in older adults.

\section{Theoretical Framework}

The mechanism for balance is delicately dependent on the complex interactions of the visual, vestibular, somatosensory and the musculoskeletal sub-centers of the neural network (Tideiksaar, 2010). The seamless integration of cognition, biomechanical, anticipatory, and postural components enables stability and prevents falling during perturbations and displacement of the center of mass outside the base of support (King \& Horak, 2013; Wang, Skubic, Abbott \& Keller, 2010). Age-related physiological changes tend to diminish the coordination of the sensory feedback and motor execution in older adults, and increase the likelihood of falls (Yeh, Cinelli, Lyons and Lee, 2015). The burden of normal aging on the balance sub-system, and the presence of chronic comorbidities such as degenerative joints diseases, peripheral neuropathy, neurodegenerative diseases, and cardiovascular abnormalities put older adults at the greatest fall risks (Nolan, Nitz, Choy, and IIIing, 2010; Tideiksaar, 2010). 
Age-related physiological changes affecting the brain structures and functions significantly increase the risk of falls in older adults (Ward, 2006). Age-related changes in the brain tend to affect the structural and functional integrity, it has been estimated the in older adults, the cerebral volume decreases by as much as $0.23 \%$ annually (Liu, Chan \& Yan, 2014). Significant loss of brain volume occurs in the frontal and pre-frontal lobes leading to deterioration in memory, attention, inhibitory control, and accuracy in safety judgement in older adults (Greenwood, 2007; Liu, Chan \& Yuan, 2014; Raz \& Rodrigue, 2006). Studies have shown that as individual advance in age, the normal brain motor automaticity and movement planning, as seen in the quality of mobility is reduced (Ren, Wu, Chan \& Yan, 2013). Additionally, latelife depression has been related to loss of cortical tissue in the limbic neural network which affects emotional functions in older adults, this has been found to lead to heightened risk of falling (Sexton et al., 2012).

The association between personality types and falls has been established (Kloseck, Crilly, \& Gibson, 2008; Zhang, Ishikawa-Takata, Yamazaki, \& Ohta, 2004). This association revealed that some of the five personality types (extroversion, agreeableness, conscientiousness, neuroticism, and openness) showed wide variation with aging, and that falls affects the personality types that vary most with risk taking, increased gait speed, impulsivity, and emotionally self-regulation, notably neuroticism (Kloseck et al., 2008). Mann, Birks, Hall, Torgerson and Watt (2006) conducted a large cross-sectional study involving 1,691 communitydwelling older adult females, 70 years and above, to determine whether the core personality trait dimension of neuroticism can predict fear of falling. The study found that neuroticism is a significant personality factor in falls and post-fall anxiety syndrome.

\section{Evidence-based Fall Intervention Programs}


All health care professions and clinical practice settings widely advocate and promote the use of research evidence in making clinical decisions in patients' care (Jewell, 2018). Evidencebased practice is defined as the conscientious, explicit, and judicious use of current best evidence in making decisions about the care of individual patients (Jette et al., 2003; Jewell, 2018). The American Physical Therapy Association (APTA, 2012) guidelines describe evidence-based practice as accessing, applying and integrating evidence to guide clinical-decision making to deliver the best patient care, including the integration of best available research, clinical expertise, and patient or client-centered care.

In 2015, the Center for Disease Control made an evidence-based recommendation for the management of falls in older adults to include physical activities that focus on balance and strength functions, medication review to identify medications that may cause dizziness and drowsiness, regular eye exams to optimize visual health, and home safety modifications to reduce environmental hazards. Similarly, arising from this recommendation was the CDC Compendium of Effective Fall Interventions: What Works for Community-Dwelling Older Adults, compiled by Stevens and Burns (2015). The compendium categorizes fall interventions into two broad groups of single interventions and multifaceted interventions (Stevens \& Burns, 2015). The single interventions comprise 15 various therapeutic exercises, 4 home environmental modifications, and 10 clinical interventions that focus on fall risk factors such as gait and balance dysfunctions, while the 12 multifaceted interventions focus on patient's specific multiple risks factors and individualized treatment plans (Stevens \& Burns, 2015).

The American Geriatric Society and the British Geriatrics Society (AGS, 2011) also issued an evidence-based clinical practice guideline for the management of falls in older adults to include patient specific multimodal physical activity programs and strategies to reduce fall risk 
factors. The essential feature of the CDC recommendations and the American and British Geriatric Societies' elements are contained in the CDC compendium of interventions.

\section{Compendium's Single Therapy Interventions}

\section{Stay Safe, Stay Active Program}

The stay safe, stay active program according to Stevens and Burns (2015) was conducted in southwest Australia to a group of 163 older adults, 65 years or older, with various fall risk factors such as lower extremity weakness, poor balance and abnormal reaction time with perturbation. The exercise in the stay safe, stay active program was carried out for one hour a week for 37 weeks with specific focus on balance, resistant-strength training, coordination, and aerobic exercises (Barnett, Smith, Lord, Williams \& Baumand, 2003; Stevens \& Burns, 2015). The study showed that participants in the stay safe, stay active group demonstrated $40 \%$ lower fall rate compared to the control group $(\mathrm{RR}=0.60,95 \%$ CI 0.36-0.99) (Barnett, Smith, Lord, Williams \& Baumand, 2003).

\section{Otago Exercise Program}

The inclusion of exercises in the form of balance exercises or strength training as a component of a multimodal fall prevention programs has long been recognized as an effective tool and strategy in improving overall safety and preventing falls in older adults (Stubbs, Brefka \& Denkinger, 2015). These exercises have been administered as a combination therapy of both strength training and balance exercise (Carter, et al., 2003; Gschwind, et al., 2013), or as a single therapy involving each intervention of balance exercise or strength training program (Faber, Bosscher, Chin A Paw \& Van Wieringen, 2006; Rosendahl, Gustafson, Nordin, Lundin-Olsson \& Nyberg, 2008; Steadman, Donaldson \& Kalra, 2003). An all-inclusive evidence-based fall prevention program is the Otago Exercise Program (OEP). The OEP contains all the 
recommended elements of an effective fall program, namely, balance, strength, and mobility training, including environment modifications and the medication review component (Shubert, Smith, Goto, Jiang \& Ory 2017; Son, Ryu, Jeong, Jang \& Kim, 2016). The OEP was originally developed and validated in New Zealand in the late 1990s, since then the clinical outcome of OEP has been replicated in multiple studies and settings internationally (Kyrdalen, Moen, Roysland \& Helbostad, 2013; Son, Ryu, Jeong, Jang \& Kim 2016).

Physical therapists have reported that the OEP can improve balance, strength, and reduce the incidence of falls among older adults (Campbell \& Robertson, 2003; Shubert, Smith, Goto, Jiang \& Ory, 2017). In a study with 165 elderly participants, Yang et al. (2012) found that the OEP significantly improved Functional Reach and lower extremity strength in participants compared with a control group. In meta-analyses of Randomized Control Trials (RCT), Stubbs, Brefka \& Denkinger (2015) found that the OEP was consistently effective in reducing falls in community-dwelling older adults. In a multicenter RCT in Canada and Australia involving 160 participants, researchers administered the OEP to participants to determine the incident of falls with vertebral fractures in women 65 years or above, and they found the OEP significantly reduced falls with vertebral fractures (Giangregorio, et al., 2014). In a RCT involving 1016 community-dwelling older adults aged 65 years to 97 years, Campbell \& Robertson (2003) and Campbell (1999) found that OEP was effective in reducing by $35 \%$ both the number of falls and the number of injuries resulting from falls, and that the program was equally effective in both men and women.

The study also found that the OEP improved participants' strength and balance functions and maintained their confidence in carrying out everyday activities without falling. In 2011 and 2014, the Center for Disease Control and the Administration for Community Living (ACL) 
endorsed the OEP as an effective and evidence-based fall prevention program (Boutaugh \& Lawrence, 2015; Kaniewski, Stevens, Parker, Lee, 2015; Shubert, Smith, Goto, Jiang \& Ory, 2017). The features of the OEP have been used in a combined therapy approach of both strength training and balance exercise (Carter, et al., 2002; Gschwind, et al., 2013; Yang, et al., 2012), or as a single therapy approach of balance exercise or strength training program with excellent results and improvements in functional abilities and independence in activities of daily living (Faber, Bosscher, Chin A Paw \& Van Wieringen, 2006; Rosendahl, Gustafson, Nordin, LundinOlsson \& Nyberg, 2008; Steadman, Donaldson \& Kalra, 2003).

\section{LiFE (Lifestyle Approach to Reducing Falls Through Exercise)}

The LiFE program was designed as a way of minimizing the risk of falling by incorporating balance and strength activities into activity of daily living for older adults (Clemson, Fiatarone-Singh, \& Munro, 2014). LiFE program study was conducted in Sidney, Australia to a group of community-dwelling older adults, 70 years or older, who have had multiple falls in the previous 12 months (Stevens \& Burns, 2015). The LiFE program focused on integrating balance functions and strength exercises in routine daily activities such as when doing the laundry, during personal hygiene, when answering the telephone, etc, each session lasted 40 to 60 minutes for a total of 5 weeks, the study found that older adults in the LiFE exercise program had $31 \%$ lower fall incidence compared to the control (Stevens \& Burns, 2015).

\section{Erlangen Fitness Intervention}

Erlangen Fitness Intervention research was a randomized control trial (RCT) done in Erlangen, Germany to a group of 217 community-dwelling older adults, 70 years or older, with multiple fall risk factors (Freiberger, Menz, Abu-Omar, Rütten, 2007). The Erlangen fitness 
program focused on Strength, coordination, balance and endurance exercises (Stevens \& Burns, 2015). The goal of this study was to determine the effect of two intervention techniques, namely, psychomotor intervention and physical fitness intervention in reducing falls (Stevens \& Burns, 2015). The study was for one hour session, twice a week for 16 weeks, at the end of the study, the physical fitness group reported $23 \%$ fewer falls than the control group $(\mathrm{RR}=0.77$, 95\% CI 0.60-0.97) (Freiberger et al., 2007).

\section{Senior Fitness and Prevention (SEFIP)}

Senior Fitness and Prevention (SEFIP) was a RCT single-blinded study conducted in the Erlangen-Nuremberg area of Germany, to a group of 246 independent living older adult females with the goal of determining how a single group of high intensity exercise intervention of balance and strength training affects falls, fracture risk, coronary heart disease and health care costs (Kemmler, von Stengel, Engelke, Häberle, \& Kalender, 2010; Stevens \& Burns, 2015). The SEFIP exercise program session was for 60 minutes, once a week for 18 months, the study found that SEFIP participants reported $46 \%$ reduction in the likelihood of falls and $67 \%$ reduction in the likelihood of fall-related injuries compared with control group (Stevens \& Burns, 2015).

\section{Adapted Physical Activity Program}

The adapted physical activity program was a RCT conducted by Kovács, Prókai, Mészáros and Gondos in 2013 for a period of 25 weeks. This study was done on a group of 67 older adult females, 60 years old or above, with the goal of determining the functional outcomes of adapted physical activity program of progressive balance exercise program and safe functional activities on balance, fall risks and quality of life (Kovács et al., 2013). The study found that participants in the adapted physical activity group reported a $60 \%$ reduction in the likelihood of falling compared with the control (Stevens \& Burns, 2015). 


\section{Tai Chi}

Tai Chi, an ancient Chinese practice, has demonstrable multiple health benefits including improving balance functions and reducing the incidence of falls in older adults who regularly engage in this form of exercise (Li, et al., 2005; NCCIH, 2015). In a RCT by Li et al. (2005), Tai Chi was administered for 6 months to 256 elderly participants, ages $70-92$ years old. The primary outcome measure in this study was the number of falls and the secondary outcome was improvement in balance functions measured by the Berg Balance scale, Dynamic Gait Index, Functional Reach test and Single Leg Stance. At 6 months (three times a week), the intervention group that received Tai Chi demonstrated significant fewer falls $(n=38)$ than the stretching control group $(n=73) \mathrm{p}=0.007$; lower proportion of fallers $(28 \%$ versus control $46 \% ; \mathrm{p}=0.01)$, the risk for multiple falls in the Tai Chi group was 55\% lower than that of the control group (RR $0.45 ; 95 \%$ confidence interval, 0.30 to 0.70$)$.

In another study using community-based Tai Chi exercise, Lin, Hwang, Wang, Chang \& Wolf, (2006) investigated the effect of Tai Chi training on functional outcome measured by the Tinetti scale. The study participants were 1,200 elderly community residents randomized into Tai Chi intervention group and the control group (which received only fall educational instructions). After 12 months of intervention, the scores for the Tai Chi group increased by 1.8 points (95\% $\mathrm{CI}=0.2-3.4)$ on the balance component of Tinetti Scale and an increase of 0.9 point $(95 \% \mathrm{CI}=$ 0.1-1.8) on the gait component of Tinetti Scale. This study showed that Tai Chi is an effective intervention in preventing deterioration in functional balance in the elderly with fall risk. The outcome of this study by Lin, Hwang, Wang, Chang and Wolf, (2006) is consistent with the findings of the simplified tai chi study conducted by Wolf et al. (1996) which found that simplified tai chi reduced fall incidence by $47.5 \%$. 
In Australia, Voukelato, Cumming, Lord and Rissel, (2007) conducted a 16-week study to determine the effectiveness of Tai Chi exercise in reducing falls and improving balance functions in 702 older adults, aged 60 years and above. The study demonstrated fewer falls in the Tai Chi group compared with the control group. Using the Cox regression analysis, the time before the first fall and the hazard ratio after 16 weeks was $0.72(95 \% \mathrm{CI}=0.51-1.01, \mathrm{p}=0.06)$, and after 24 weeks was $0.67(95 \% \mathrm{CI}=0.49-0.93, \mathrm{p}=0.02)$.

\section{Australian Group Exercise Program}

The Australian group exercise program was a 12 month duration study conducted in a retirement facility in Sydney and Wollongong, Australia (Lord, et al., 2003). The study involved 551 participants ages 62 to 95 years old, with the goal of determining whether a group of exercises of aerobic, progressive strength training and mobility training administered for one hour, twice a week for 12 months can improve functional outcomes and reduce fall incidences (Lord, et al., 2003; Stevens \& Burns, 2015). The Australian group exercise program participants demonstrated $22 \%$ lower fall rate compared with the control $(\mathrm{RR}=0.78,95 \% \mathrm{CI}=0.62-0.99)$ and $31 \%$ fewer falls in participants who fell the previous year of the study compared with the control group $(\mathrm{RR}=0.69,95 \% \mathrm{CI}=0.48-0.99)$ (Lord, et al., 2003).

\section{Yaktrax Walker}

The Yaktrax Walker is a nonmedical traction device worn over shoes in winter weathers to prevent falls in older adults (McKiernan, 2005). The device was tested in a group of 109 older adults, 65 years or above, in Wisconsin during the winter months, to determine if the device could prevent injurious and non-injurious falls in this population (McKiernan, 2005; Stevens \& Burns, 2015). The study found that participants who used this device reported $50 \%$ fewer slips, 
and $60 \%$ reduction in the likelihood of falling compared to the control group (Stevens \& Burns, 2015).

\section{Veterans Affairs Group Exercise Program}

This study was a RCT conducted by Rubenstein et al. (2000) in a Veteran Affairs ambulatory center in California, the goal was to determine the outcome of a group of low to moderate intensity exercises of progressive resistant strength training, balance and endurance exercises on balance, strength, mobility and fall incidence in older adults with chronic impairments. The participants were 59 older adult males, 70 years or above, the participants received this group exercise program for 90 minutes a session, three times a week for 12 weeks duration (Rubenstein, et al., 2000). The study demonstrated that participants reported 66\% reduction in the likelihood of falls when compared to the control (6 falls/1000 hours of activity vs 16.2 falls/1000 hours, $\mathrm{p}<.05)$ (Rubenstein, et al., 2000).

\section{Falls Management Exercise (FaME) Intervention}

FaME was a RCT designed to determine the outcome of a 36 week individually tailored group of exercises and home care intervention on lower extremity and core strength and patient's dynamic balance functions (Skelton, Dinan, Campbell, \& Rutherford, 2005). The participants were 50 independent living older adult females, 65 years or above, with a history of multiple falls, the participants received balance and strength specific exercises for an hour a week for 36 weeks (Stevens \& Burns, 2015). The FaME study demonstrated that participants who received these individually tailored exercises reported $31 \%$ fewer falls than the control group (RR 0.69, 95\% CI 0.50-0.96, P = 0.029) (Skelton, Dinan, Campbell, \& Rutherford, 2005).

\section{Music-Based Multitask Exercise Program}


Another evidence-based fall prevention program for older adults in the CDC compendium is the music-based multitask exercise program. This RCT study was conducted in Geneva Switzerland for a group of 134 community-dwelling older adults with multiple fall risk factors and previous history of falls (Trombetti, et al., 2011). Participants received multitask exercise program performed to Jaques-Dalcroze eurhythmics music for an hour a week for 6 months, at the end of the study, participants reported fewer falls and 54\% reduction in the likelihood of fall (relative risk, $0.61 ; 95 \%$ confidence interval, 0.39-0.96) (Stevens \& Burns, 2015; Trombetti, et al., 2011).

\section{Multi-target Stepping Program (MTS).}

The MTS study was a RCT conducted on a group of 264 community-dwelling older adults in Kyoto, Japan, who demonstrated poor balance, general debility and multiple fall risk factors (Yamada, et al., 2013). The program involved targeted stepping in and out of multiple squares aimed at improving functional mobility, balance and safe foot positioning (Stevens \& Burns, 2015). The participants received this intervention for 7 minutes a session for 24 weeks, at the end of the study a third of the participants reported fewer non-injurious and injurious falls compared to the control group $(\mathrm{RR}=0.35,95 \% \mathrm{CI}=0.19-0.66)$ (Stevens \& Burns, 2015; Yamada, et al., 2013).

\section{Other Single Therapy Intervention Exercises}

\section{Balance Exercise Programs}

Balance exercises or lower extremity strength training is often used by physical therapists as a stand-alone intervention in the management of falls in older adults to improve balance functions, self-confidence, quality of life, safety in the performance of daily activities and reduce falls (Faber, Bosscher, Chin A Paw \& Van Wieringen, 2006; Steadman, Donaldson \& Kalra, 
2003). Rosendahl, Gustafson, Nordin, Lundin-Olsson and Nyberg (2008), conducted a RCT of fall prevention program by administering a high-intensity multi-faceted functional balance exercises to the intervention group, and the control group received non-specific aerobic activities. Using the number of falls in the participants as outcome measure, the study found that the intervention group had a lower fall rate compared to the control group (intervention 2.7 falls per Person Years, control 5.9 falls per Person Years), RR was (95\% CI) 0.44 (0.21-0.91), p = 0.03 .

In a multi-center RCT Faber, Bosscher, Chin A Paw and Van Wieringen, (2006), sought to determine the effect of a 20 -week moderate intensity balance exercises on the number of falls and performance of functional activities among elderly residents of long-term care facilities. The results showed a reduction in the number of falls (2.4 falls per year) and falls risk (Hazard Ratio $=0.39 ; 95 \% \mathrm{CI} ; 0.18-0.88)$ among the intervention group compared to the control group (5.5 falls per year).

Mansfield, Wong, Bryce, Knorr and Patterson, (2015) investigated the effectiveness of perturbation-based balance exercise program on the number of falls in the elderly population with neurological disorders. This study, a systematic review and meta-analysis of RCT involved 404 older adults. Results of this study showed that participants who completed the perturbationbased balance training were less likely to fall $(\mathrm{RR}=0.71 ; 95 \%$ confidence interval $=0.52,0.96$; $\mathrm{p}=0.02)$ and reported fewer falls than those in the control group $(\mathrm{RR}=0.54 ; 95 \% \mathrm{CI}=0.34$, 0.85; $\mathrm{p}=0.007)$. Balance training programs of multiple variations such as the Tai Chi and perturbation-based training, have all demonstrated good efficacy in reducing fall incidences and improving functional balance outcomes in older adults with fall risks (Stevens \& Burns, 2015).

\section{Strength Training Programs}


Strength training program is another component of the multi-factorial fall intervention program that is often administered as a single intervention besides balance training. Strength training program is administered to reduce or delay the age-related sarcopenia in older adults that tends to weaken muscle strength and reduce muscle bulk in older adults (Ji, Han \& Won, 2015; Tideiksaar, 2010). Aging tends to manifest the cumulative systemic impairments and multiple disease processes that potentially weaken the musculoskeletal system that make older adults susceptible to falls (Soriano, DeCherrie \& Thomas, 2007). Strength training exercise is aimed at slowing down the progressive muscle weakness commonly found in older adults.

In an RCT by Liu-Ambrose et al. (2004), conducted a study to determine the effects of lower extremity strength training program in reducing falls in community dwelling older women. The single-blinded study had 98 participants that received resistance strength exercises administered for 25 weeks, the fall risk was measured using the physiological profile assessment (PPA). The result showed a significant reduction in the PPA of 57.3\% in the strength training group versus $20.2 \%$ in the control group $(\mathrm{p}=0.005)$. Lower extremity strength training program can significantly lower the fall risks, improve balance functions and self-confidence in older female adults (Liu-Ambrose, et al., 2004).

Similarly, Cho and An (2014) investigated the effect of an 8-week strength training program on the balance functions of older female adults over the age of 75 years with multiple fall risks factors. A total of 55 subjects participated in this study. Muscle strength and balance were measured before and after intervention, using the hand held dynamometer and Tetrax Fall Index respectively. After the intervention, the Fall Index score of the strength training group decreased from $59.0(22.0)$ to $44.5(17.4)$, showing a statistically significant decrease $(\mathrm{t}=5.77 ; \mathrm{p}$ 
$<0.001)$. The balance index score is rated between $0-100$, the higher the index, the higher the risk of falling.

In an outpatient rehabilitation setting, Hauer et al. (2001) conducted a RCT involving 57 female participants, to determine the safety and efficacy of progressive resistance training on the number of falls. After 3 months intervention (for 3 times weekly), fall incidence was reduced by $25 \%$ in the intervention group compared with the control group $(\mathrm{RR}=0.753 \mathrm{CI}=0.455-1.245)$. This study demonstrated that progressive resistance strength training is a safe and effective means of reducing falls in frail, high risk geriatric patients with a history of injurious falls (Hauer et al., 2001).

Strength training exercise is an effective intervention in preventing falls in older people with fall risks (Stevens \& Burns, 2015). In 2003, Barnett, Smith, Lord, Williams \& Baumand, (2003) conducted a research to determine the effect of strength training intervention on balance, health status and fall prevention in at risk community-dwelling older adults. The study participants were 163 older adults aged 65 years and above, with multiple fall risk factors, identified to be at risk for falls based on their performance on a 30-second chair sit to stand test. Participants were randomized into intervention and control groups, after 12 months of intervention, the rate of falls in the intervention group was $40 \%$ lower than that of the control group $(\mathrm{RR}=0.60 ; 95 \%$ CI $0.36-0.99)$ who received no treatment. This study, and other similar studies, supports the use of strength training exercise in fall prevention in the older adults' population.

Age-related physiological muscle weakness in the elderly is directly proportional to functional decline and is reversible with resistance exercise training (Chandler, 1998; Tideiksaar, 2010). Functional decline can manifests in inability to perform common activities of daily living 
such as chair to bed transfers, bathroom transfers, sit to stand transfers, household mobility with or without mobility device, grooming and dressing (Guggenheimer, Olsen, Kurvers \& Barron, 2017). Strength training in the elderly does not only reduce falls, but also forestalls the effects of aging on functional limitations, disability and the attendant declines in quality of life (McAuley, Szabo, Gothe, \& Olson, 2011; Seguin \& Nelson, 2003). Sedentary lifestyles and general physical inactivity in the elderly is usually due to psychological fear of falling which further compounds and complicates physiological impairments associated with the aging process (Guggenheimer, Olsen, Kurvers \& Barron, 2017; McAuley et al., 2011). According to CDC (2015), other benefits of strength training exercises include ability to reduce signs and symptoms of several chronic disease conditions, such as: arthritis, diabetes, osteoporosis, obesity, back pain, and depression, enhance quality of sleep, and improved cardiac health, self-confidence, self-esteem and general quality of life.

\section{Home Modification}

The CDC compendium also include four evidence-based home modification studies, namely, the VIP Trials, Home Visits by an Occupational Therapist, Falls-HIT (Home Intervention Team) Program and the Home Assessment and Modification program (Stevens \& Burns, 2015). These studies were shown to improve environmental safety for older adults at risk of falling, and reduced the risks posed by hazards in the immediate living environment. These home modification studies were carried out on a one-on-one home visits by occupational therapists with the aim of evaluating and reducing home environmental hazards and encouraging healthy behavioral changes (Campbell, et al., 2005; Cumming, et al., 1999; Nikolaus \& Bach, 2003; Pighills, Torgerson, Sheldon, Drummond, \& Bland, 2011). Participants in these studies reported significantly fewer numbers of falls compared to the control group (Campbell et al., 
2005; Cumming, et al., 1999; Nikolaus \& Bach, 2003; Pighills, Torgerson, Sheldon, Drummond, \& Bland, 2011).

\section{Clinical Interventions}

The clinical interventions component of the CDC compendium included ten studies of interventions that are outside the scope of physical therapy practice. These clinical interventions range from medications prescription and use, to cataract surgery and podiatry procedures (Stevens \& Burns, 2015). The medications that were commonly prescribed and administered in the clinical interventions studies to older adults with risk of falling were cholecalciferol and calcium (Stevens \& Burns, 2015), these studies demonstrated that older adults on a daily dose of cholecalciferol and calcium reported on an average of $44 \%$ fewer falls and reduced fracture incidence compared with control (Bischoff-Ferrari, Orav, \& Dawson-Hughes, 2006; Gallagher, Fowler, \& Sherman, 2001; Harwood, Sahota, Gaynor, Masud, \& Hosking, 2004; Pfeifer, et al., 2009). Additionally, when certain classes of medications like the psychotropic medications (benzodiazepine, antidepressant, or major tranquilizer) are withdrawn from older adults, participants achieved $64 \%$ reduction in fall rates (Campbell, Robertson, Gardner, Norton, \& Buchner, 1999).

Other components of the clinical interventions are cardiac pacemaker placement for fall risk older adults with cardiovascular health condition called cardio-inhibitory sinus hypersensitivity, cataract eye surgeries and visual exams to improve vision and ocular health, and podiatry procedures to repair foot deformities and use of orthotic devices to improve balance and functional mobility (Stevens \& Burns, 2015). Participants who received these clinical interventions demonstrated significantly reduced fall incidence compared with the control (Haran, et al., 2010; Harwood, et al., 2005; Kenny, et al., 2001; Spink, et al., 2011). 


\section{Multifaceted Interventions}

\section{Stepping On}

The Stepping On study is one of the twelve components of the multifaceted interventions of the CDC compendium. This study was conducted on a group of 310 community-dwelling older adults, aged 70 years or above, with previous history of falls (Stevens \& Burns, 2015). The Stepping On involved lower extremity strength training, balance exercises, environmental modification program, medication review and behavioral safety components (Clemson et al., 2004). The study was administered to the participants for two hours a week for seven weeks, at the end of the study, the participants on the Stepping On program achieved a $31 \%$ reduction in the fall rate $(\mathrm{RR}=0.69,95 \% \mathrm{CI}=0.50-0.96 ; \mathrm{P}=.025)$ (Clemson, et al., 2004; Stevens \& Burns, 2015).

\section{PROFET (Prevention of Falls in the Elderly Trial)}

The PROFET study was a RCT conducted by a team of inter-disciplinary health professionals on a group of 184 older adults, aged 65 years or older, who had presented to the emergency room for a fall related accidents (Close et al., 1999; Stevens \& Burns, 2015). The participants received a multifaceted intervention of screening and treatment for vision, postural hypotension, cognition and depression, also included were medications review, home environmental modifications, and balance specific exercises (Stevens \& Burns, 2015). The interventions were provided by a team of expert physicians and occupational therapists for 60 minutes a week for 12 months, at the conclusion of the study, participants in the PROFET study demonstrated $67 \%$ reduction in the likelihood of falling compared with control group (odds ratio $=0.39,95 \%$ CI 0.23-0.66) accidents (Close et al., 1999; Stevens \& Burns, 2015).

\section{Accident \& Emergency Fallers}


The accident and emergency fallers program was another RCT conducted by a team of inter-disciplinary health professionals on a group of 313 fall risk older adults, aged 65 years or above, with of multiple falls and emergency room visits for fall related injuries (Davison, Bond, Dawson, Steen, \& Kenny, 2005; Stevens \& Burns, 2015). The participants in this program received a multifaceted intervention of neurological, cardiovascular, visual and medications examinations and review, also provided in the study were strength, balance and functional mobility training with home hazards modification (Davison et al., 2005; Stevens \& Burns, 2015). The accident and emergency fallers program was provided by a team of physicians, occupational and physical therapists for an hour a session, twice a week for 12 months, the study found that participants in the program showed $36 \%$ reduction in falls compared with the control group (RR 0.64, 95\% CI 0.46-0.90) (Davison et al., 2005; Stevens \& Burns, 2015).

\section{The NoFalls Intervention}

The NoFalls Intervention RCT was conducted in Sidney, Australia, on a group of 1090 older adults with multiple fall risk factors, this NoFalls intervention comprise strength, balance and flexibility exercises and visual examination with home hazards modifications (Day et al., 2002). The study participants, aged, 70 years or above, received this multifaceted intervention as a group exercise for 90 minutes a session for 15 weeks (Stevens \& Burns, 2015) and at the conclusion of the study participants in the NoFalls group reported $30 \%$ reduction in the likelihood of falling and 14\% fewer falls compared with the control group (RR 0.67 (0.51 to 0.88, $\mathrm{P}=0.004)$ (Day et al., 2002).

\section{The Study of Accidental Falls in the Elderly (SAFE) Health Behavior and Exercise Intervention}


The SAFE study was a large RCT involving 3,182 older adults with high risk of falls in Oregon and Washington states (Hornbrook et al., 1994). The participants, aged 65 years or older, received a multifaceted intervention of home safety modifications, exercises program with special focus on strength, posture and balance, with behavioral safety modifications (Stevens \& Burns, 2015). The SAFE study was conducted for 90 minutes a session, for four times a week, for one month, participants in the SAFE study reported $15 \%$ less fall compared with the control group (Hornbrook et al., 1994; Stevens \& Burns, 2015).

\section{Falls Team Prevention Program}

The Falls Team Prevention Program was a RCT conducted by a team of inter-disciplinary health care professionals of physicians, nurses, physical and occupational therapists on a group of 204 older adults, aged 60 or older, with a history of falls (Logan et al., 2010). The participants received a multifaceted intervention of fall education, home modifications, medication reviews, balance and strength training programs in a group setting for two hours a session, twice a week, for a total of six weeks (Logan et al., 2010; Stevens \& Burns, 2015). At 12 months follow-up after the conclusion of the study, participants in the falls team prevention program reported 55\% reduction in the incidence of falls compared with the control group (Logan et al., 2010, Stevens \& Burns, 2015).

\section{KAAOS (Falls and Osteoporosis Clinic)}

The KAAOS study was a RCT conducted by a team of inter-disciplinary health professionals on a group of 1314 older adults, aged 70 years or more, with multiple fall risk factors and fall related injuries in Finland (Palvanen et al., 2014; Stevens \& Burns, 2015). The participants received a multifaceted intervention of individualized balance and strength training exercises, medication review and prescription for calcium and cholecalciferol coupled with home 
modification program with the view of identifying and removing home safety hazards (Palvanen et al., 2014; Stevens \& Burns, 2015). The interventions were provided by physicians, nurses and physical therapists for 60 minutes a week for 52 weeks, at the end of the study, older adults in the KAAOS group reported $28 \%$ reduction in fall incidence and $26 \%$ reduction in likelihood of injurious falls compared with the control (Palvanen et al., 2014; Stevens \& Burns, 2015).

\section{Multifactorial Fall Prevention Program}

This RCT study was not as effective in reducing the overall fall rate in the participants (Stevens \& Burns, 2015). The multifactorial fall study was conducted by Salminen, Vahlberg, Salonoja, Aarnio, and Kivelä in Finland in 2009 on a group of 591 older adults, aged 65 years or more, the study did not show significant improvement in the overall fall incident rate in the participants that received the multifaceted intervention of fall education program and home hazards modification (Salminen et al., 2009; Stevens \& Burns, 2015). But among the participants in a subgroup of those who have had three or more falls the previous year of the study, there was $41 \%$ reduction in the fall rate (Salminen et al., 2009; Stevens \& Burns, 2015).

\section{Nijmegen Falls Prevention Program (NFPP) for adults with Osteoporosis}

The NFPP was a RCT conducted on a group of 96 older adult participants with an established medical diagnosis of osteoporosis and a history of falls (Smulders et al., 2010; Stevens \& Burns, 2015). The participants in this study were community-dwelling older adults, aged 65 years or more, received multifaceted fall intervention program of fall education, functional gait variability training, resistant strength training and safe falling strategy, these interventions were administered by a team of physical and occupational therapists for up to 3 hours a session for 5.5 weeks duration (Smulders et al., 2010; Stevens \& Burns, 2015). The study concluded with a significant reduction in the fall rate of $39 \%$ in the NFPP participants compared 
with the control group (.72 vs 1.18 falls/person-year; risk ratio, .61; 95\% confidence interval, .40-.94) (Smulders et al., 2010; Stevens \& Burns, 2015).

\section{The Winchester Falls Project}

The Winchester falls project was a cluster RCT conducted in the United Kingdom with the goal of investigating the outcome of primary and secondary care based multifaceted interventions on fall rate reduction in older adults (Spice et al., 2009: Stevens \& Burns, 2015). The study participants were 505 older adults, aged 65 years or above, with a history of multiple falls living in the community (Spice et al., 2009; Stevens \& Burns, 2015). The participants received a physician assessment and care (for medication review, visual examination and advice on alcohol cessation), nurse assessment and care (for postural hypotension and continence), physical therapy intervention (for gait, balance and strength training program) and occupational therapist care (for safe foot wares and environmental safety modification) (Spice, et al., 2009; Stevens \& Burns, 2015). The participants in the Winchester falls project demonstrated a 50\% reduction in the likelihood of falls compared with the control group (Spice et al., 2009; Stevens \& Burns, 2015).

\section{Yale FICSIT (Frailty and Injuries: Cooperative Studies of Intervention Techniques)}

The Yale FICSIT study was conducted by Tinetti et al. (1994) on a group of 301 older adult participants, aged 70 years or more, with at least one of the following risk factors: postural hypotension, polypharmacy, gait abnormality, lower extremity strength, and joints range of motion limitations, and inability to safely transfer. The participants received multifaceted intervention from a nurse practitioner and a physical therapist with individualized focus on progressive resistant strength and balance training with medication review, home safety modification and visual examination (Stevens \& Burns, 2015; Tinetti et al., 1994). The 
participants in the Yale FICSIT group reported $30 \%$ fewer fall rate compared with the control group (Stevens \& Burns, 2015; Tinetti et al., 1994).

\section{A Multifactorial Program}

The study outcome of this program, like the multifactorial fall prevention program, was not as successful as other studies in the multifaceted intervention section of the CDC compendium. The study participants demonstrated a modest $10 \%$ reduction in the fall incidence compared with the control (Wagner et al., 1994). The participants were 1559 older adults with multiple fall risk factors and received a fall education program on vision and hearing impairments, home modification, medication review, need to exercise and alcohol use (Stevens \& Burns, 2015; Wagner et al., 1994).

\section{Multifaceted Combination of Balance and Strength Interventions}

In a systemic review of multiple RCT of interventions to reduce falls in communitydwelling older people, Gillespie et al. (2012) researched 40 trials that used a combination therapy of strength training and balance exercises in participants 65 years or above. The studies showed that the combination therapy group demonstrated a significantly reduced rate of falls (RR 0.71 , 95\% CI 0.63 to $0.82 ; 16$ trials; 3622 participants) and risk of falling (RR $0.85,95 \%$ CI 0.76 to 0.96; 22 trials; 5333 participants). Joshua et al. (2014) arrived at the same conclusion that combination therapy of strength and balance exercises can significantly reduce the incidence of falls in older adults with multiple risk factors.

Rapp et al. (2008) conducted a similar study to determine the effect of combination therapy of strength training and balance exercises, involving residents of several nursing homes in Germany, who were at risk of falls or have had multiple falls. The participants in this study were 725 older adults with a median age of 86 years. The result showed a significant decrease in 
the number of falls among the intervention group, the incidence rate ratio (RR) for the effect of combination therapy on the number of falls was $0.56(95 \% \mathrm{CI}=0.42-0.74)$ and the time before the participants' first fall was a hazard ratio of $0.70(95 \% \mathrm{CI}=0.56-0.87)$.

In a British study involving 1,256 participants over the age of 65 years, Iliffe et al. (2014) conducted a RCT to evaluate the impact of strength training and balance exercises on the number of falls in older adults with multiple fall risk factors. After 12 months of intervention, with 150 minutes per week, there was a significant reduction in the number of falls in the intervention group which received a combination therapy of lower extremities strength training and balance exercises compared with the control group (RR $0.74,95 \%$ CI 0.55 to $0.99 ; \mathrm{p}=0.042$ ) which received only chair aerobics. Therefore, as shown in this study, elderly participants who engage in physical activities of strength training and balance exercises can significantly reduce their risk of falls, incidence of hip fractures and mortality from all causes (Iliffe, et al., 2014).

In a study involving 149 female individuals aged 70-78 years, Karinkanta, Kannus, UusiRasi, Heinonen and Sievänen, (2015) conducted a RCT trial to evaluate the effect of combined strength training and balance exercises in reducing injurious falls. The results showed the rate of injured fallers was $62 \%$ lower in the intervention group compared with the control group (HR $0.38,95 \%$ CI 0.17 to 0.85 ) who received only chair aerobics. Additionally, the intervention group had $51 \%$ less injurious falls (RR $0.49,95 \%$ CI 0.25 to 0.98 ) and $74 \%$ less fractures (RR 0.26, $95 \%$ CI 0.07 to 0.97 ) compared with the control group (Karinkanta et al., 2015).

The combination therapy of progressive strength training and balance exercises is an important component of falls management therapy; it is also an essential factor in improving bone architectural density older adults (Duckham et al., 2015). Improved bone density in older adults can significantly reduce the risk of fractures after a fall. Among older adults, fractures, 
especially hip fractures, are the most common injuries resulting from falls and the leading cause of placement in long-term care facilities (Boye et al., 2012; Hartholt et al., 2011). In a 12 month study by Gianoudis et al. (2014), involving 162 elderly participants, the study demonstrated the impact of resistance strength training on bone mineral density (BMD) of femoral neck and lumbar spine measured by Dual-energy X-ray absorptiometry before and after intervention. A significant increase was demonstrated in the femoral neck and lumbar spine BMD (1.0\% to $1.1 \% ; \mathrm{p}<0.05$ ), functional muscle power (measured by Timed Stair Climb, 5\%; $<<0.05$ ) and dynamic balance (measured by Four Square Step Test 6\%, p $<0.01$; Sit-to-Stand, 16\%; $\mathrm{p}<0.001$ ) relative to the control group (Gianoudis et al., 2014). From these studies, a multimodal exercise program is an effective approach in older adults with multiple musculoskeletal dysfunctions with falls risk factors and low BMD (Gianoudis et al., (2014).

\section{STEADI Fall Prevention Measure}

In 2012, the CDC developed its own evidence-based fall prevention tool kit called STEADI (Stopping Elderly Accidents, Deaths, \& Injuries) for health care providers (CDC, 2017). STEADI was developed in line with the recommendations of the American and British Geriatrics Societies' (AGS/BGS) fall prevention practice guidelines (CDC, 2017; Stevens \& Phelan, 2013). The STEADI program seeks to identify patients at low, moderate, and high risk for a fall, identify modifiable risk factors, and offer individually designed effective intervention programs (Sarmiento \& Lee, 2017; Stevens, 2013). The STEADI toolkit contains an algorithm for basic information about falls, standardized balance, gait, and lower extremity strength assessment tests such as the Timed Up and Go test, the 30-second chair sit to stand, and the 4stage balance test (CDC, 2017; Sarmiento \& Lee, 2017; Stevens, 2013). It also includes directions for measuring orthostatic blood pressure because postural hypotension is a frequent 
cause of falls in the older population, and directions for referral to fall-clinical specialists (physical therapists, neurologists, $\&$ podiatrists) and community fall prevention programs and centers (Stevens, 2013; Stevens \& Phalen, 2013).

\section{Physical Therapists Behaviors and Attitudes in Using Evidenced-based Practice}

The need to implement evidence in clinical practice has been advocated by numerous health care professions because of the multiple benefits to the health care system (Jewell, 2017; French et al., 2009; Ward, Baloh, Zhu \& Stewart, 2017). According to Stroud (2014), physical therapists have positive opinions and attitudes toward evidence-based practice and majority view it as being valuable in achieving positive health outcomes.

In a cross-sectional, web-based questionnaire study, Nilsagard and Lohse (2010) sampled 2,160 physical therapists to determine their knowledge, attitudes, and behaviors in using evidence-based practice. The authors found that the more advanced educational qualifications the physical therapists possess, the greater their knowledge and willingness to use evidence-based practice, and the fewer their reported barriers. This study also found that other commonly reported barriers to the use of evidence-based practice was lack of support and interest from facility managers.

In a similar study, Fruth et al. (2010) conducted a study to determine physical therapists' opinion, beliefs and practices in using evidence-based practice in Sweden. The authors sampled 24 US physical therapists from various clinical settings and found that, while the majority of the sampled physical therapists agreed that evidence-based practice must be utilized at all time, they do not always utilize the evidence due to multiple barriers such as lack of access to publications and what to do with the evidence. 
In 2009 in Belgium, Hannes, Staes, Goedhuys and Aertgeerts conducted a study to determine the obstacles to the implementation of evidence-based practice in clinical interventions. The authors sampled 43 physical therapists and found that the barriers to the implementation of research evidence in health care among physical therapists were the burdensome regulations, lack of physical therapy practice autonomy and professional struggle among various health care professionals in Belgium.

In 2014, Stroud conducted a study to determine physical therapists attitudes toward the use of evidence-based practice. Stroud sampled 316 U.S. physical therapists and found that the more experienced physical therapists tend to consistently use evidence-based practice and report fewer barriers than those with less years of experience. The study also showed that majority of the sampled physical therapists believed evidence-based practice utilization is important to patients' care, they do not utilize the available evidence due to time constraints in accessing literature.

\section{Promoting Action on Research Implementation in Health Services (PARiHS)}

PARiHS was first conceptualized in 1998 to promote the framework of implementing synthesized clinical research and evidence in health care practice (National Collaborating Centre for Methods and Tools [NCCMT] (2011). Since inception in 1998, PARiHS has gone through three phases of updates to accurately capture the complex interplay of the sub-elements of PARiHS, namely, evidence (E), context (C) and facilitation (F) (NCCMT, 2011; Stetler, Damschroder, Helfrich \& Hagedorn, 2011; Ward, Baloh, Zhu \& Stewart, 2017). The success or failure of PARiHS has been found to be dependent on the quality of the available evidence and the willingness to implement the evidence in practice by health care professionals (NCCMT, 2011; Kitson, et al., 2008). For unknown reasons, only a small fraction of available research and 
evidence are translated into practice in health care (Damschroder, et al., 2009; McGlynn, et al., 2003). The need to identify the barriers in research implementation and bridge the associated gap has been advocated in literature (Harvey \& Kitson, 2016; Stroud, 2014).

\section{Barriers to Fall Prevention Programs in Older Adults:}

Individually tailored exercise programs are part of the most successful interventions to prevent falls in older adults, improve balance functions and improve confidence in older adults with high risk for falls (Chang, et al., 2004; Haas, et al., 2012; Mailey, Phillips, Dlugonski, \& Conroy, 2016). The probability of older adults complying with and continuing prescribed fall prevention exercise program depends on the type, intensity, and duration of the exercises (Henry, Rosemond \& Eckert 1999). The goal of fall prevention exercise prescription should be the successful integration of exercise principles, risk avoidance and behavioral modification that motivates the older adults to be compliant in achieving the stated goals (Mailey, Phillips, Dlugonski, \& Conroy, 2016).

The use of general exercise programs is known to reduce disability and improve quality of life, but chronic debility and physical disabilities associated with chronic diseases such as congestive heart failure, chronic obstructive pulmonary disease, pneumonia, Parkinson disease, cancers, etc. are common barriers to exercise participation in older adults (Blaney, et al., 2010; Ellis, et al., 2013; Hoffmann, et al., 2016). Other notable barriers to participation in fall prevention exercise program among older adults include advancing age, depression, poor perceived health, poor body image, fear of injury, lack of time, and family obligations (Forkan, et al., 2006; Schutzer, 2004).

Physical therapists' beliefs, perceptions and attitudes can contribute to barriers in the use of standardized fall prevention exercise programs in older adults (Salbach, et al., 2007; Stroud, 
2014). Stenberg and Wenn-Hansson (2010) found that though evidence-based practice guidelines are effective in reducing fall incidence in acute care settings, health care professional do not frequently use them due to barriers such time constraints to search literature databases, what to do with the evidence, and lack access to current research evidence. These barriers tend to increase health care costs and facilitate waste (Al-muqiren, Al-Eisa, Alghadir \& Anwer 2017; Jette et al., 2003; Stenberg \& Wenn-Hensson, 2010). Jette, et al. (2003) found that the number of years since licensure, and access to, and knowledge of these research evidences also contribute as barriers to effective fall prevention program on the part of health care professionals. According to Wheeler, Coogle, Fix, Owens and Waters (2018) and Loganathan, Ng, Tan and Low (2015), health care professionals can inadvertently contribute to poor functional outcomes in older adults receiving evidence-based fall prevention program due to knowledge deficits of these practice guidelines and or perception of the guidelines. Other contributing factors and barriers to the effectiveness of fall prevention program in older adults include ethnic and cultural differences between older adults and the health care professionals, poor inter-professional communication, and health care professionals' perception of their working environment (Amacher, et al., 2016; Loganathan, Ng, Tan \& Low, 2015).

\section{Summary}

The review of literature showed that falls are a significant problem and are a concern among community-dwelling older adults and also for those living in long term care facilities. The consequences of falling considerably impact the quality of life of older adults and constitute a significant economic burden to society. Injuries are frequently associated with falls in older adults, which begins a downward spiral in functional independence, institutionalization, and death. Physical therapists play a major part in the prevention and management of falls among 
older adults. Evidence-based intervention programs have been developed and are widely available for use as demonstrated in this literature review. Numerous studies show physical therapists' perceptions, beliefs and attitudes are positive toward the use of evidence-based practice in fall prevention in older adults, and that a majority of physical therapists believe these practice guidelines are valuable in patient care. For unknown reasons, physical therapists do not always utilize the research evidence in the management of falls in older adults in their practice. Because of this, a study is warranted to investigate physical therapists' perceptions of the use of evidence-based fall prevention programs for patients 65 years and above, and to identify barriers in its implementation. 


\section{Chapter Three}

\section{Research Design and Methodology}

\section{Introduction}

This chapter provides the procedures and methods that were utilized in this study. It also outlined and explained the essential components of this chapter, namely, purpose of the study, research question, research design, participants, data collection procedures, and data analysis. The problem, as previously identified in chapter one, is that despite the availability of numerous evidence-based fall prevention programs and studies that highlight the effectiveness of fall prevention interventions in older adults (Carter, et al., 2003; Rapp, et al., 2008), the literature demonstrates that physical therapists do not always use these available evidence-based programs (Jette et al., 2003; Stroud, 2014).

\section{Purpose of the Study}

The purpose of this mixed methods study was to identify barriers perceived by physical therapists to the use of evidence-based fall prevention interventions with individuals of 65 years of age or older.

The literature shows that among physical therapists and other health care professionals, there is a growing gap between clinical research synthesis and the implementation of evidencebased practice (Gudjonsdottir \& Arnadottir, 2015; Jette, et al., 2003; Loganathan, Ng, Tan \& Low, 2015; Stroud, 2014). Though the available literature shows physical therapists have a positive opinion and attitudes toward the use of evidence-based practice, and a majority of them view it as being valuable in achieving positive health outcomes (Stroud, 2014), in spite of this, few physical therapists claim to consistently use these practice guidelines in general patients' 
care and in fall prevention with older adults (Jette, et al., 2003; Loganathan, Ng, Tan \& Low, 2015; Stroud, 2014).

\section{Research Question}

This mixed methods research seeks to answer the following question:

RQ 1. What are the barriers perceived by physical therapists to the use of evidence-based fall prevention programs with individuals of 65 years of age or older?

\section{Research Design}

This study employed a mixed method descriptive research design. This study employed a web-based questionnaire in order to gather both quantitative and qualitative data to evaluate the topic under investigation. This study utilized an online survey platform (PsychData) to collect data to investigate and identify the barriers perceived by physical therapists to the use of evidence-based fall prevention programs with individuals of 65 years of age or older.

The preference of PsychData over other web-based research platforms is due to its data quality, integrity, confidentiality and privacy superiority. PsychData provides $100 \%$ highly secured end-to-end Secure Sockets Layer (SSL) encryption of all participants' survey data. Also, PsychData has the skip logic capability, which allows participants to skip unrelated questions based on their initial response. Similarly, the forced answer feature of the platform requires participants to provide an answer to question before advancing to the next question (PsychData, 2018).

The research question was evaluated using the current version of the predictive analytics software, SPSS 25. Responses from the participants, obtained from PsychData, were exported to SPSS. Analyses were done using descriptive statistics analysis to answer the research question 
and determine the relationships among the variables in the survey. The qualitative data was analyzed using the qualitative thematic analysis method (Trochim \& Donnelly, 2008).

\section{Participants}

This study utilized a sample of physical therapists licensed in the state of Texas. This purposive sampling was to specifically target Texas physical therapists who work with older adults at risk for falls, with goal of investigating the barriers perceived by physical therapists to the use of evidence-based fall prevention programs with individuals of 65 years of age or older.

The inclusion criterion was that participants must be licensed as a physical therapist in Texas State, and were excluded from the study if they were not licensed in Texas State. The licensed physical therapists' emails were obtained from the Texas State Board of Physical Therapy Examiners (TBOPTE). All the licensed physical therapists were contacted via email (appendix A) with the Uniform Resource Locator (URL) or web address for the online questionnaire, and a reminder emails (appendix B) were sent a week after the initial email message. According to the TBOPTE there were 17,085 actively licensed physical therapists in Texas as of 2016 (TBOPTE, 2018). 6,022 of the emails sent came back as not delivered, another 2,095 came back with automatic reply from recipients as not available to respond to emails. A total of 302 licensed physical therapists completed the survey.

\section{Data Collection Procedures}

The Institutional Review Board (IRB) of the University of St Augustine approved this research on September 21, 2018 (appendix C). Immediately following the IRB approval, notification emails were sent to the potential study participants inviting them to participate in the study. The e-mail notification contained the Uniform Resource Locator (URL) where the online survey was completed. The survey was conducted using the online survey platform called 
PsychData. The online survey platform was activated after IRB approval was received, and was left opened for 21 days for responses. Reminder emails (appendix B) were sent to the participants in the second week after the PsychData online platform was activated. According to Sheehan (2001), email survey duration does not influence response rate, and that responses tend to peak by the seventh day, and start declining thereafter. The online survey platform was deactivated after 21 days. The web-based questionnaire (appendix D) contained a total of 15 questions. The first 6 questions were demographic in nature, while the next 8 questions were designed to provide answers to the research question by using Likert scale and rank order typeresponse. The last question was an open-ended question, to afford participants to provide what they perceived as barriers in using evidence-based fall prevention interventions with individuals of 65 years of age or older.

\section{Data Analysis}

The licensed physical therapists provided their responses to the online survey questions on the PsychData platform. The responses were downloaded as Excel files and analyzed using the current version of SPSS, version 25. The quantitative results were analyzed using descriptive statistics and percentages of responses to describe items on the survey and provide answers to the research question.

The qualitative data were analyzed using the qualitative thematic method (Trochim \& Donnelly, 2008). The qualitative thematic method involved categorizing the qualitative responses into themes (Trochim \& Donnelly, 2008). The themes were coded to determine the respondents' frequently mentioned barriers perceived to the use of evidence-based fall prevention programs with individuals of 65 years of age or older. The coded responses were 
analyzed using percentages to represent the extent to which the themes were reported as being barriers by the respondents.

\section{Summary}

This chapter on the research methodology showed the design of this mixed method study, how the participants were recruited, the data collection procedures and the statistical analysis methods used. The statistical analysis used mainly the descriptive statistics methods to explain and describe the quantitative items surveyed. The qualitative thematic analysis was used to analyze the qualitative component of the study. 


\section{CHAPTER FOUR}

\section{ANALYSIS OF DATA}

This chapter contains the results of the study and the statistical analyses used to evaluate the results and provide answers to the research question.

\section{Results}

\section{Demographics of the Respondents}

The potential population of the study sample was 17,085 actively licensed physical therapists in Texas State, email survey requests were sent to all 17, 085. A total of 303 respondents completed the survey via the online PsychData platform. One response was eliminated from the results, having been partially completed by a non-licensed physical therapist, the skip logic nature of the platform automatically ended the survey for this non-licensed respondent. Therefore, a total of 302 responses (1.8\% response rate) were used for the data analyses. Of the 302 respondents, $49 \%$ have a doctorate in physical therapy, $24.7 \%$ of the respondents have a master's degree in physical therapy and $26.4 \%$ of the respondents have a bachelor's degree in physical therapy.

Of the 302 responses, $254(84.2 \%)$ of the respondents indicated not having American Board of Physical Therapy Specialty certification, 24 (7.9\%) of the respondents held Orthopedic certification, $8(2.6 \%)$ of the respondents held neurologic certification, $7(2.3 \%)$ of the respondents held geriatric certification, $5(1.7 \%)$ of the respondents held pediatric certification, 3 respondents $(1 \%)$ held sport certification and 1 respondent $(0.3 \%)$ held certification in women's health.

The respondents indicated their current physical therapy practice setting as follows: 109 respondents (36\%) indicated outpatient, 63 respondents $(21 \%)$ indicated other (academia \& 
retired), 48 respondents $(15.8 \%)$ indicated acute care, 45 respondents $(15 \%)$ indicated home health, 24 respondents (7.9\%) indicated inpatient rehabilitation, and 13 respondents (4.3\%) indicated skilled nursing facility.

The respondents indicated their level of employment in physical therapy practice as follows: 199 respondents (66\%) indicated they were employed full-time for at least 40 hours a week, 49 respondents $(16.3 \%)$ indicated part time employment, 33 respondents $(10.8 \%)$ indicated they were employed on a per requested need (PRN) basis, and 21 respondents (6.9\%) indicated other (retired or not working). Similarly, respondents indicated the patient population they work with the most as follows: a total of 147 respondents $(48.7 \%)$ indicated they work with geriatric population (65 years of age or above), 33 respondents (10.9\%) indicated they work with a pediatric population (under 18 years of age), and 122 respondents (40.4\%) indicated they work with an adult population $(18-64$ years of age).

\section{Familiarity with CDC Compendium and STEADI Tool Kit Questions}

Respondents were asked to indicate their level of familiarity with the document "A CDC Compendium of Effective Fall Interventions: What Works for Community-Dwelling Older Adults" (Stevens \& Burns, 2015), of the 269 responses, 54 (20\%) of the respondents indicated they were familiar with the compendium document and $215(80 \%)$ of the respondents indicated that they were not familiar with the document. Similarly, when the surveyed physical therapists were asked about their knowledge or use of the STEADI tool kit, of the 269 responses, 213 (79.3\%) respondents indicated they were not familiar with or has not used the STEADI tool kit, only $56(20.7 \%)$ respondents indicated they were familiar with, or have used the STEADI stool kit.

\section{Use of Evidence-based Interventions}


Respondents were asked to indicate how frequently they treat older adults who are fall risks, of the 269 respondents, $160(59.6 \%)$ of the respondents indicated they treat older adults with fall risks on a daily basis, 37 (13.9\%) indicated they treat older adults with fall risks at least three times a week, $30(11 \%)$ respondents indicated once or twice a week, $19(6.9 \%)$ respondents indicated once or twice a month, while $23(8.6 \%)$ respondents indicated they treat older adults with fall risk less than once a month.

Respondents were asked to indicate, on a Likert scale, how frequently they utilize interventions to reduce fall risks in older adults. Of the 269 respondents, a majority of the respondents 174 (64.5\%) indicated they utilize interventions on a daily basis to reduce fall risks in older adults; $29(10.6 \%)$ indicated at least three times a week; $25(9.4 \%)$ indicated once or twice a week; $17(6.5 \%)$ indicated once or twice a month; while $24(9 \%)$ indicated less than once a month.

Respondents were asked to indicate, on a Likert scale, how frequently they use current research evidence to guide their selection of fall prevention interventions. The breakdown is as follows: of the 269 respondents, a majority of the respondents $95(35.5 \%)$ indicated on a daily basis, $35(13.1 \%)$ indicated at least three times a week, 29 (10.6\%) indicated once or twice a week, $42(15.5 \%)$ indicated once or twice a month, and $68(25.3 \%)$ indicated less than once a month.

Respondents were asked to indicate how frequently they utilize A CDC Compendium of Effective Fall Interventions: What Works for Community-Dwelling Older Adults (Stevens \& Burns, 2015). When asked if they were familiar with the compendium, only 54 (20\%) of the respondents indicated they were familiar with this document. Of the 54 respondents familiar with this document, $11(20.9 \%)$ of the respondents indicated they use the compendium once or twice a 
week, $10(18.6 \%)$ of the respondents indicated less than once a month, another $10(18.6 \%)$ of the respondents indicated once or twice a month, nine (16.3\%) of the respondents indicated daily, eight $(14 \%)$ indicated at least three times a week, while six $(11.6 \%)$ of the respondents indicated they never use the compendium.

Participants were also asked to indicate how frequently they utilize the STEADI tool kit with older adults for fall risks intervention. When the participants were asked if they were familiar with, or have used the STEADI took kit, only 56 (20.9\%) of the respondents reported being familiar with this intervention program. One $(1.4 \%)$ of the 56 respondents indicated using the STEADI tool kit on a daily basis, another one $(2.3 \%)$ respondent indicated at least three times a week, two $(2.8 \%)$ of the respondents indicated once or twice a week, three $(5.2 \%)$ indicated once or twice a month, two (3.8\%) indicated they use the STEADI tool kit less than once a month and a majority of the respondents and $47(84.5 \%)$ respondents indicated they never use this intervention.

\section{Research Question and the Results}

Analysis of the results of the last two survey questions provided the answer to the research question in this study, which is to know the barriers perceived by physical therapists to the use of evidence-based fall prevention programs with individuals of 65 years of age or older. Participants were asked to rank order perceive barriers to the use of evidence-based fall prevention program. The potential barriers to be rank ordered were drawn from those barriers reported in the literature (Fruth et al., 2010; Hannes, Staes, Goedhuys \& Aertgeerts, 2009; Salbach, et al., 2007). Table 1 indicates the percentage or participants who responded to each ranking from 1 to 5 (Greatest barrier $=1 \ldots$ Least barrier $=5)$. The majority of the respondents $36.9 \%$ ranked "lack of time" as the greatest barrier, "professional knowledge deficit" was ranked 
first by $24.6 \%$ of the respondents, "patient's exercise tolerance" was ranked first by $17.7 \%$ of the respondents, "healthcare system bureaucracy" was ranked first by $9.6 \%$ of the respondents, and "lack of support from facility" was ranked the greatest barrier by $9.2 \%$ of respondents (Table 1). Table 2 indicates the mean rankings of the perceived barriers to the implementation of evidencebased fall prevention programs. Lack of time was the most highly ranked with a mean ranking of 2.4 (Table 2), and was rated as the greatest barrier by $36.9 \%$ of the respondents (Table 1). Lack of support from facility was the lowest ranked barrier, with a mean ranking of 3.9 (Table 2), being ranked as the greatest barrier by only $9.2 \%$ of the respondents (Table 1 ).

Table 1

Ranking of reported perceived barriers to the implementation of evidence-based fall prevention programs

\begin{tabular}{|c|c|c|c|c|c|}
\hline \multirow{2}{*}{$\begin{array}{l}\text { Perceived } \\
\text { Barriers }\end{array}$} & \multicolumn{3}{|c|}{ greatest barrier } & \multicolumn{2}{|c|}{ least barrier } \\
\hline & 1 & 2 & 3 & 4 & 5 \\
\hline Lack of time & $36.9 \%$ & $21.9 \%$ & $19.8 \%$ & $10.2 \%$ & $11.2 \%$ \\
\hline $\begin{array}{l}\text { Patient's exercise } \\
\text { tolerance }\end{array}$ & $17.7 \%$ & $27.4 \%$ & $23.8 \%$ & $17.7 \%$ & $13.4 \%$ \\
\hline $\begin{array}{l}\text { Professional } \\
\text { knowledge deficit }\end{array}$ & $24.6 \%$ & $15.2 \%$ & $20.9 \%$ & $15.7 \%$ & $23.6 \%$ \\
\hline $\begin{array}{l}\text { Healthcare system } \\
\text { bureaucracy }\end{array}$ & $9.6 \%$ & $21.9 \%$ & $21.5 \%$ & $23.5 \%$ & $23.5 \%$ \\
\hline $\begin{array}{l}\text { Lack of facility } \\
\text { support }\end{array}$ & $9.2 \%$ & $11.3 \%$ & $18.4 \%$ & $25.4 \%$ & $35.7 \%$ \\
\hline
\end{tabular}

Note: Ranking of perceived barriers from 1 to 5 (Greatest barrier $=1 \ldots$ Least barrier $=5)$ 
Table 2

Mean ranking of perceived barriers to the implementation of evidence-based fall prevention programs as reported in the literature

\begin{tabular}{ll}
\hline Perceived barriers & Mean rank
\end{tabular}

\begin{tabular}{ll}
\hline Lack of time & 2.4
\end{tabular}

$\begin{array}{ll}\text { Patient's exercise tolerance } & 2.8\end{array}$

$\begin{array}{ll}\text { Professional knowledge deficit } & 3.0\end{array}$

Healthcare system bureaucracy $\quad 3.3$

$\begin{array}{ll}\text { Lack of support from your facility } & 3.9\end{array}$

Participants were asked to state what other factors not listed in question 14, that they perceived as barriers to the use of evidence-based fall prevention interventions with individuals of 65 years of age or older. 122 participants responded to this question with open-ended responses (Appendix E). All the responses were coded and categorized into six themes to express the respondents reported perceived barriers (Table 3). Patient's comorbidity was the most frequently reported barrier (35.2\% of the respondents), and was closely followed by the perceived lack of resources or equipment by $31.9 \%$ of the respondents, productivity was reported by $13.9 \%$ of the respondents, staffing needs or manpower level was reported by $9.8 \%$ of the respondents, insurance regulations was reported by $6.5 \%$ of the respondents, while remuneration was reported by $2.5 \%$ of the respondents. 
Table 3

Additional perceived barriers to the implementation of evidence-based fall prevention programs

Frequencies (f) and percentages (p) of theme, sub-themes and codes $(n=122)$

\begin{tabular}{|c|c|c|c|c|}
\hline Themes & Sub-themes & Codes & $\mathrm{f}$ & $\mathrm{p}$ \\
\hline $\begin{array}{l}\text { Patient's comorbidity } \\
35.2 \%\end{array}$ & $\begin{array}{l}\text { Patient's diseases } \\
\text { Medical condition of patients } \\
\text { Patient's willingness }\end{array}$ & $\begin{array}{l}\text { Patient's Illness } \\
\text { Comorbidities } \\
\text { Patient's cognition } \\
\text { Patient's conditions } \\
\text { Patient's Motivation }\end{array}$ & $\begin{array}{l}12 \\
11 \\
6 \\
8 \\
6\end{array}$ & $\begin{array}{l}27.9 \% \\
25.5 \% \\
14 \% \\
18.6 \% \\
14 \%\end{array}$ \\
\hline $\begin{array}{l}\text { Lack of resources } \\
\text { or equipment } \\
31.9 \%\end{array}$ & & $\begin{array}{l}\text { Lack of space } \\
\text { Lack of resources } \\
\text { Availability of tool-ki } \\
\text { Lack of tools } \\
\text { Limited resources } \\
\text { Lack of equipment }\end{array}$ & $\begin{array}{l}5 \\
4 \\
\mathrm{t} 2 \\
7 \\
10 \\
11\end{array}$ & $\begin{array}{l}12.8 \% \\
10.3 \% \\
5.1 \% \\
17.9 \% \\
25.7 \% \\
28.2 \%\end{array}$ \\
\hline $\begin{array}{l}\text { Productivity expectations } \\
\qquad 13.9 \%\end{array}$ & & $\begin{array}{l}\text { Productivity } \\
\text { Caseload } \\
\text { Scheduling conflict }\end{array}$ & $\begin{array}{l}7 \\
5 \\
5\end{array}$ & $\begin{array}{l}41.2 \% \\
29.4 \% \\
29.4 \%\end{array}$ \\
\hline $\begin{array}{l}\text { Staffing needs or levels } \\
\qquad 9.8 \%\end{array}$ & & $\begin{array}{l}\text { Lack of skill } \\
\text { Lack of staff } \\
\text { Inconsistent staff }\end{array}$ & $\begin{array}{l}1 \\
9 \\
2\end{array}$ & $\begin{array}{l}8 \% \\
75 \% \\
17 \%\end{array}$ \\
\hline $\begin{array}{l}\text { Insurance regulations } \\
6.5 \%\end{array}$ & & $\begin{array}{l}\text { Documentation } \\
\text { requirements } \\
\text { Administrative } \\
\text { burden }\end{array}$ & $\begin{array}{l}6 \\
2\end{array}$ & $\begin{array}{l}75 \% \\
25 \%\end{array}$ \\
\hline Remuneration & & Pay & 3 & $100 \%$ \\
\hline
\end{tabular}




\section{Summary}

Among the physical therapists surveyed in this study, $75.1 \%$ reported treating older adults with fall risk daily or at least three times a week, similarly, $73.5 \%$ reported using some form of interventions with older adults with fall risk daily or at least three times a week.

Furthermore, only $48.6 \%$ of the respondents indicated that they use current research evidence to guide their choice of fall prevention program on a daily basis or at least three times a week. As shown, only $30.3 \%$ of the respondents indicated they use the CDC compendium daily or at least three times a week, and $3.7 \%$ of the respondents indicated they use the STEADI tool kit daily or at least three times a week. These findings showed that among the physical therapists surveyed there is a gap in knowledge of effective fall prevention programs that needs to be bridged.

The main purpose of this study was to identify barriers perceived by physical therapists to the use of evidence-based fall prevention interventions with individuals of 65 years of age or older. The barriers identified by the respondents, to various degrees, were lack of time, lack of facility support, patient's exercise tolerance, professional knowledge deficit, healthcare system bureaucracy, remuneration, staffing needs or levels, patient's comorbidity, insurance regulations, lack of resources or equipment, and productivity expectations. 


\section{CHAPTER FIVE}

\section{SUMMARY, CONCLUSIONS, AND RECOMMENDATIONS FOR FUTURE \\ RESEARCH}

This chapter presents the discussions from the study results, conclusions and recommendations for future study.

\section{Summary}

A fall is caused by the complex interplay of both intrinsic and extrinsic factors resulting in the displacement of center of mass outside the base of support and consequently results in an inability to maintain balance in response to changes in sensory information in the older adults (Wang, Skubic, Abbott, \& Keller, 2010). The intrinsic factors are the internal risk factors occurring within the older individuals, while external or environmental risk factors make up the extrinsic factors (Tideiksaar, 2010).

Falling is a major health concern among older adults and is one of the leading causes of injury, debility, institutionalization and premature death in individuals 65 years or above (Kruschke \& Butcher, 2017; USPSTF, 2017). The most common fall- related injuries leading to hospitalization in the elderly are fractures of the femoral neck, tibia, fibula, radius, ulna, vertebrae, pelvis and ribs, with hip fractures being the most consequential (Lord, Sherrington, \& Menz, 2001).

The balance mechanism is delicately dependent on the complex interactions of the visual, vestibular, somatosensory and the musculoskeletal sub-centers of the neural network (Tideiksaar, 2010). The conceptual framework of falling in older adults is based on the age-related musculoskeletal changes and the malalignment of the usual seamless integration of cognition, biomechanical, anticipatory, and postural components which enable stability and prevent falling 
during perturbations and displacement of the center of mass outside the base of support (King \& Horak, 2013; Wang, Skubic, Abbott \& Keller, 2010). The consequences of the malalignment and the age-related musculoskeletal changes in older adults can be delayed or reversed by engaging in regular physical activities with emphasis on flexibility, balance and strength training (Stevens \& Burns, 2015; Tideiksaar, 2010).

Physical therapists and other health care professionals play a major role in the prevention and treatment of falls in the older adult population by using the current best research evidence (Carter et al., 2003; Rapp, Lamb, Gisela, Ranjit, Lindermann, \& Becker, 2008). The current best evidence-based practice in the management of falls in older adults includes the identification of the relevant intrinsic and extrinsic causative factors and designing appropriate corrective measures (AGS, 2011; CDC, 2015; USPSTF, 2017). This current best research evidence is contained in the CDC Compendium of Effective Fall Interventions: What Works for Community-Dwelling Older Adults and the STEADI tool kit (Stevens \& Burns, 2015).

Despite the availability of these current evidence-based fall intervention programs and numerous studies that highlight the effectiveness of these interventions (Carter, et al., 2003; Rapp, Lamb, Gisela, Ranjit, Lindermann, \& Becker, 2008), physical therapists do not always use these available programs (Jette, et al., 2003; Loganathan, Ng, Tan \& Low, 2015; Stroud, 2014).

\section{Discussion and Implications of Findings}

Evidence-based practice is defined as the conscientious, explicit, and judicious use of current best research evidence in making decisions about the care of individual patients (Jette et al., 2003; Jewell, 2018). The APTA guideline (2012) advocated the integration of current research evidence in clinical decision-making for quality patient's care. A growing number of physical therapists accept and appreciate the need to consistently implement research findings in 
patient's care, but this study, and many others, find a disconnect between clinical practice and the use of evidence-based practice (Ramírez-Vélez, Bagur-Calafat, Correa-Bautista, \& GirabentFarrés, 2015).

The PARiHS conceptual framework for the successful implementation of research into clinical practice asserts that successful integration of research into practice is a function of the interaction among: the available evidence, the context of the implementation of the available evidence, and the process of facilitation in which a facilitator provides the needed support to affect the necessary change of clinical behavior (NCCMT, 2011; Rycroft-Malone, 2004). The evidence in this framework is not only the current available research, but a sum of the clinician's derived knowledge, also from experience and from patient's interactions, that has been previously utilized and found to be credible (Rycroft-Malone, 2004).

This study found that despite the availability of credible research evidence in the management and prevention of falls in older adults, physical therapists do not use the available evidence to guide their practice due to some perceived barriers. According to Kitson, Harvey and McCormack (1998), for the successful implementation of research evidence in practice, the evidence must be obtained from a high quality research, high consensus of clinical experience and close partnership that integrate patient's preferences in their care. Though this is a descriptive study, the findings are consistent with what is known in literature as barriers in the implementation of research in physical therapy practice.

The context, according to the PARiHS framework, is the working environment where research implementation is done (Stetler, Damschroder, Helfrich \& Hagedorn, 2011; Ward, Baloh, Zhu \& Stewart, 2017). The health care practice environment can contribute to the successful implementation of evidence-based practice or constitute an impediment. This is 
clearly evident in home-health practice setting, where in most cases, the patient's home is an unpredictable and uncontrolled environment to the clinician. It is not uncommon, in some home environments, to encounter severe clutter with hoarders, dirt and multiple pets making care delivery less than ideal. Against this background, the environment can be pivotal in the transformation of research into practice. According to Kitson, Harvey and McCormack (1998) research implementation in practice is easier in an environment or context that is patient centered, in a context that provides clearly defined roles for its employees and provides high quality improvement measures. This study identified lack of facility support in the implementation of research evidence in practice. Therefore, without clear organizational support, and structure in place to emphasis and encourage the use of current research in practice, health care providers are bound to exhibit low morale and not be motivated (Kitson, Harvey \& McCormack, 1998).

Facilitation is the actual process of transforming research evidence into clinical practice that is made possible by the facilitators (NCCMT, 2011; Rycroft-Malone, 2004). In this framework, the facilitators are the individual clinicians with the requisite knowledge and skills, available, able and willing to be preceptors to help other clinicians to consistently use current evidence to guide clinical practice (Rycroft-Malone, 2004). The facilitators usually lead by example and point the way to other clinicians in exhibiting and implementing current best professional practices. The results of this study show that there is a continuing need for greater facilitation of the change process to better enable integration of evidence into fall prevention practice. Organizations that seek to improve the facilitation process must bring in highly knowledgeable and motivated individuals to change the low morale culture in such organizations and implement a culture of excellence and promote patient centered care. 
The main purpose of this mixed methods study was to identify the barriers perceived by physical therapists to the use of evidence-based fall prevention interventions with individuals of 65 years of age or older. The barriers identified by the respondents, the degree to which these factors were perceived as barriers and the mean rankings are displayed in Tables 1, 2 and 3. As shown in Table 2, the mean ranking of the perceived barriers demonstrates an inverse relationship with the mean ranking score value. That is, the higher the mean ranking value of an item, the less it was perceived as a barrier. The inverse relationship between the mean ranking values of the perceived barriers and their rank order is due to the ranking scale used in the survey. Participants ranked perceived barriers from 1 to 5 (Greatest barrier $=1 \ldots$ Least barrier $=$ 5). "Lack of time" has the lowest mean ranking score of 2.4 and was ranked as the greatest barrier by $36.9 \%$ of the respondents as seen in Table 1. "Lack of support from facility" has the highest mean ranking of 3.9 and was ranked as the least barrier by $9.2 \%$ of the respondents.

This study has validated previously known and identified additional perceived barriers that hinder physical therapists from consistently using current available research evidence. The outcome of this study is consistent with the findings of other studies. In this study, a majority of the respondents $36.9 \%$ (Table 1) rated "lack of time" as the greatest perceived barrier to the implementation of research evidence in practice. Similarly, Ramírez-Vélez, Bagur-Calafat, Correa-Bautista, and Girabent-Farrés (2015) and Stroud (2014) found that lack of time was a major barrier identified by physical therapists for not using evidence based practice in clinical interventions, especially among physical therapists with bachelor's degree and those with limited clinical experience. Fruth et al. (2010) reached the same conclusion that lack of time to research current literature was a barrier in implementing research evidence in practice. 
Similarly, Nilsagard and Lohse (2010) and Ramírez-Vélez, Bagur-Calafat, CorreaBautista, and Girabent-Farrés (2015) identified "lack of support from facility" management as an important impediment and barrier for physical therapists using research evidence to guide their daily practice. This is consistent with the outcome of this study. As displayed in Table 1, 9.2\% of the respondents in this study rated lack of facility support as the greatest perceived barrier to the use of fall prevention program. Lack of facility support can manifest in multiple ways, namely, paying little to no attention to educational opportunity for staff members within the organization, facilities that focus on profit and not on staff development, and facilities that will not encourage innovative use of current research evidence in practice.

Salbach et al. (2007) identified professional knowledge deficit by physical therapists as an important factor in the use of evidence based practice. Professional knowledge deficit findings by Salbach et al. (2007) and Stroud (2014) are also demonstrated in this study with 80\% of the respondents not familiar with the CDC compendium or the STEADI tool kit. Table 1 showed that professional knowledge deficit was rated as the greatest perceived barrier by $24.6 \%$ of the respondents in this study. Stroud (2014) further stated that professional knowledge deficit tends to be common among physical therapists that have little or no access to current professional literature. Ramírez-Vélez, Bagur-Calafat, Correa-Bautista, and Girabent-Farrés (2015) found that professional knowledge deficit is not only manifested as deficiency in requisite professional knowledge, but also as lack of research skills needed to understand research findings and apply such findings to specific patient's conditions.

Another significant finding among the physical therapists surveyed in this study was that $75.1 \%$ reported treating older adults with fall risk daily or at least three times a week, similarly, $73.5 \%$ reported using some form of interventions with older adults with fall risk daily or at least 
three times a week. Furthermore, only $48.6 \%$ of the respondents indicated that they use current research evidence to guide their choice of fall prevention program on a daily basis or at least three times a week. As shown, only $30.3 \%$ of the respondents indicated they use the CDC compendium daily or at least three times a week, and 3.7\% of the respondents indicated they use the STEADI tool kit daily or at least three times a week. These findings showed that among the physical therapists surveyed there is a gap in knowledge of effective fall prevention programs that needs to be bridged. The professional knowledge gap is evident in that only $20 \%$ of the respondents indicated being familiar with the CDC compendium and the STEADI tool kit.

Another possible explanation of these findings beyond professional knowledge deficit could be all or some combination of the qualitative responses as shown in Table 3. A majority of the respondents $35.5 \%$ indicated that patient's exercise tolerance was a perceived barrier in their implementation of evidence-based fall prevention program. This was closely followed by lack of resources or equipment by $31.9 \%$ of the respondents. The findings of this study and others show a continuing gap between clinical practice and the use of available research evidence.

The qualitative data displayed in Table 3 shows that the respondents perceived barriers to the implementation of evidence-based practice beyond those identified in the literature which they rank-ordered as displayed in Table 1 . Of the 122 respondents to the qualitative question, 82 respondents $(67.1 \%)$ indicated that patient's comorbidity or lack of resources was the main barrier to their implementation of current research evidence in clinical practice. While the other 40 respondents $(32.9 \%)$ indicated productivity expectations, or staffing needs, or insurance regulation, or remuneration as perceived barriers in their practice. The pattern of response showed that more than half of the respondents indicated patient's comorbidity or lack of resources as a barrier. 
While participants were not specifically asked about their perceptions of comorbid medical conditions that may constitute barriers to the implementation of evidence-based fall prevention programs, a few of the respondents indicated those conditions in their qualitative response (Appendix E). Among the medical conditions that were specifically mentioned were poor cognition, chronic obstructive pulmonary disease (COPD), congestive heart failure (CHF), Parkinson disease and multiple sclerosis (MS). Basic understanding of these health conditions shows that comprehension of therapeutic and safety instructions, and exercise endurance are suspect.

Falls are significantly higher in older adults with poor cognition compared with those who are cognitively intact (Amboni, Barone \& Hausdorff, 2013), the annual incidence and prevalence of falls among cognitively impaired older adults is approximately $80 \%$ higher than the cognitively intact older adults (Herman, Mirelman, Giladi, Schweiger, \& Hausdorff, 2010; Montero-Odasso, Verghese, Beauchet \& Hausdorff, 2012). In older adults with poor cognition, short term memory, retention and carry-over of safety instructions are severely impaired (Rao, Gilman \& Louis, 2014; Yogev-Seligmann, Hausdorff \& Giladi, 2008). The inability to comprehend, remember and teach back therapeutic and safety instructions provided by physical therapists may have heavily influenced the physical therapists' perception of poor cognition as a barrier in the implementation of evidence-based practice in this category of patients.

Cardiopulmonary conditions (COPD \& CHF) mentioned in the qualitative response are generally noted for causing shortness of breath with minimal exertions and low energy reserve (Carey \& Potter, 2001). The low energy reserve, with the associated orthostatic hypotension in these patients, makes activities of daily living very difficult and prone to high fall risks (Jansen, et al., 2016). Similarly, patients with neurodegenerative conditions such as Parkinson disease 
and multiple sclerosis experience extreme fatigue and poor endurance with activities of daily living (Allen, Schwarzel \& Canning, 2013). Exercise tolerance and fatigue associated with patients with cardiopulmonary and neurodegenerative conditions may have influenced physical therapists perception of these conditions as barriers in the implementation of evidence-based practice. Even with the use of energy conservation techniques in patients with these conditions, motivation to exercise is usually low due to high energy cost of routine activities of daily living.

In addition to the patient's comorbidity, respondents also indicated lack of resources or equipment as a limiting factor in the implementation of evidence-based practice. Though no specific equipment or resource was mentioned in the qualitative response, in a broad view, this could mean lack of major equipment in physical therapy practice or no access to literature database. Resource availability and access to relevant databases can expose physical therapists to a wealth of research evidence that can enhance clinical practice. In a study by Gorgon, Barrozo, Mariano, and Rivera (2013) lack of adequate equipment was found to be a huge factor in the implementation of current research evidence among physical therapists in some developing countries. In a related study, Stroud (2014) found that lack of access to literature database was reported as a barrier among physical therapists in implementing research evidence in practice. A number of the surveyed physical therapists cited insurance regulations as a barrier to the use of evidence-based practice. Insurance providers typically have specific documentation expectations which require healthcare providers to justify the services they provide in order to be reimbursed for their services. But the unintended consequence of reducing patient's quality of care is real (Bodenheimer \& Grumbach, 2009). Physical therapists and other health care providers usually view these constantly changing regulations as administrative burden that inevitably reduce the actual time spent in providing care to patients (Bodenheimer \& Grumbach, 
2009). The perception of insurance regulation as a barrier in research implementation is supported by the findings of Hannes, Staes, Goedhuys and Aertgeerts, (2009) citing health care system bureaucracy.

One of the findings of this study is that physical therapists do not consistently use evidence-based practice prevention programs for the care of older adults due to some perceived barriers that have been identified by this study. Another finding of this study is that the physical therapists surveyed lacked professional knowledge of the available evidence-based fall prevention programs.

The identified professional knowledge deficit of effective fall prevention programs can be remedied by having clinicians take continuous education courses that address these issues such as the Academy of Geriatric Physical Therapy's Certified Exercise Experts for Aging Adults (CEEAA) (AGPT, 2018). Courses such as the CEEAA would enhance professional knowledge of effective fall prevention programs and position physical therapists to deliver evidence-based fall interventions. Also, employers can incentivize their employees by providing free or reduced monthly subscription to professional journals and symposia. Additionally, in keeping with the "facilitation" construct of the PARiHS framework for enabling the implementation of evidence based practice, organizational leaders can hire highly capable and knowledgeable individuals or facilitators to implement and promote a culture of clinical excellence, leadership, accountability and innovativeness in the organizations (Kitson, Harvey \& McCormack, 1998).

\section{Conclusion}

The conclusion that can be drawn from this study is that physical therapists licensed in the state of Texas identified and perceived to various degrees, the following factors listed below, 
as barriers to the use of evidence-based fall prevention interventions with individuals of 65 years of age or older. The barriers are:

- Lack of time,

- Lack of facility support,

- Patient's exercise tolerance,

- Professional knowledge deficit,

- Healthcare system bureaucracy,

- Remuneration

- Staffing needs or levels,

- Patient's comorbidity,

- Insurance regulations,

- Lack of resources or equipment,

- Productivity expectations.

\section{Limitations}

1. The findings of this study from 302 respondents may not be generalized to the entire licensed physical therapists in the United States.

2. This study was an online survey of self-reported perceived barriers; the accuracy of these reported data cannot be verified.

\section{Recommendations for Future Study}

This study showed that among the factors perceived as barriers by physical therapists to the use of evidence-based fall prevention interventions with individuals of 65 years of age or older, patient's comorbidity was identified by $35.2 \%$ of the respondents in the qualitative item 
surveyed. It will be worth investigating in future studies the specific systemic comorbidities that constitute these barriers.

Secondly, of the quantitative items surveyed, lack of time was ranked as the greatest barriers perceived by $36.9 \%$ of the physical therapists to the use of evidence-based fall prevention interventions with individuals of 65 years of age or older. Further study is needed to determine how lack of time affects the use of evidence-based practice and the role of physical therapist's caseload in their various clinical practice settings.

\section{Recommendations for Physical Therapy Practice}

The importance of consistently implementing current research evidence in patients' care is a theme that is recognized by physical therapists (Stroud, 2014). Physical therapists must step beyond what is recognized as being necessary, and follow up with actual implementation of evidence in clinical practice. According to Rycroft-Malone (2004), the concept of implementing change in any setting, primarily clinical research into practice, is complex, challenging and not straightforward. With the ever-increasing health care cost, these changes are not only necessary but compulsory (Rycroft-Malone, 2004).

In this and many other researches, physical therapists consistently cite lack of time as a notable barrier in the implementation of research evidence in their practice. Employers of labor must be aware that lack of time can lead to poor patients' satisfaction and reduced functional outcomes as physical therapists rush through their caseload to meet daily productivity expectations or quotas. Against this background, adequate caseload would provide opportunity for physical therapists to access current literature in-between patients' care.

In numerous studies, professional knowledge deficit continues to be reported as a barrier in physical therapy practice. This knowledge gap can be bridged through regular facility in- 
service training by one of their knowledgeable staff, mentor or preceptor. Also, professional associations like the American Physical Therapy Association can disseminate this knowledge to their members electronically or via their monthly bulletin. Similarly, third party payers can recommend or mandate the use of current research evidence as part of evaluation and intervention tools, though balance must be sort between necessary documentation and burdensome regulation.

The need to consistently use current research evidence in patients' should be a multidisciplinary approach, involving other health care professionals such as occupational therapists, physical and occupational therapy assistants, speech therapists, nursing staff, and others. This collaborative effort will lead to a culture of excellent clinical practice, high patients' satisfaction rate, improved outcome measures and perhaps reduced health care cost by preventing high patient's utilization of health care facilities. 


\section{References}

Academy of Geriatric Physical Therapy (2018). Certified exercise experts for aging adults. Retrieved from https://geriatricspt.org/events/courses/ceeaa/

Agency for Healthcare Research and Quality. (2014). Trends in health care expenditures for the elderly, age 65 and over: 2001, 2006, and 2011. Retrieved from http://meps.ahrq.gov/mepsweb/data_files/publications/st429/stat429.pdf

Al-Aama, T. (2011). Falls in the elderly: Spectrum and prevention. Canadian Family Physician, 57(7), 771-776.

Al-Muqiren, T. N., Al-Eisa, E. S., Alghadir, A. H., \& Anwer, S. (2017). Implementation and use of standardized outcome measures by physical therapists in Saudi Arabia: Barriers, facilitators and perceptions. BMC Health Services Research, 17(1), 748-758. doi: $10.1186 / \mathrm{s} 12913-017-2693-2$

Allen, N. E., Schwarzel, A. K., \& Canning, C. G. (2013). Recurrent falls in Parkinson's disease: A systematic review. Parkinson's Disease, 1-16. doi:10.1155/2013/906274

Amacher, A. E., Nast, I., Zindel, B., Schmid, L., Krafft, V., \& Niedermann, K. (2016). Experiences of general practitioners, home care nurses, physiotherapists and seniors involved in a multidisciplinary home-based fall prevention programme: A mixed method study. BMC Health Services Research, 16(1). doi: 10.1186/s12913-016-1719-5.

Amboni, M., Barone, P., \& Hausdorff, J. M. (2013). Cognitive contributions to gait and falls: Evidence and implications. Movement Disorders, 28(11), 1520-1533. doi: 10.1002/mds.25674.

Ambrose, A. F., Paul, G., \& Hausdorff, J. M. (2013). Risk factors for falls among older adults: A review of the literature. Maturitas, 75(1), 51-61. doi: 10.1016/j.maturitas.2013.02.009. 
America College of Sport Medicine (1998). Position stand: Exercise and physical activity for older adults. Medicine \& Science in Sports \& Exercise 30(6), 992-1008.

American Geriatrics Society and British Geriatrics Society Panel on Prevention of Falls in Older Persons. (2011). Summary of the updated American Geriatrics Society/British Geriatrics Society clinical practice guideline for prevention of falls in older persons. Journal of the American Geriatrics Society, 59(1), 148-157. doi: 10.1111/j.1532-5415.2010.03234.x.

American Physical Therapy Association. (2012). Vision 2020. Retrieved from http://www.apta.org/Vision2020/

Ashburn, A., Hyndman, D., Pickering, R., Yardley, L., \& Harris, S. (2008). Predicting people with stroke at risk of falls. Age Ageing, 37(3), 270-276. doi: 10.1093/ageing/afn066.

Avanecean, D., Calliste, D., Contreras, T., Lim, Y., \& Fitzpatrick, A. (2017). Effectiveness of patient-centered interventions on falls in the acute care setting compared to usual care. JBI Database of Systematic Reviews and Implementation Reports, 15(12), 3006-3048. doi: 10.11124/JBISRIR-2016-003331.

Avin, K. G., Hanke, T. A., Kirk-Sanchez, N., Mcdonough, C. M., Shubert, T. E., Hardage, J., \& Hartley, G. (2015). Management of falls in community-dwelling older adults: Clinical guidance statement from the Academy of Geriatric Physical Therapy of the American Physical Therapy Association. Physical Therapy, 95(6), 815-834. doi: 10.2522/ptj.20140415.

Bakken, R. C., Carey, J. R., DiFabio, R. P., Erlandson, T. J., Hake, J. L., \& Intihar, T. W. (2001). Effect of aerobic exercise on tracking performance in elderly people: A pilot study. Physical Therapy, 81(12), 1870-1879. doi: 10.1093/ptj/81.12.1870.

Barnett, A., Smith, B., Lord, S. R., Williams, M., \& Baumand, A. (2003). Community-based 
group exercise improves balance and reduces falls in at-risk older people: A randomized controlled trial. Age and Ageing, 32(4), 407-414. doi: 10.1093/ageing/32.4.407

Bateni, H., \& Maki, B. E. (2005). Assistive devices for balance and mobility: Benefits, demands, and adverse consequences. Archives of Physical Medicine and Rehabilitation, 86(1), 134-145. doi: 10.1016/j.apmr.2004.04.023.

Berg, R. L., \& Cassells, J. (1992). The second fifty years: Promoting health and preventing disability. Washington, DC: National Acad. Press.

Bischoff-Ferrari, H. A., Orav, E. J., Dawson-Hughes, B. (2006). Effect of cholecalciferol plus calcium on falling in ambulatory older men and women: a 3-year randomized controlled trial. Archives of Internal Medicine 166(4), 424-30. doi:10.1001/archinte.166.4.424.

Blair, S. N., Sallis, R. E., Hutber, A., \& Archer, E. (2012). Exercise therapy - the public health message. Scandinavian Journal of Medicine \& Science in Sports, 22(4), 24-28. doi: 10.1111/j.1600-0838.2012.01462.x

Blaney, J., Lowe-Strong, A., Rankin, J., Campbell, A., Allen, J., \& Gracey, J. (2010). The cancer rehabilitation journey: Barriers to and facilitators of exercise among patients with cancer-related fatigue. Physical Therapy, 90(8), 1135-1147. doi: 10.2522/ptj.20090278.

Bodenheimer, T. S., Grumbach, K. (2009). Understanding health policy: A clinical approach (5 Ed.), San Francisco, CA: McGraw-Hill.

Boss, G., \& Seegmiller, J. E. (1981). Age-related physiological changes and their clinical significance. Western Journal of Medicine, 135(6), 434-440.

Boutaugh, M. L., \& Lawrence, L. J. (2015). Fostering healthy aging through evidence-based prevention programs: Perspectives from the administration for community 
living/administration on aging. Frontiers in Public Health, 2.

doi:10.3389/fpubh.2014.00236

Boyle, N. D., Van Lieshout, E. M., Van Beeck, E. F., Hartholt, K. A., Van Der Cammen, T. J., \& Patka, P. (2013). The impact of falls in the elderly. Trauma, 15(1), 29-35. doi: $10.1177 / 1460408612463145$.

Bradley, C. (2013). Hospitalizations due to falls by older people, Australia 2009-10. Retrieved from https://www.aihw.gov.au/getmedia/8df14bfa-2234-485d-8db0e6a8aff5eeb9/14820.pdf.aspx?inline=true

Bradley, S., \& Hernandez, C. (2011). Geriatric assistive devices. American Family Physician, 84(4), 405-411.

Burns, E. R., Stevens, J. A., \& Lee, R. (2016). The direct costs of fatal and non-fatal falls among older adults — United States. Journal of Safety Research, 58, 99-103. doi: 10.1016/j.jsr.2016.05.001.

Campbell, A. J., Robertson, M. C., Grow, S. J., Kerse, N. M., Sanderson, G. F., Jacobs, R. J., \&. . Hale, L. A. (2005). Randomized controlled trial of prevention of falls in people aged $\geq 75$ with severe visual impairment: The VIP trial. British Medical Journal, 331(7520), 817-820. 10.1136/bmj.38601.447731.55.

Campbell, A.J., Robertson, M.C., Gardner, M.M., Norton, R.N., \& Buchner, D.M. (1999). Falls prevention over 2 years: A randomized controlled trial in women 80 years and older. Age and Ageing, 28(6), 513-518. doi:10.1093/ageing/28.6.513.

Campbell, A. J., Robertson, M. C., Gardner, M. M., Norton, R. N., Buchner, D. M. (1999). Psychotropic medication withdrawal and a home-based exercise program to prevent falls: a randomized, controlled trial. Journal of the American Geriatrics Society 
47(7):850-853. doi 10.1111/j.1532-5415.1999.tb03843.x.

Campbell, A. J., \& Robertson, M. C. (2003). Otago exercise program to prevent falls in older adults. Retrieved from http://www.hfwcny.org/Tools/BroadCaster/Upload/Project13/Docs/Otago_Exercise_Pro g ramme.pdf

Carey, B. J., \& Potter, J. F. (2001). Cardiovascular causes of falls. Age and Ageing, 30(4), 19-24. doi: 10.1093/ageing/30.suppl_4.19

Carter, N. D., Khan, K. M., McKay, H. A., Petit, M. A., Waterman, C., Heinonen, A., \& Flicker, L. (2002). Community-based exercise program reduces risk factors for falls in 65- To 75-Year-old women with osteoporosis: Randomized controlled trial. Canadian Medical Association Journal, 167(9), 997-1004.

Center for Disease Control and Prevention. (2017). Physical inactivity. Retrieved from https://www.cdc.gov/healthcommunication/toolstemplates/entertainmented/tips/Physical Inactivity.html

Center for Disease Control and Prevention. (2008). Preventing falls: How to develop community- based fall prevention programs for older adults. Retrieved from http://www.cdc.gov/homeandrecreationalsafety/images/cdc_guide-a.pdf

Center for Disease Control and Prevention. (2014). Costs of falls among older adults. Retrieved from http://www.cdc.gov/HomeandRecreationalSafety/Falls/fallcost.htm

Center for Disease Control and Prevention. (2017). STEADI - older adult fall prevention. Retrieved from https://www.cdc.gov/steadi/index.html

Center for Disease Control and Prevention (National Center for Injury Prevention and Control). (2015). Preventing Fall: A Guide To Implementing Effective Community-based Fall 
Prevention Programs (2nd ed.). Atlanta, GA: Center for Disease Control and Prevention.

Chandler, J. M., Duncan, P. W., Kochersberger, G., \& Studenski, S. (1998). Is lower extremity strength gain associated with improvement in physical performance and disability in frail, community-dwelling elders? Archives of Physical Medicine and Rehabilitation, 79(1), 24-30. doi:10.1016/s0003-9993(98)90202-7

Chang, J. T., Morton, S. C., Rubenstein, L. Z., Mojica, W. A., Maglione, M., Suttorp, M. J., \& Shekelle, P. G. (2004). Interventions for the prevention of falls in older adults: Systematic review and meta-analysis of randomised clinical trials. British Medical Journal, 328(7441), 680. doi: 10.1136/bmj.328.7441.680

Chase, C. A., Mann, K., Wasek, S., \& Arbesman, M. (2012). Systematic review of the effect of home modification and fall prevention programs on falls and the performance of community-dwelling older adults. American Journal of Occupational Therapy, 66(3), 284-291. doi: 10.5014/ajot.2012.005017.

Cho, S.I., \& An, D.H. (2014). Effects of a fall prevention exercise program on muscle strength and balance of the old-old elderly. Journal of Physical Therapy Science, 26(11), 17711774. doi: 10.1589/jpts.26.1771.

Cho, K., Lee, K., Lee, B., Lee, H., \& Lee, W. (2014). Relationship between postural sway and dynamic balance in stroke patients. Journal of Physical Therapy Science, 26(12), 19891992. doi: 10.1589/jpts.26.1989

Cho, S., \& An, D. (2014). Effects of a fall prevention exercise program on muscle strength and balance of the old-old elderly. Journal of Physical Therapy Science, 26(11), 1771-1774. doi 10.1589/jpts.26.1771. 
Clemson, L., Cumming, R. G., Kendig, H., Swann, M., Heard, R., Taylor, K. (2004).

The effectiveness of a community-based program for reducing the incidence of falls in the elderly: A randomized trial. Journal of the American Geriatrics Society 52(9):148794. doi: 10.1111/j.1532-5415.2004.52411.x

Clemson, L., Fiatarone-Singh, M., Munro, J. (2014). Lifestyle-Integrated Functional Exercise (LiFE) Program to reduce falls. Trainer's manual. Sydney: Sydney University Press.

Close, J., Ellis, M., Hooper, R., Glucksman, E., Jackson, S., Swift, C. (1999). Prevention of Falls in the Elderly Trial (PROFET): A randomized controlled trial. Lancet 353(9147):93-97. doi: 10.1016/S0140-6736(98)06119-4

Court-Brown, C., Clement, N., Duckworth, A., Biant, L., \& Mcqueen, M. (2017). The changing epidemiology of fall-related fractures in adults. Injury, 48(4), 819-824. doi: 10.1016/j.injury.2017.02.021.

Cumming, R. G., Thomas, M., Szonyi, M., Salkeld, G., O’Neill, E., Westburg, C., Frampton, G. (1999). Home visits by an occupational therapist for assessment and modification of environmental hazards: A randomized trial of falls prevention. Journal of the American Geriatrics Society 47(12):1397-1402. doi: 10.1111/j.15325415.1999.tb01556.x

Damschroder, L. J., Aron, D. C., Keith, R. E., Kirsh, S. R., Alexander, J. A., \& Lowery, J. C. (2009). Fostering implementation of health services research findings into practice: A consolidated framework for advancing implementation science. Implementation Science, 4(1). doi: 10.1186/1748-5908-4-50.

Darowski, A., Chambers, S. C., \& Chambers, D. J. (2009). Antidepressants and falls in the elderly. Drugs \& Aging, 26(5), 381-394. doi: 10.2165/00002512-200926050-00002. 
Davies, E. A., \& Omahony, M. S. (2015). Adverse drug reactions in special populations - The elderly. British Journal of Clinical Pharmacology, 80(4), 796-807. doi: 10.1111/bcp. 12596

Davison, J., Bond, J., Dawson, P., Steen, I. N., Kenny, R. A. (2005). Patients with recurrent falls attending accident and emergency benefit from multifactorial intervention: A randomized controlled trial. Age and Ageing 34(2):162-168. doi: 10.1093/ageing/afi053

Day, L., Fildes, B., Gordon, I., Fitzharris, M., Flamer, M., Lord, S. (2002). Randomized factorial trial of falls prevention among older people living in their own homes. British Medical Journal 325(7356):128-133. doi: 10.1136/bmj.325.7356.128

Diener, D. D., \& Mitchell, J. M. (2005). Impact of a multifactorial fall prevention program upon falls of older frail adults attending an adult health day care center. Topics in Geriatric Rehabilitation, 21(3), 247-257. doi: 10.1097/00013614-200507000-00011

Duckham, R. L., Masud, T., Taylor, R., Kendrick, D., Carpenter, H., Iliffe, S., . . BrookeWavell, K. (2015). Randomized controlled trial of the effectiveness of community group and home-based falls prevention exercise programs on bone health in older people: The proAct65 bone study. Retrieved from http://www.ncbi.nlm.nih.gov/pubmed/25906791

Ellis, T., Boudreau, J. K., Deangelis, T. R., Brown, L. E., Cavanaugh, J. T., Earhart, G. M., .. . Dibble, L. E. (2013). Barriers to exercise in people with Parkinson disease. Physical Therapy, 93(5), 628-636. doi: 10.2522/ptj.20120279.

Enderlin, C., Rooker, J., Ball, S., Hippensteel, D., Alderman, J., Fisher, S. J., . . Jordan, K. (2015). Summary of factors contributing to falls in older adults and nursing implications. Geriatric Nursing, 36(5), 397-406. doi: 10.1016/j.gerinurse.2015.08.006.

Faber, M. J., Bosscher, R. J., Chin A Paw, M. J., \& Van Wieringen, P. C. (2006). Effects of 
exercise programs on falls and mobility in frail and pre-frail older adults: A Multicenter randomized controlled trial. Archives of Physical Medicine Rehabilitation, 87(7), 885896. Doi: 10.1016/j.apmr.2006.04.005

Federal Interagency Forum on Aging Related Statistics. (2012). Older Americans 2012: Key indicators of well-being. Retrieved from http://www.agingstats.gov/Main_Site/Data/2012_Documents/Population.aspx

Fish, D. E., Krabak, B. J., Johnson-Greene, D., \& Delateur, B. J. (2003). Optimal resistance training: Comparison of DeLorme with oxford techniques. American Journal of Physical Medicine \& Rehabilitation, 82(12), 903-909. doi:

10.1097/01.PHM.0000098505.57264.DB

Florence, C. S., Bergen, G., Atherly, A., Burns, E., Stevens, J., \& Drake, C. (2018). Medical costs of fatal and nonfatal falls in older adults. Journal of the American Geriatrics Society, 66(4), 693-698. doi: 10.1111/jgs.15304

Forkan, R., Pumper, B., Smyth, N., Wirkkala, H., Ciol, M., \& Shumway-Cook, A. (2006). Exercise adherence following physical therapy intervention in older adults with impaired balance. Physical Therapy, 83(3), 401-410. doi: 10.1093/ptj/86.3.401.

French, B., Thomas, L. H., Baker, P., Burton, C. R., Pennington, L., \& Roddam, H. (2009). What can management theories offer evidence-based practice? A comparative analysis of measurement tools for organizational context. Implementation Science, 4(1). doi: $10.1186 / 1748-5908-4-28$.

Freiberger, E., Menz, H. B., Abu-Omar, K., Rutten A. (2007). Preventing falls in physically active community-dwelling older people: a comparison of two intervention techniques. Gerontology 53(5):298-305. doi: 10.1159/000103256. 
Fruth, S., Van Veld, R., Despos, C., Martin, R., Hecker, A., \& Sincroft, E. (2010). The influence of a topic-specific, research-based presentation on physical therapists' beliefs and practices regarding evidence-based practice. Physiotherapy theory and Practice, 26(8), 537-557. doi: 10.3109/09593980903585034

Fuller, G. F. (2000). Falls In The Elderly. American Family Physician, 61(7), 2159-2168.

Giangregorio, L. M., Thabane, L., Adachi, J. D., Ashe, M. C., Bleakney, R. R., Braun, E. A., .. . Papaioannou, A. (2014). Build better bones with exercise: Protocol for a feasibility study of a multicenter randomized controlled trial of 12 months of home exercise in women with a vertebral fracture. Physical Therapy, 94(9), 1337-1352. doi: $10.2522 / \mathrm{ptj} .20130625$

Gianoudis, J., Bailey, C. A., Ebeling, P. R., Nowson, C. A., Sanders, K. M., Hill, K., \& Daly, R. M. (2014). Effects of a targeted multimodal exercise program incorporating high-speed power training on falls and fracture risk factors in older adults: A community-based randomized controlled trial. Journal of Bone Mineral Research, 29(1), 182-191. doi: 10.1002/jbmr.2014.

Gillespie, L. D., Robertson, M. C., Illespie, W. J., Sherringto, C., Gates, S., Clemson, L. M., \& Lamb, S. E. (2012). Interventions for preventing fall in older people living in the community. Cochrane Database Systematic Review, 3. doi:CD007146.

Gorgon, E.J., Barrozo, H.G., Mariano, L.G., Rivera, E.F. (2013). Research evidence uptake in a developing country: a survey of attitudes, education and self-efficacy, engagement, and barriers among physical therapists in the Philippines. Journal of Evaluation in Clinical Practice 19(5):782-790 doi: 10.1111/j.1365-2753.2012.01849.x

Greenwood, P. M. (2007). Functional plasticity in cognitive aging: Review and hypothesis. 
Neuropsychology, 21(6), 657-673. doi: 10.1037/0894-4105.21.6.657

Gschwind, Y. J., Kressig, R. W., Lacroix, A., Muehlbauer, T., Pfenninger, B., \& Granacher, U. (2013). A best practice fall prevention exercise program to improve balance, strength/power, and psychosocial health in older adults: Study Protocol for a randomized controlled trial. BMC Geriatrics, 13(105). doi:10.1186/1471-2318-13-105.

Gudjonsdottir, B., \& Arnadottir, S. (2015). Physical therapists' attitudes toward the adoption of innovation and evidence-based practice. Physiotherapy, 101(1), 490-491. doi:10.1016/j.physio.2015.03.215

Guggenheimer, J., Olsen, S., Kurvers, D., \& Barron, N. (2017). Strength training for older adults: Psychosocial and physiological adaptations. Innovation in Aging, 1(Suppl_1), 13531354. doi: 10.1093/geroni/igx004.4972

Haas, R., Maloney, S., Pausenberger, E., Keating, J. L., Sims, J., Molloy, E., . . Haines, T. (2012). Clinical decision making in exercise prescription for fall prevention. Physical Therapy, 92(5), 666-679. doi: 10.2522/ptj.20110130.

Hannes, K., Staes, F., Goedhuys, J., \& Aertgeerts, B. (2009). Obstacles to the implementation of evidence-based physiotherapy in practice: A focus group-based study in Belgium (Flanders). Journal Physiotherapy Theory and Practice 25(7), 476-488. doi: $10.3109 / 09593980802661949$.

Haran, M. J., Cameron, I. D., Ivers, R. Q., Simpson, J. M., Lee, B. B., Tanzer, M., et al. (2010) Effect on falls of providing single lens distance vision glasses to multifocal glasses wearers: VISIBLE randomised controlled trial. British Medical Journal (Clinical research ed) 340:c2265. doi: 10.1136/bmj.c2265.

Hartholt, K. A., Van Beeck, E. F., Polinder, S., Van der Velde, N., Van Lieshout, E. M., 
Panneman, M. J., . . Patka, P. (2011). Societal consequences of falls in the older population: Injuries, healthcare costs, and long-term reduced quality of life. The Journal of Trauma, 71(3), 748-753. doi: 10.1097/TA.0b013e3181f6f5e5.

Harvey, G., \& Kitson, A. (2015). PARIHS revisited: From heuristic to integrated framework for the successful implementation of knowledge into practice. Implementation Science, 11(1). doi: 10.1186/s13012-016-0398-2.

Harwood, R. H., Foss, A. J., Osborn, F., Gregson, R. M., Zaman, A., Masud, T. (2005). Falls and health status in elderly women following first eye cataract surgery: a randomised controlled trial. British Journal of Ophthalmology 89(1):53-59. doi: 10.1136/bjo.2004.049478.

Harwood, R. H., Sahota, O., Gaynor, K., Masud, T., Hosking, D. J (2004). Nottingham Neck of Femur (NONOF) Study. A randomised, controlled comparison of different calcium and vitamin D supplementation regimens in elderly women after hip fracture: The Nottingham Neck of Femur (NONOF) Study. Age and Ageing 33(1):45-51. doi: 10.1093/ageing/afh002.

Hauer, K., Rost, B., Rutschle, K., Opitz, H., Specht, N., Bartsch, P., \& Schlierf, G. (2001). Exercise training for rehabilitation and secondary prevention of fall in geriatric patients with a history of injurious falls. Journal of the American Geriatrics Society, 49(1), 1020. doi:10.1046/j.1532-5415.2001.49004.x

Hausdorff, J. M. (2005). Gait variability: Methods, modeling and meaning. Jurnal of Neuroengineering and Rehabilitation, 2(2), 19-25. 10.1186/1743-0003-2-19.

Henry, K., Rosemond, C., \& Eckert, L. (1999). Effect of number of home exercises on compliance and performance in adults over 65 years of age. Physical Therapy, 79(3), 
270-277. doi: 10.1093/ptj/79.3.270

Herman, T., Mirelman, A., Giladi, N., Schweiger, A., \& Hausdorff, J. M. (2010). Executive control deficits as a prodrome to falls in healthy older adults: A prospective study linking thinking, walking, and falling. The Journals of Gerontology: Series A, 65A(10), 1086-1092. doi: 10.1093/gerona/glq077.

Hoffmann, T. C., Maher, C. G., Briffa, T., Sherrington, C., Bennell, K., Alison, J., \& Glasziou, P. P. (2016). Prescribing exercise interventions for patients with chronic conditions. Canadian Medical Association Journal, 188(7), 510-518. doi: 10.1503/cmaj.150684

Hollman, J. H., Kovash, F. M., Kubik, J. J., \& Linbo, R. A. (2007). Age-related differences in spatiotemporal markers of gait stability during dual task walking. Gait \& Posture, 26(1), 113-119. doi: 10.1016/j.gaitpost.2006.08.005.

Hornbrook, M. C., Stevens, V. J., Wingfield, D. J., Hollis, J. F., Greenlick, M. R., Ory, M. G. (1994). Preventing falls among community-dwelling older persons: Results from a randomized trial. The Gerontologist 34(1),16-23.

Iliffe, S., Kendrick, D., Morris, R., Masud, T., Gage, H., Skelton, D., \& Belcher, C. (2014). Multicenter cluster randomized trial comparing a community group exercise program and home-based exercise with usual care for people aged 65 years and over in primary care. Health Technology Assessment, 18(49), 7-27. doi: 10.3310/hta18490

Jackson, K. M. (2016). Improving nursing home falls management program by enhancing standard of care with collaborative care multi-interventional protocol focused on fall prevention. Journal of Nursing Education and Practice, 6(6), 84-96.

Jansen, S., Bhangu, J., De Rooij, S., Daams, J., Kenny, R. A., \& Van der Velde, N. (2016). The association of cardiovascular disorders and falls: A systematic review. Journal of the 
American Medical Directors Association, 17(3), 193-199. doi:

10.1016/j.jamda.2015.08.022

Jette, D., Bacon, K., Batty, C., Carlson, M., Ferland, A., Hermingway, R., \& Volk, D. (2003).

Evidence-based practice: Beliefs, attitudes, knowledge, and behaviors of physical therapists. Physical Therapy, 83(9), 786-805. doi: 10.1093/ptj/83.9.786

Jewell, D. V. (2018). Guide to evidence-based physical therapist practice. Burlington, MA: Jones \& Bartlett Learning.

Ji, H. M., Han, J., \& Won, Y. Y. (2015). Sarcopenia and osteoporosis. Hip \& Pelvis, 27(2), 7276. doi: $10.5371 / \mathrm{hp} .2015 .27 .2 .72$.

Jones, J., \& Rose, D. (2005). Physical activity instruction of older adults. Champaign, IL: Human Kinetics.

Jong, M. R., Elst, M. V., \& Hartholt, K. A. (2013). Drug-related falls in older patients: Implicated drugs, consequences, and possible prevention strategies. Therapeutic Advances in Drug Safety, 4(4), 147-154. doi: 10.1177/2042098613486829.

Joshua, A. M., D’Souza, V., Unnikrishnan, B., Mithra, P., Kamath, A., Acharya, V., \& Venugopapal, A. (2014). Effectiveness of progressive resistance strength training versus traditional balance exercise in improving balance among the elderly - A randomized controlled trial. Journal of Clinical and Diagnostic Research, 8(3), 98-102. doi: 10.7860/JCDR/2014/8217.4119.

Kahla, R. B., Barkaoui, A., \& Merzouki, T. (2018). Age-related mechanical strength evolution of trabecular bone under fatigue damage for both genders: Fracture risk evaluation. Journal of the Mechanical Behavior of Biomedical Materials, 84, 64-73. doi:

10.1016/j.jmbbm.2018.05.006. 
Kaniewski, M., Stevens, J. A., Parker, E. M., \& Lee, R. (2015). An introduction to the centers for disease control and prevention's efforts to prevent older adult falls. Frontiers in Public Health, 2 119. doi: 10.3389/fpubh.2014.00119.

Karinkanta, S., Kannus, P., Uusi-Rasi, K., Heinonen, A., \& Sievänen, H. (2015). Combined resistance and balance-jumping exercise reduces older women's Injurious falls and fractures: 5-year follow-up study. Age and Ageing, 44(5), 784-789. doi: 10.1093/ageing/afv064.

Kemmler, W., von Stengel, S., Engelke, K., Häberle, L., Kalender, W. A. (2010). Exercise effects on bone mineral density, falls, coronary risk factors, and health care costs in older women: the randomized controlled senior fitness and prevention (SEFIP) study. Archive of Internal Medicine 170(2):179-85. doi: 10.1001/archinternmed.2009.499.

Kenny, R. A., Richardson, D. A., Steen, N., Bexton, R. S., Shaw, F. E., Bond, J. (2001). Carotid sinus syndrome: a modifiable risk factor for nonaccidental falls in older adults (SAFE PACE). The Journal of American College of Cardiology 38(5):1491-1496. doi 10.1016/S0735-1097(01)01537-6.

Kim, S., Lockhart, T., \& Roberto, K. (2009). The effects of eight-week balance training or weight training: For the elderly on fear of falling measures and social activity levels. Quality in Ageing and Older Adults, 10(4), 37-48. doi: 10.1108/14717794200900030

King, L. \& Horak, F. (2013). On The mini-BESTest: Scoring and the reporting of total scores. Physical Therapy, 93(4), 571-575. doi: 10.2522/ptj.2013.93.4.571.

Kitson, A., Harvey, G., \& McCormack, B. (1998). Enabling the implementation of evidence based practice: A conceptual framework. Quality in Health Care, 7, 149-158.

Kitson, A. L., Rycroft-Malone, J., Harvey, G., Mccormack, B., Seers, K., \& Titchen, A. (2008). 
Evaluating the successful implementation of evidence into practice using the PARiHS framework: Theoretical and practical challenges. Implementation Science, 3(1). doi: 10.1186/1748-5908-3-1.

Kloseck, M., Crilly, R. G., \& Gibson, M. (2008). Can personality theory help us understand risk of falls? Journal of Rehabilitation and Research Development, 45(8), 1125-1134. doi: 10.1682/JRRD.2007.08.0135.

Kovács, E., Prókai, L., Mészáros, L., Gondos, T. (2013). Adapted physical activity is beneficial on balance, functional mobility, quality of life and fall risk in community-dwelling older women: a randomized single-blinded controlled trial. European Journal of Physical and Rehabilitation Medicine 49(3), 301-310.

Kruschke, C. \& Butcher, H. K. (2017). Evidence-based practice guideline: Fall prevention for older adults. Journal of Gerontological Nursing, 43(11), 15-21. doi: 10.3928/0098913420171016-01

Kyrdalen, I. L., Moen, K., Røysland, A. S., \& Helbostad, J. L. (2013). The otago exercise program performed as group training versus home training in fall-prone older people: A randomized controlled trial. Physiotherapy Research International, 19(2), 108-116. doi: 10.1002/pri.1571

Laroche, D. P., Greenleaf, B. L., Croce, R. V., \& Mcgaughy, J. A. (2014). Interaction of age, cognitive function, and gait performance in 50-80-year-olds. Age, 36(4). doi: $10.1007 / \mathrm{s} 11357-014-9693-5$

Lawlor, D. A., Patel, R., \& Ebrahim, S. (2003). Association between falls in elderly women and chronic diseases and drug use: Cross Sectional Study. British Medical Journal, 327(7417), 712-715. doi: 10.1136/bmj.327.7417.712. 
Leipzig, R. M., Cumming, R. G., \& Tinetti, M. E. (1999). Drugs and falls in older people: A systematic review and meta-analysis: I. psychotropic drugs. Journal of the American Geriatrics Society, 47(1), 30-39.doi: 10.1111/j.1532-5415.1999.tb01898.x

Li, F., Harmer, P., Fisher, K. J., McAuley, E., Chaumeton, N., Eckstrom, E., \& Wilson, N. L. (2005). Tai Chi and fall reductions in older adults: A randomized controlled trial. Journal of Gerontology series A: Biological Sciences \& Medical Sciences., 60(2), 187194.doi: 10.1093/gerona/60.2.187.

Lin, M. R., Hwang, H. F., Wang, Y. W., Chang, S. H., \& Wolf, S. L. (2006). Community-based Tai Chi and Its effect on injurious falls, balance, gait, and fear of falling in older people. Physical Therapy, 86(9), 1189-1201. doi: 10.2522/ptj.20040408

Liu, H., Quiben, M., Holmes, C., Connors, M., \& Salem, Y. (2017). Differences in the limits of stability between older rolling walker users and older single-tip-cane users - A preliminary study. Rehabilitation Nursing, 42(2), 109-116.doi: 10.1002/rnj.228.

Liu, Y., Chan, J. S., \& Yan, J. H. (2014). Neuropsychological mechanisms of falls in older adults. Frontiers in Aging Neuroscience, 6(64). doi: 10.3389/fnagi.2014.00064

Liu-Ambrose, T., Khan, K. M., Eng, J. J., Janssen, P. A., Lord, S., \& McKay, H. A. (2004). Resistant and agility training reduce fall risk in women aged 75 to 85 with low bone mass: A six-month randomized controlled trial. Journal of the American Geriatrics Society, 52(5), 657-665. DOI: 10.1111/j.1532-5415.2004.52200.x

Logan, P. A., Coupland, C. A., Gladman, J. R., Sahota, O., Stoner-Hobbs, V., Robertson, K., et al. (2010). Community falls prevention for people who call an emergency ambulance after a fall: randomized controlled trial. British Medical Journal (Clinical Research Ed). 340:c2102. doi: 10.1136/bmj.c2102. 
Loganathan, A., Ng, C. J., Tan, M. P., \& Low, W. Y. (2015). Barriers faced by healthcare professionals when managing falls in older people in Kuala Lumpur, Malaysia: A qualitative study. British Medical Journal Open, 5(11), 1-9. doi: 10.1136/bmjopen-2015008460.

Lord, S. R., Castell, S., Corcoran, J., Dayhew, J., Matters, B., Shan, A., Williams, P. (2003). The effect of group exercise on physical functioning and falls in frail older people living in retirement villages: a randomized, controlled trial. Journal of the American Geriatrics Society 51(12):1685-1692. doi 10.1046/j.1532-5415.2003.51551.x

Lord, S. R., Menz, H. B., \& Sherrington, C. (2006). Home environment risk factors for falls in older people and the efficacy of home modifications. Age and Ageing, 35(Suppl_2), Ii55-Ii59. doi: 10.1093/ageing/afl088

Lord, S. R. \& Close, J. C. (2018). New horizons in fall prevention. Age and Ageing. doi:10.1093/ageing/afy059

Lord, S., Sherrington, C., \& Menz, H. B. (2001). Falls in olderpPeople: Risk factors and strategies for prevention. Cambridge, UK: Cambridge university press.

Lutz, W., Sanderson, W., \& Scherbov, S. (2008). The coming acceleration of global population ageing. Nature, 451(7179), 716-719. doi: 10.1038/nature06516.

Luukinen, H., Viramo, P., Herala, M., Kervinen, K., Kesäniemi, Y. A., Savola, O., \& Hillbom, M. (2005). Fall-related brain injuries and the risk of dementia in elderly people: A population-based study. European Journal of Neurology, 12(2), 86-92. DOI: 10.1111/j.1468-1331.2004.00953.x

Mailey, E. L., Phillips, S. M., Dlugonski, D., \& Conroy, D. E. (2016). Overcoming barriers to exercise among parents: A social cognitive theory perspective. Journal of Behavioral 
Medicine, 39(4), 599-609. doi: 10.1007/s10865-016-9744-8

Mann, R., Birks, Y., Hall, J., Torgerson, D., \& Watt, I. (2006). Exploring the relationship between fear of falling and neuroticism: A cross-sectional study in community-dwelling women over 70. Age and Ageing, 35(2), 143-147. doi: 10.1093/ageing/afj013.

Mansfield, A., Wong, J. S., Bryce, J., Knorr, S., \& Patterson, K. K. (2015). Does perturbationbased balance training prevent falls? Systematic review and meta-analysis of preliminary randomized controlled trials. Physical therapy, 95(5), 700-709. doi: 10.2522/ptj.20140090.

Masnoon, N., Shakib, S., Kalisch-Ellett, L., \& Caughey, G. E. (2017). What is polypharmacy? A systematic review of definitions. BMC Geriatrics, 17(1). doi: 10.1186/s12877-017-06212.

McAuley, E., Szabo, A., Gothe, N., \& Olson, E. A. (2011). Self-efficacy: Implications for physical activity, function, and functional limitations in older adults. American Journal of Lifestyle Medicine, 5(4), 1-16. doi: 10.1177/1559827610392704.

Mcglynn, E. A., Asch, S. M., Adams, J., Keesey, J., Hicks, J., Decristofaro, A., \& Kerr, E. A. (2003). The quality of health care delivered to adults in the United States. New England Journal of Medicine, 348(26), 2635-2645. DOI: 10.1056/NEJMsa022615.

McKiernan, F. E. (2005). A simple gait-stabilizing device reduces outdoor falls and non-serious injurious falls in fall-prone older people during the winter. Journal of the American Geriatrics Society 53(6):943-7. doi: 10.1111/j.1532-5415.2005.53302.x

Michael, Y. L., Lin, J. S., Whitlock, E. P., Gold, R., Fu, R., O'connor, E., . . Lutz, W. (2010). Interventions to prevent falls in older adults: An updated systematic review. Retrieved from http://www.ncbi.nlm.nih.gov/books/NBK51688/ 
Montero-Odasso, M., Verghese, J., Beauchet, O., \& Hausdorff, J. M. (2012). Gait and cognition: A complementary approach to understanding brain function and the risk of falling. Journal of the American Geriatrics Society, 60(11), 2127-2136. doi: 10.1111/j.15325415.2012.04209.x

Mouton, C. P., Bazaldua, O. V., Pierce, B., \& Espino, D. V. (2001). Common infections in older adults. American Family Physician, 63(2), 257-268.

National Center for Complementary and Integrative Health. (2015). Tai chi: An introduction. Retrieved from https://nccih.nih.gov/health/taichi/introduction.htm

National Collaborating Centre for Methods and Tools [NCCMT] (2011). PARiHS framework for implementing research into practice Retrieved from http://www.nccmt.ca/resources/search/85

National Center for Health Statistics. (2016). Health, United States, 2016: With Chart-book on Long-term Trends in Health. Hyattsville, MD.

National Center for Injury Prevention and Control. (2003). National Center for Injury Prevention and Control. Web-based Injury Statistics Query and Reporting System (WISQAR).

National Center for Injury Prevention and Control. (2010). 10 leading causes of injury deaths by age group highlighting unintentional injury deaths, United States - 2010. Retrieved from https://www.cdc.gov/injury/wisqars/pdf/10lcid_unintentional_deaths_2010-a.pdf National Council on Aging [NCOA], (2017). Top 10 chronic conditions in adults 65+ and what you can do to prevent or manage them. Retrieved from https://www.ncoa.org/blog/10common-chronic-diseases-prevention-tips/

Netelenbos, J. C., Lems, W. F., Geusens, P. P., Verhaar, H. J., Boermans, A. J., Boomsma, M. M., \& apapoulos, S. E. (2008). Spine radiographs to improve the identification of 
women at high risk for fractures. Osteoporosis International, 20(8), 1347-1352. doi $10.1007 / \mathrm{s} 00198-008-$

Nikolaus, T., Bach, M. (2003). Preventing falls in community-dwelling frail older people using a home intervention team (HIT): Results from the randomized falls-HIT trial. Journal of the American Geriatrics Society 51(3), 300-305. doi: 10.1046/j.15325415.2003.51102.x

Nilsagard, Y., Lohse, G. (2010). Evidence-based physiotherapy: A survey of knowledge, behaviour, attitudes and prerequisites. Journal Advances in Physiotherapy 12(4), 179186. doi: 10.3109/14038196.2010.503812

Nolan, M., Nitz, J., Choy, N., \& IIIing, S. (2010). Age-related changes in musculoskeletal function, balance and mobility measures in men aged 30 -80 years. The Aging Male: The Journal of the International Society for the Study of Aging Male, 13(3), 194-201. doi: $10.3109 / 13685531003657818$

Nyberg, L. \& Gustafson, Y. (1995). Patient falls in stroke rehabilitation. A challenge to rehabilitation strategies. Stroke, 26(5), 838-842. doi: 10.1161/01.STR.26.5.838.

Paans, N., Van den Akker-Scheek, I., Dilling, R. G., Bos, M., Van der Meer, K., Bulstra, S. K., \& Stevens, M. (2013). Effect of exercise and weight loss in people who have hip osteoarthritis and are overweight or obese. Physical Therapy, 93(2), 137-146. doi: $10.2522 / \mathrm{ptj} .20110418$

Palvanen, M., Kannus, P., Piirtola, M., Niemi, S., Parkkari, J., \& Järvinen, M. (2014). Effectiveness of the chaos falls clinic in preventing falls and injuries of home-dwelling older adults: A randomised controlled trial. Injury 45(1):265-271. doi: 10.1016/j.injury.2013.03.010. 
Pariente, A., Dartigues, J., Benichou, J., Letenneur, L., Moore, N., \& Fourrier-Réglat, A. (2008). Benzodiazepines and injurious falls in community-dwelling elders. Drugs \& Aging, 25(1), 61-70. doi: 10.2165/00002512-200825010-00007.

Paul, B., Gieroba, Z., \& Mangoni, A. A. (2007). Influence of co-morbidities and medication use on tilt table test outcome in elderly patients. Heart, Lung and Circulation, 16, 540-543. doi: 10.1111/j.1540-8159.2007.00705.x

Pearlman, R. A. \& Uhlmann, R. F. (1988). Quality of life in chronic diseases: Perceptions of elderly Patients. Journal of Gerontology, 43(2), 25-30. DOI: 10.1093/geronj/43.2.M25.

Peel, N. M. (2011). Epidemiology of falls in Older Age. Canadian Journal on Aging / La Revue Canadienne Du Vieillissement, 30(01), 7-19.doi: 10.1017/S071498081000070X

Pfeifer, M., Begerow, B., Minne, H. W., Suppan, K., Fahrleitner-Pammer, A., \& Dobnig, H. (2009). Effects of a long-term vitamin D and calcium supplementation on falls and parameters of muscle function in community-dwelling older individuals. Osteoporosis International 20(2):315-22. doi: 10.1007/s00198-008-0662-7.

Pighills, A. C., Torgerson, D. J., Sheldon, T. A., Drummond, A. E., \& Bland, J. M. (2011) Environmental assessment and modification to prevent falls in older people. Journal of the American Geriatrics Society 59(1):26-33. doi: 10.1111/j.1532-5415.2010.03221.x.

Pountney, D. (2009). Preventing and managing falls in residential care settings. Nursing and Residential Care, 11(8), 410-414.doi: 10.12968/nrec.2009.11.8.43320.

Prerost, F. J. (2013). Aging. Salem, MA: Encyclopedia of Science.

Priest, A. W., Salamon, K. B., \& Hollman, J. H. (2008). Age-related differences in dual task walking: A cross sectional study. Journal of NeuroEngineering and Rehabilitation, 5(1), 29. doi: 10.1186/1743-0003-5-29 
Pérez-Ros, P., Martínez-Arnau, F., Navarro-Illana, E., Tormos-Minana, I., \& TarazonaSantabalbina, F. J. (2013). Relationship between the risk of falling and prescribed medication in community-dwelling elderly subjects. Advances in Pharmacology and Pharmacy, 1(1), 29-36. doi: 10.13189/app.2013.010106

PsychData, (2018). Library: Compare us. Retrieved from https://www.psychdata.com/content/compare.asp

Ramírez-Vélez, R., Bagur-Calafat, M. C, Correa-Bautista, J. E., \& Girabent-Farrés, M. (2015). Barriers against incorporating evidence-based practice in physical therapy in Colombia: current state and factors associated. BMC Medical Education 15, 220. doi 10.1186/s 12909-015-0502-3.

Rao, A. K., Gilman, A., \& Louis, E. D. (2014). Balance confidence and falls in nondemented essential tremor patients: The role of cognition. Archives of Physical Medicine and Rehabilitation, 95(10), 1832-1837. doi: 10.1016/j.apmr.2014.04.001.

Rapp, K., Lamb, S. E., Gisela, B., Ranjit, L., Lindermann, U., \& Becker, C. (2008). Prevention of falls in nursing homes: Subgroup analyses of a randomized fall prevention trial. Journal of American Geriatric Society, 56(6), 1092-1097. doi:10.1111/j.15325415.2008.01739.x

Raz, N. \& Rodrigue, K. M. (2006). Differential aging of the brain: Patterns, cognitive correlates and modifiers. Neuroscience \&amp; Biobehavioral Reviews, 30(6), 730-748. doi: 10.1016/j.neubiorev.2006.07.001

Ren, J., Wu, Y. D., Chan, J. S., \& Yan, J. H. (2013). Cognitive aging affects motor performance and learning. Geriatrics \&amp; Gerontology International, 13(1), 19-27. doi: 10.1111/j.1447-0594.2012.00914.x 
Richardson, K., Bennett, K., \& Kenny, R. A. (2014). Polypharmacy including falls riskincreasing medications and subsequent falls in community-dwelling middle-aged and older adults. Age and Ageing, 44(1), 90-96. doi: 10.1093/ageing/afu141

Robin, M. \& Baum, H. M. (1981). The National Survey of Stroke. Incidence. Stroke, 12(2 Pt 2 Suppl 1), 145-157.

Rosendahl, E., Gustafson, Y., Nordin, E., Lundin-Olsson, L., \& Nyberg, L. (2008). A randomized controlled trial of fall prevention by a high-intensity functional exercise program for older people living in residential care facilities. Aging Clinical and Experimental Research, 20(1), 67-75. doi: 10.1007/BF03324750.

Rubenstein, L. (2006). Falls in older people: Epidemiology, risk factors and strategies for prevention. Age and Ageing, 37-41. doi: 10.1093/ageing/afl084.

Rubenstein, L. Z., Josephson, K. R., Trueblood, P. R., Loy, S., Harker, J. O., Pietruszka, F. M., Robbins, A. S. (2000). Effects of a group exercise program on strength, mobility, and falls among fall-prone elderly men. Journal of Gerontology: Medical Sciences 55(6):M317-321. doi: 10.1093/gerona/55.6.M317.

Rycroft-Malone, J. (2004). The PARiHS framework-A framework for guiding the implementation of evidence-based practice. Journal of Nursing Care Quality 19(4): 297304.

Saito, T., Murata, C., Aida, J., \& Kondo, K. (2017). Cohort study on living arrangements of older men and women and risk for basic activities of daily living disability: Findings from the AGES project. BMC Geriatrics, 17(1). doi: 10.1186/s12877-017-0580-7.

Salbach, M., Jagial, S., Korner-Bitensky, N., Rappolt, S., \& Davis, D. (2007). Practitioner and organizational barriers to evidence based practice of physical therapists for people with 
stroke. Journal of the Physical Therapy Association, 87(10) 1284-1303. doi:

$10.2522 /$ ptj. 20070040

Salminen, M. J., Vahlberg, T. J., Salonoja, M. T., Aarnio, P. T, \& Kivelä, S. L. (2009). Effect of a risk-based multifactorial fall prevention program on the incidence of falls. Journal of the American Geriatrics Society 57(4):612-619. doi: 10.1111/j.1532-

5415.2009.02176.x.

Sarmiento, K. \& Lee, R. (2017). STEADI: CDCs approach to make older adult fall prevention part of every primary care practice. Journal of Safety Research, 63(1), 105-109. doi: 10.1016/j.jsr.2017.08.003

Schutzer, K. (2004). Barriers and motivations to exercise in older adults. Preventive Medicine, 39(5), 1056-1061. DOI: 10.1016/j.ypmed.2004.04.003

Seguin, R., \& Nelson, M. E. (2003). The benefits of strength training for older adults. American Journal of Preventive Medicine, 3(Suppl 2), 141-149. Doi: 10.1016/S07493797(03)00177-6

Sheehan, K.B. (2001). E-mail survey response rates: A review. Journal of computer-mediated communication 6:0-0 doi 10.1111/j.1083-6101.2001.tb00117.x

Sexton, C. E., Allan, C. L., Masurier, M. L., Mcdermott, L. M., Kalu, U. G., Herrmann, L. L., . . . Ebmeier, K. P. (2012). Magnetic resonance imaging in late-life depression. Archives of General Psychiatry, 69(7), 680-689. doi: 10.1001/archgenpsychiatry.

Shubert, T., Smith, M., Goto, L., Jiang, L., \& Ory, M. (2017). Otago exercise program in the United States: Comparison of 2 implementation model. Physical Therapy, 97(2), 187197. doi: 10.2522/ptj.20160236.

Shumway-Cook, A., Ciol, M. A., Hoffman, J., Dudgeon, B. J., Yorkston, K., \& Chan, L. (2009). 
Falls in the medicare population: Incidence, associated factors, and impact on health care. Physical Therapy, 89(4), 324-332. doi: 10.2522/ptj.20070107

Shumway-Cook, A., Brauer, S., \& Woollacott, M. (2000). Predicting the probability for falls in community-dwelling older adults using the Timed Up \& Go test. Physical therapy, 80(9), 896-903.doi: 10.1093/ptj/80.9.896

Sirkin, A. J., \& Rosner, N. G. (2009). Hypertensive management in the elderly patient at risk for falls. Journal of the American Academy of Nurse Practitioners, 21(7), 402-408. doi: 10.1111/j.1745-7599.2009.00418.x.

Skelton, D., Dinan, S., Campbell, M., \& Rutherford, O. (2005). Tailored group exercise (Falls Management Exercise -- FaME) reduces falls in community-dwelling older frequent fallers (an RCT). Age Ageing 34(6):636-639. doi: 10.1093/ageing/afi174.

Smulders, E., Weerdesteyn, V., Groen, B. E., Duysens, J., Eijsbouts, A., \& Laan, R. (2010). Efficacy of a short multidisciplinary falls prevention program for elderly persons with osteoporosis and a fall history: a randomized controlled trial. Archives of Physical Medical Rehabilitation 91(11):1705-1711. doi: 10.1016/j.apmr.2010.08.004.

Son, N., Ryu, Y. U., Jeong, H., Jang, Y., \& Kim, H. (2016). Comparison of 2 different exercise approaches. Journal of Geriatric Physical Therapy, 39(2), 51-57. doi: 10.1519/JPT.0000000000000042.

Soriano, A. T., DeCherrie, L. V., \& Thomas, D. C. (2007). Falls in the community-dwelling older adult: A review for primary-care providers. Clinical Interventions in Aging, 2(4), $545-553$.

Spice, C. L., Morotti, W., George, S., Dent, T. H., Rose, J., \& Harris, S. (2009).

The Winchester Falls Project: A randomized controlled trial of secondary prevention of 
falls in older people. Age and Aging 38(1):33-40. doi: 10.1093/ageing/afn192.

Spink, M. J., Menz, H. B., Fotoohabadi, M. R., Wee, E., Landorf, K. B., \& Hill, K. D. (2011) Effectiveness of a multifaceted podiatry intervention to prevent falls in community dwelling older people with disabling foot pain: randomised controlled trial. British Medical Journal (Clinical Research Ed) 342:d3411. doi 10.1136/bmj.d3411

Spirduso, W., Francis, K., \& MacRae, P. (2005). Physical Dimensions Of Aging (2nd ed.). Champaign, IL: Human Kinetics.

Springer, S., Giladi, N., Peretz, C., Yogev, G., Simon, E. S., \& Hausdorff, J. M. (2006). Dualtasking effects on gait variability: The role of aging, falls, and executive function. Movement Disorders, 21(7), 950-957. doi: 10.1002/mds.20848

Steadman, J., Donaldson, N., \& Kalra, L. (2003). A randomized controlled trial of an enhanced balance training program to improve mobility and reduce falls in elderly patients. Journal of the American Geriatrics Society, 51(6), 847-852.doi 10.1046/j.13652389.2003.51268.x

Stenberg, M., \& Wann-Hansson, C. (2011). Health care professionals' attitudes and compliance to clinical practice guidelines to prevent falls and fall injuries. Worldviews on EvidenceBased Nursing, 8(2), 87-95. doi: 10.1111/j.1741-6787.2010.00196.x

Stevens, J. \& Phelan, E. (2013). The development of STEADI-A fall prevention tool kit for us healthcare providers. Health Promotion Practice., 14(5), 706-714. doi: $10.1177 / 1524839912463576$

Stevens, J. (2013). The STEADI tool kit: A fall prevention resource for health care providers. The IHS Primary Care Provider, 39(9), 162-166.

Stevens, J. A. (2005). Falls among older adults_risk factors and prevention strategies. Journal 
of Safety Research, 36(4), 409-411. DOI: 10.1016/j.jsr.2005.08.001

Stevens, J. A. \& Burns, E. R. (2015). A CDC compendium of effective fall interventions: What works for community-dwelling older adults (3rd Ed.). Atlanta, GA: Centers for Disease Control and Prevention, National Center for Injury Prevention and Control.

Stroud, M. A. (2014). Physical therapists clinical practices regarding intrinsic and extrinsic fall risk factors and their attitudes toward the use of evidence-based practice (Unpublished doctoral dissertation). Southern Illinois University Carbondale, IL.

Stubbs, B., Brefka, S., \& Denkinger, M. D. (2015). What works to prevent falls in communitydwelling older adults? Umbrella review of meta-analyses of randomized controlled trials. Physical therapy, 95(8), 1095-1110.doi 10.2522/ptj.20140461

Summary of the updated American Geriatrics Society/British Geriatrics Society clinical practice guideline for prevention of falls in older persons. (2011). Journal of the American Geriatrics Society, 59(1), 148-157. doi: 10.1111/j.1532-5415.2010.03234.x.

Taylor, D. (2013). Physical activity is medicine for older adults: Table 1. Postgraduate Medical Journal, 90(1059), 26-32. doi: 10.1136/postgradmedj-2012-131366

Tella, S. H., \& Gallagher, J. C. (2014). Prevention and treatment of postmenopausal osteoporosis. The Journal of Steroid Biochemistry and Molecular Biology, 142, 155-170. doi: 10.1016/j.jsbmb.2013.09.008.

Texas Board of Physical Therapy Examiners (2018). What is physical therapy? Web-page retrieved from https://www.ptot.texas.gov/page/physicaltherapy

Thorell, K., Ranstad, K., Midlöv, P., Borgquist, L., \& Halling, A. (2014). Is use of fall riskincreasing drugs in an elderly population associated with an increased risk of hip fracture, after adjustment for multimorbidity level: A cohort study. BMC Geriatrics, 
14(1), 1-15. doi: 10.1186/1471-2318-14-131.

Tideiksaar, R. (2010). Falls in older people: Prevention and management (4th Ed.). Baltimore, MD: Health Professions Press.

Tinetti, M. E., \& Williams, C. S. (1997). Falls, injuries due to falls, and the risk of admission to a nursing home. New England Journal of Medicine, 337(18), 1279-1284. doi:

10.1056/NEJM199710303371806

Tinetti, M. E., Baker, D. I., McAvay, G., Claus, E. B., Garrett, P., \& Gottschalk, M. (1994). A multifactorial intervention to reduce the risk of falling among elderly people living in the community. The New England Journal of Medicine, 331, 821-827. doi: 10.1056/NEJM199409293311301.

Trochim, W., \& Donnelly, J. (2008). The research methods knowledge base ( $3^{\text {rd }}$ Ed.). Mason, $\mathrm{OH}$ : Cengage Learning.

Trombetti, A., Hars, M., Herrmann, F. R., Kressig, R. W., Ferrari, S., \& Rizzoli, R. (2011). Effect of music-based multitask training on gait, balance, and fall risk in elderly people: a randomized controlled trial. Archives of Internal Medicine 171(6):525-533. doi: 10.1001/archinternmed.2010.446.

Tsur, A., \& Segal, Z. (2010). Falls in stroke patients: Risk factors and risk management. The Israel Medical Association Journal, 12(4), 216-219.

United States Census Bureau. (2010). The next four decades: The older population in the United States: 2010 to 2050. Washington, DC: U.S. department of commerce, economics and statistics administration.

United States Census Bureau. (2014). An aging nation: The older population in the United States. Retrieved from http://www.census.gov/prod/2014pubs/p25-1140.pdf 
United States Preventive Services Task Force [USPSTF] (2017). Final recommendation statement falls prevention in community-dwelling older adults: Interventions. Retrieved from https://www.uspreventiveservicestaskforce.org/Page/Document/RecommendationStatem entFinal/falls-prevention-in-older-adults-interventions1

Unsworth, J. \& Mode, A. (2003). Preventing falls in older people: Risk factors and primary prevention through physical activity. British Journal of Community Nursing, 8(5), 214220. doi: 10.12968/bjen.2003.8.5.11200

Verbrugge, L. M., Lepkowski, J. M., \& Konkol, L. L. (1991). Levels of disability among U.S. adults with arthritis. Journal of Gerontology, 46(2), 71-83.doi: 10.1093/geronj/46.2.S71

Verbrugge, L. M., Gates, D. M., \& Ike, R. W. (1991). Risk factors for disability among U.S. adults with arthritis. Journal of Clinical Epidemiology, 44(2), 167-182. doi: 10.1016/0895-4356(91)90264-A •

Verghese, J., Levalley, A., Hall, C. B., Katz, M. J., Ambrose, A. F., \& Lipton, R. B. (2006). Epidemiology of gait disorders in community-residing older adults. Journal of the American Geriatrics Society, 54(2), 255-261.doi 10.1111/j.1532-5415.2005.00580.x Voukelatos, A., Cumming, R. G., Lord, S. R., \& Rissel, C. (2007). A randomized controlled trial of tai chi for the prevention of falls: The central Sydney tai chi trial. Journal of the American Geriatrics Society, 55(8), 1185-1191. doi: 10.1111/j.1532-5415.2007.01244.x

Wang, F., Skubic, M., Abbott, C., \& Keller, J. (2010). Body sway measurement for fall risk assessment using inexpensive webcam. Retrieved from https://eldertech.missouri.edu/files/Papers/WangF/Body Sway Measurement for Fall Risk Assessment.pdf 
Wagner, E. H., LaCroix, A. Z., Grothaus, L., Leveille, S. G., Hecht, J., Artz, K., et.al (1994). Preventing disability and falls in older adults: A population-based randomized trial. American Journal of Public Health 84(11):1800-1806. doi 10.2105/AJPH.84.11.1800.

Ward, N. S. (2006). Compensatory mechanisms in the aging motor system. Ageing Research Reviews, 5(3), 239-254. doi: 10.1016/j.arr.2006.04.003

Ward, M. M., Baloh, J., Zhu, X., \& Stewart, G. L. (2017). Promoting action on research implementation in health services framework applied to Team-STEPPS implementation in small rural hospitals. Health Care Management Review, 42(1), 2-13. doi: 10.1097/HMR.0000000000000086

Weir, E. \& Culmer, L. (2004). Fall prevention in the elderly population. Canadian Medical Association Journal, 171(7), 724-724. doi.org/10.1503/cmaj.1041381

West, B. A., Bhat, G., Stevens, J., \& Bergen, G. (2015). Assistive device use and mobilityrelated factors among adults aged $\geq 65$ years. Journal of Safety Research, 55, 147-150. doi: 10.1016/j.jsr.2015.08.010

Wheeler, E., Coogle, C., Fix, R. C., Owens, M., \& Waters, L. (2018). Physical and occupational therapy practice improvement following inter-professional evidence-based falls prevention training. Journal of Allied Health, 47(1), 9-18.

Whitbourne, S. B., \& Whitbourne, S. K. (2010). Adult development and aging: Biopsychosocial perspectives. (4th ed.). Hoboken, NJ.

Wolf, S. L., Barnhart, H. X., Kutner, N. G., McNeely, E., Coogler, C., \& Xu, T. (1996). Reducing frailty and falls in older persons: an investigation of Tai Chi and computerized balance training. Atlanta FICSIT Group. Frailty and Injuries: Cooperative Studies of 
Intervention Techniques. Journal of the American Geriatrics Society 44(5):489-497. doi: 10.1111/j.1532-5415.1996.tb01432.x

Woolcott, J. C. (2009). Meta-analysis of the impact of 9 medication classes on falls in elderly persons. Archives of Internal Medicine, 169(21), 1952-1960. doi:

10.1001/archinternmed.2009.357.

World Health Organization (2013). Diet and physical activity factsheet: Secondary diet and physical activity factsheet. Retrieved from http://www.who.int/dietphysicalactivity/factsheet_inactivity/en/index.html

World Health Organization. (2010). Global recommendations on physical activity for health. Geneva, Switzerland: World Health Organization.

World Health Organization. (2008). WHO global report on falls prevention in older age. Geneva, Switzerland: World Health Organization.

Yamada, M., Higuchi, T., Nishiguchi, S., Yoshimura, K., Kajiwara, Y., Aoyama, T. (2013). Multitarget stepping program in combination with a standardized multicomponent exercise program can prevent falls in community-dwelling older adults: a randomized, controlled trial. Journal of the American Geriatrics Society 61(10):1669-1675. doi: 10.1111/jgs.12453.

Yang, X. J., Hill, K., Moore, K., Williams, S., Dowson, L., Borschmann, K., \& Dharmage, S. C. (2012). Effectiveness of a targeted exercise intervention in reversing older people's mild balance dysfunction: A randomized controlled trial. Physical Therapy, 92(1), 24-37.doi: $10.2522 / \mathrm{ptj} .20100289$

Yeh, T., Cinelli, M. E., Lyons, J. L., \& Lee, T. D. (2015). Age-related changes in postural control to the demands of a precision task. Human Movement Science, 44(1), 134-142. 
doi: 10.1016/j.humov.2015.08.021

Yingyongyudh, A., Saengsirisuwan, V., Panichaporn, W., \& Boonsinsukh, R. (2015). The minibalance evaluation systems test (mini-BESTest) demonstrates higher accuracy in identifying older adult participants with history of falls than do the BESTest, Berg balance scale, or Timed Up And Go test. Journal of Geriatric Physical Therapy, 39(2), 64-70. doi: 10.1519/JPT.0000000000000050.

Yogev-Seligmann, G., Hausdorff, J. M., \& Giladi, N. (2008). The role of executive function and attention in gait. Movement Disorders, 23(3), 329-342. doi: 10.1002/mds.21720

Zhang, J., Ishikawa-Takata, K., Yamazaki, H., \& Ohta, T. (2004). Is a type A behavior pattern associated with falling among the community-dwelling elderly? Archives of Gerontology and Geriatrics, 38(2), 145-152.doi: 10.1016/j.archger.2003.09.001

Ziere, G., Dieleman, J. P., Hofman, A., Pols, H. A., T. J. M. Van Der Cammen, \& Stricker, B. H. (2006). Polypharmacy and falls in the middle age and elderly population. British Journal of Clinical Pharmacology, 61(2), 218-223. doi: 10.1111/j.1365-2125.2005.02543.x 


\section{Appendix A}

Participant recruitment introductory letter

Dear fellow PT,

I would appreciate if you would take a few minutes to complete a short survey to help me gather data for my doctoral dissertation research. My name is Charles Agbonghae, PT, DPT. I am a Doctor of Health Science (DHSc) student at the University of St Augustine. I am conducting a study titled: Physical therapists' perceptions of barriers to the use of evidence-based fall prevention interventions with individuals of 65 years of age or older. The purpose of the study is to identify barriers perceived by physical therapists to the use of evidence-based fall prevention interventions with individuals of 65 years of age or older. I am contacting you because you are a licensed PT in the state of Texas. The survey consists of 15 questions and will take between 510 minutes to complete. There are no known risks to participation in this study. This study offers no direct health benefits to the participants. But it does contribute to the body of knowledge by identifying what are physical therapists' perceptions about evidence-based practice and what constitute barriers for not implementing these programs. If you have any concerns about your participation in the study, you should discuss them with the Principal Investigator, Charles Agbonghae at 1-254-421-9364. If you continue to have concerns you may contact the Faculty Research Advisor, Steven M. Gerardi at (737) 202-3313). If these resources are not able to address your concerns, you may contact Elizabeth Ardolino, PT, PhD, at the University of St. Augustine for Health Sciences - Austin TX campus: 1-512-394-9766 x3151 or 855-384-9965 x3151. Participation in this study is voluntary. You may refuse to participate and you may withdraw from the study at any time without penalty. Your participation in this study is anonymous and all information obtained in this study is strictly confidential unless disclosure is 
required by law. There are no identified risks or benefits to participation in this study.

The University of St. Augustine is not liable for any cost or compensations incurred as a result of participating in this study. Participation in this research project is totally voluntary, and your consent is required before you can participate. By clicking on the survey link and completing the questionnaire, you indicate your informed consent to participate and for your response to be utilized in my research.

To participate, please click on the following link:https://www.psychdata.com/s.asp?SID=182878 Thank you for your participation in this study!

Charles Agbonghae, PT, DPT.

University of St Augustine

c.agbonghae@usa.edu 


\section{Appendix B}

Reminder Email - Participant recruitment introductory letter

Dear fellow PT,

Last week I sent you an invitation to participate in a study I am conducting. If you have already completed this survey, thank you! If you have not, I would appreciate if you would take a few minutes to complete a short survey to help me gather data for my doctoral dissertation research. My name is Charles Agbonghae, PT, DPT. I am a Doctor of Health Science (DHSc) student at the University of St Augustine. I am conducting a study titled: Physical therapists' perceptions of barriers to the use of evidence-based fall prevention interventions with individuals of 65 years of age or older.

The purpose of the study is to identify barriers perceived by physical therapists to the use of evidence-based fall prevention interventions with individuals of 65 years of age or older. I am contacting you because you are a licensed PT in the state of Texas. The survey consists of 15 questions and will take between 5-10 minutes to complete.

There are no known risks to participation in this study. This study offers no direct health benefits to the participants. But it does contribute to the body of knowledge by identifying what are physical therapists' perceptions about evidence-based practice and what constitute barriers for not implementing these programs.

If you have any concerns about your participation in the study, you should discuss them with the Principal Investigator, Charles Agbonghae at 1-254-421-9364.”

If you continue to have concerns you may contact the Faculty Research Advisor, Steven M.

Gerardi at (737) 202-3313). If these resources are not able to address your concerns, you may contact Elizabeth Ardolino, PT, PhD, at the University of St. Augustine for Health Sciences - 
Austin TX campus: 1-512-394-9766 x3151 or 855-384-9965 x3151.

Participation in this study is voluntary. You may refuse to participate and you may withdraw from the study at any time without penalty. Your participation in this study is anonymous and all information obtained in this study is strictly confidential unless disclosure is required by law. There are no identified risks or benefits to participation in this study.

The University of St. Augustine is not liable for any cost or compensations incurred as a result of participating in this study.

Participation in this research project is totally voluntary, and your consent is required before you can participate. By clicking on the survey link and completing the questionnaire, you indicate your informed consent to participate and for your response to be utilized in my research.

To participate, please click on the following link: ttps://www.psychdata.com/s.asp?SID=182878

Thank you for your participation in this study!

Charles Agbonghae, PT, DPT

University of St Augustine

c.agbonghae@usa.edu 
IRB approval letter.

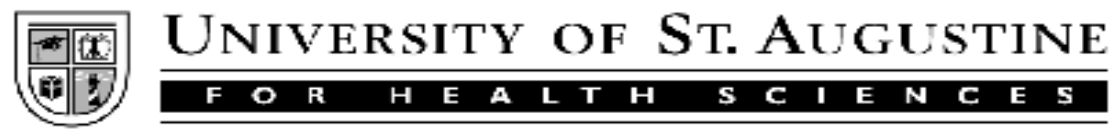

$9 / 21 / 2018$

Charles Agbonghae, PT, DPT

10021 Birch Tree Dr,

Temple, TX 76502.

RE: PT-0921-244 "Physical therapists' perceptions of barriers to the use of evidencebased fall prevention interventions with individuals of 65 years of age or older".

Dear Dr. Agbonghae:

A member of the Institutional Review Board (IRB), responsible for the review of research involving human subjects, has reviewed your expedited proposal and has granted you approval for this study. Approval for the project will be for one year, starting on 9/21/2018.

If a University of St. Augustine For Health Sciences faculty member or student leaves the University prior to completion of a USAHS IRB-approved study, the study may be continued until expiration of that IRB approval. The IRB approval will expire on 9/20/2019.

This approval is granted with the understanding that no changes may be made in the procedures to be followed, nor in the consent form(s) to be used until after such modifications have been submitted to the IRB for review and approval. Please be sure your consent form includes the IRB contact name and telephone number (Dr. Elizabeth Ardolino, Chair, University of St. Augustine for Health Sciences Institutional Review Board, 512-394-9766 ext. 3143, eardolino@usa.edu). Researchers must retain a copy of the signed consent form in their files for three years following completion of the project and must provide a copy of the consent form to the subject(s).

Any unanticipated problems involving risks to human subjects or serious adverse effects must be promptly reported to the IRB.

Prior to the expiration of this approval, you will receive notification of the need for updated information to be used for the project's continuing review. When project is completed, please notify the IRB in writing. Thank you.

Sincerely,

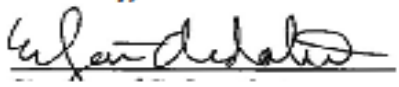

Elizabeth Ardolino, PT DPT

Chair, IRB 


\section{Appendix D (survey questionnaire)}

1. Are you a licensed physical therapist?

i. Yes. ii. No. [skip logic to end of survey if "No"].

2. Which of the following describes your highest level of physical therapy education?

i. Bachelor's degree. ii. Master's degree. iii. Doctoral degree.

3. Which of the following American Board of Physical Therapy Specialties (ABPTS) certifications do you hold?

a. Cardiovascular \& Pulmonary Certified Specialist (CCS)

b. Clinical Electrophysiologic Certified Specialist (ECS)

c. Geriatric Certified Specialist (GCS)

d. Neurologic Certified Specialist (NCS)

e. Orthopedic Certified Specialist (OCS)

f. Pediatric Certified Specialist (PCS)

g. Sports Certified Specialist (SCS)

h. Women's Health Certified Specialist (WCS)

i. None.

4. Which of the following best describes your current clinical practice setting?

i. Home Health, ii. Skilled Nursing Facility, iii. Acute care, iv. In-patient rehabilitation, v. Out-patient rehabilitation, vi. Other.

5. Which of the following describes your current level of employment in physical therapy practice? i. Full time (40 or more hrs/week), ii. Part time (under 40hrs/week), iii. PRN, iv. Other 
6. Which of the following best describes the ages of the patient population that you work with the most?

i. Pediatric (under 18 years), [skip logic to Adults (18-64 years) if "Pediatric"].

ii. Adults (18-64 years),

iii. Geriatric (65 years, or above)

7. Please respond to the following statement: "How frequently do you treat older adults who are fall risks?"

i. Daily

ii. At least three times in a week

iii. Once or twice in a week

iv. Once or twice in a month.

v. Less than once a month.

8. Please respond to the following statement "How frequently do you utilize interventions to reduce fall risks in older adults?”

i. Daily

ii. At least three times in a week

iii. Once or twice in a week

iv. Once or twice in a month.

v. Less than once a month.

9. Please respond to the following statement "How frequently do you use current research 
evidence to guide your selection of fall prevention interventions?"

i. Daily.

ii. At least three times in a week.

iii. Once or twice in a week.

iv. Once or twice in a month.

v. Less than once a month.

10. Are you familiar with the document - A CDC Compendium of Effective Fall Interventions:

What Works for Community-Dwelling Older Adults ?

i. Yes. ii. No [skip logic to question 12 if "No"].

11. Please respond to the following statement "How frequently do you utilize A CDC

Compendium of Effective Fall Interventions: What Works for Community-Dwelling

Older Adults"

i. Daily.

ii. At least three times in a week.

iii. Once or twice in a week.

iv. Once or twice in a month.

v. Less than once a month.

vi. Never.

12. Are you familiar with, or have you used the STEADI (stopping elderly accidents, death \& injuries) tool-kit for patients at fall risk?

i.Yes. ii.No.

13. Please respond to the following statement "How frequently do you utilize the STEADI tool 
kit with older adults"

i. Daily.

ii. At least three times in a week.

iii. Once or twice in a week.

iv. Once or twice in a month.

v. Less than once a month.

vi. Never

14. Consider the following list of factors that may pose a barrier to your use of current evidencebased fall interventions for the care of the elderly patients at risk of falls. Rank order these factors, from 1 to 5 (Greatest barrier $=1 \ldots$ Least barrier $=5$ ) based upon the relative degree to which they are barriers.

Lack of time,

Lack of support from your facility.

Patient's exercise tolerance.

Professional knowledge deficit.

Healthcare system bureaucracy.

15. What other factors not listed in question 14 do you think are barriers to the use of evidencebased fall prevention interventions with individuals of 65 years of age or older? 
Appendix E (qualitative thematic analysis)

\section{Theme: Remuneration}

Code: Pay

Physical therapists take home compensation

Salary not standardized across clinical settings

Clinician per hour earnings

\section{Theme: Insurance Regulations}

\section{Code: Documentation Requirements}

Additional paperwork required by insurance may limit use

Medicare required repetitive paperwork when treating elderly limits time to effectively treat

Documentation set up in emr with specific tests

Documentation requirements

Medicare and Insurance requirements that take time during treatment

Insurance standards and regulations for high fall risk patients

Code: Administrative Burden

Required administrative burden

Reimbursement limits/cap by insurance

\section{Theme: Staffing Needs or levels}

\section{Code: Lack of Skill}

Therapist's lack of skill

$\underline{\text { Code: Lack of Staff }}$

Not enough staff to treat patients

Unfavorable patient to Physical therapists ratio

Number of therapists on duty not adequate

Not enough PTs

Covering too many weekends in a month

Too many clients and few PT/PTA 
Scheduling conflict with too many clients

Lack of skilled man power

Inadequate manpower in our facility

Code: Inconsistent Staff

Inconsistent staff

Lack of carry over when patients are assigned to more than one PT/PTA after admission

\section{Theme: Productivity Expectations}

Code: Productivity

Productivity

Expected productivity trumps everything

Too many high priority patients to be seen same day

Pressure to meet daily and weekly point expectations

No down time to read up on these programs

Daily patient's quota

No time for this laborious endeavor

Code: Caseload

Heavy caseload demands good time management

Too many visits in a day

Not enough time in the day to squeeze this program in.

Time to cover my work is the largest barrier in my opinion

Good program, no time

\section{Code: Scheduling Conflict}

In home health we work late into the evenings

It all about office meetings and seeing patients

Same day documentation for all patient encounters expected.

Cannot use these measures in real world, too time consuming.

Short length of stay, high turnaround. 


\section{Theme: Lack of Resources/Equipment}

Code: Lack of space

Space limitations

Crowded work space with junks/walkers

Space-in home health if the patient is a hoarder in an apartment you can be very limited SPACE

There is no wide, clutter free and open space in my facility where I can safely assess fall risk

\section{Code: Lack of resources}

No standardized treatment protocol

Lack of opportunities for training

Joining the APTA to get the journals is expensive

Not aware of it

Code: Availability of tool-kit

No tool kit

Availability of tool-kits in clinics

$\underline{\text { Code: Lack of tools }}$

Lack of access to research engines

Management willingness to provide the equipment

Ambulatory aids deformity

No computer access when needed

Knowledge of evidence-based fall preventions materials and courses.

I do not think of it during the day, treating the patient from what you see that day their needs/goals.

Outcome measures have a ceiling effect, multifactorial reasons for falls

Code: Limited resources

Access and time

Faster, more researched tools (ex: TUG, FTSTS, 6 min walk).

Lack of resources 
Lack of access to research

Limited resources

I don't think there are barriers

Access to current studies

Slow loading speed of aging electronic systems

We don't have these resources

Limited ability/space to carry this out in my setting

Code: Lack of equipment

Time away from school, "doing what I have always done"

Minimal tools in the home environment

It takes time to fix broken equipment

Proper working equipment not always there

Access to needed equipment

Inaccessible equipment

No right equipment

Lack of proper space or equipment

Courses I have taken in various disciplines work well with my fall risk patients

No training to meet up with current materials

Sharing treatment space with other disciplines

\section{Theme: Patient's Comorbidity}

Code: Patient's Illness

Patients' functional ability/sickness

Patient sickness/inability to perform the various tests, doctors ordering inappropriate balance tests be done

PATIENT SICKNESS \& COMPLIANCE

Majority of my patients have already fallen and have fractures that limit rehab Rx options

Patients compliance with follow through due to multiple illness

Patient's illness and home environment

My patients are at too low of a functional level, most are high fall risk even at discharge 
Specific disease interventions/goals

Patient participation/fatigue/illness

Patients' abilities/illness.

Patient medical complexity

Neuro conditions with poor outcome

Code: Comorbidity

COPD

Comorbidity

Presence of Co-morbidities in elderly patient population.

Chf/shortness of breath

PD cases

MS

Advanced Parkinson patients

Patient's pain level

$\mathrm{CHF}$ with no endurance

Parkinson clients with repeated hospitalization

Multiple sclerosis and muscle weakness

Code: Patient's cognition

Cognitive status of the $\mathrm{pt}$

Patient's cognitive ability

Cognitive impairment

Patient cognition

Memory issues and safety

Not appropriate for dementia patients

Code: Patient's condition

Most of my patients are wheelchair-bound

Patients cannot tolerate standing

Patient participation due to debility 
Patients' medical diagnosis on admission

Medical condition of patients

Unable, due to low functional abilities

My facility is neuro focused and education is usually focused on stroke/TBI

My population (oncology) has so many other concerns that it is difficult to prioritize

Code: Patient's motivation

Patient motivation or lack of concern about falling due to current illness

Patient's education and compliance due to medical diagnosis.

Lack of patient compliance/endurance

Willingness of the patients as a result of their conditions

Patient motivation or lack of concern about falling

Compliance due to medical diagnosis 